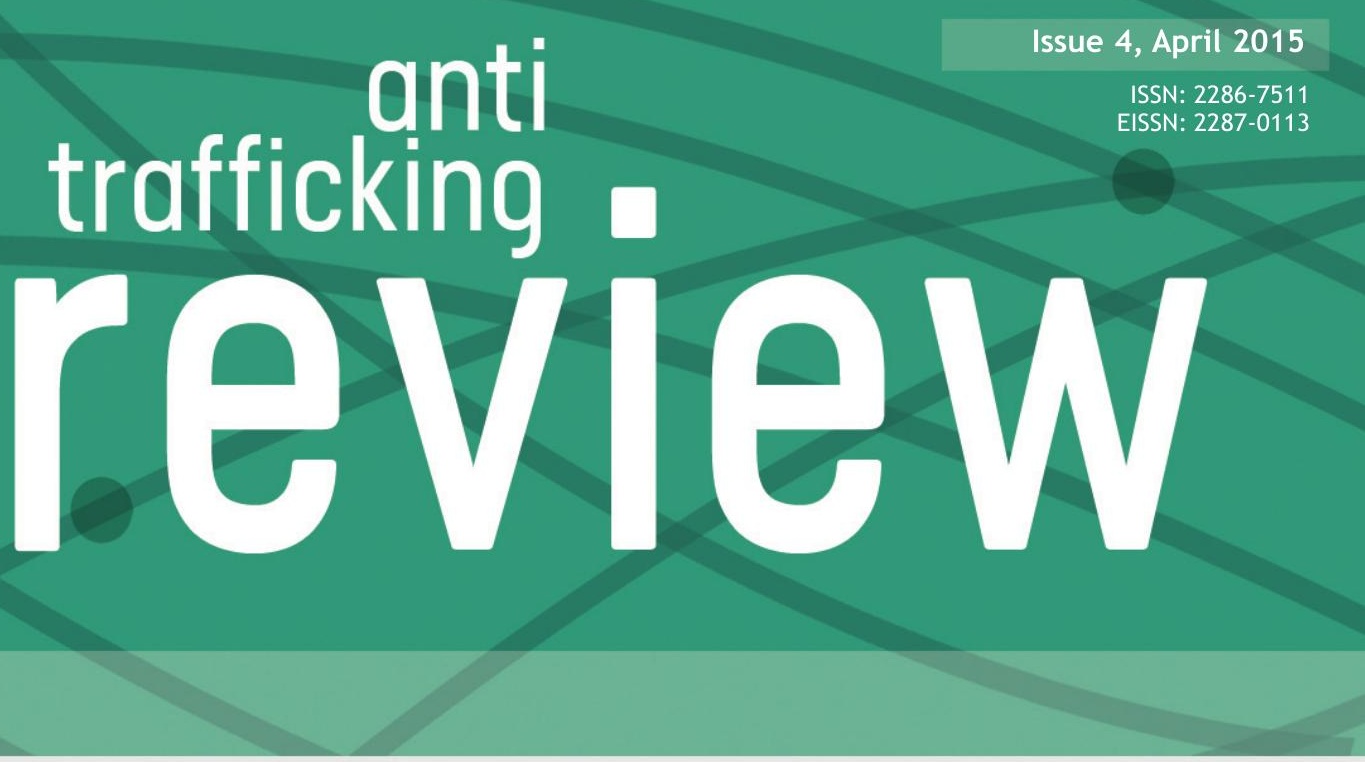

Special Issue-Fifteen Years of the UN Trafficking Protocol

Editorial: Looking Back, Looking Forward: The UN Trafficking Protocol at fifteen

Two Cheers for the Trafficking Protocol

Protocol at the Crossroads: Rethinking anti-trafficking law from an Indian labour law perspective

Purity, Victimhood and Agency: Fifteen years of the UN Trafficking Protocol

Was Trafficking in Persons Really Criminalised?

Re-evaluating Palermo: The case of Burmese women as Chinese brides

Trafficking in Persons for Ransom and the Need to Expand the Interpretation of Article 3 of the UN Trafficking Protocol

Debate: 'The Trafficking Protocol has advanced the global movement against human exploitation.'

Achievements of the Trafficking Protocol: Perspectives from the former UN Special Rapporteur on Trafficking in Persons

The Trafficking Protocol has Advanced the Global Movement against Human Exploitation: The case of the United Kingdom

From Palermo to the Streets of Oslo: Pros and cons of the trafficking framework

Trafficking as a Floating Signifier: The view from Brazil

The Trafficking Protocol and the Anti-Trafficking Framework:

Insufficient to address exploitation

Interview: Human Trafficking in Brazil: Between crime-based and human rights-based governance 


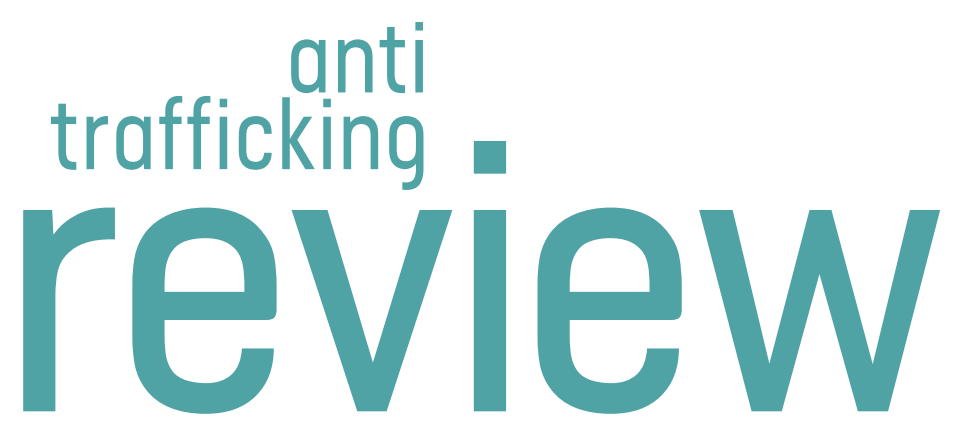

GUEST EDITOR

JACQUELINE BHABHA

EDITOR

REBECCA NAPIER-MOORE

ASSOCIATE EDITOR

JASMIN QURESHI

EDITORIAL BOARD

RUTVICA ANDRIJASEVIC, University of Leicester, UK

MARLA ASIS, Scalabrini Research Center, The Philippines

JACQUELINE BHABHA, Harvard Law School, USA

XIANG BIAO, Oxford University, UK

LUCIANA CAMPELLO, Independent consultant, Brazil

MIKE DOTTRIDGE, Independent consultant, UK

JOY NGOZI EZEILO, Former UN Special Rapporteur on Trafficking, Nigeria

ANNE GALLAGHER, Independent scholar and legal advisor, Australia

JOHN GEE, Transient Workers Count Too, Singapore

SUZANNE HOFF, La Strada International, The Netherlands

KRISTIINA KANGASPUNTA, United Nations Office on Drugs and Crime, Austria

KAMALA KEMPADOO, York University, Canada

SVERRE MOLLAND, The Australian National University, Australia

MARINA NOVAES, Centro de Apoio ao Migrante de S o Paulo, Brazil

PIA OBEROI, Office of the High Commissioner for Human Rights, Switzerland JULIA O'CONNELL DAVIDSON, University of Nottingham, UK

ELAINE PEARSON, Human Rights Watch, USA

NICOLA PIPER, University of Sydney, Australia

NIVEDITA PRASAD, Alice Salomon University of Applied Sciences, Germany

CAROLINE ROBINSON, Focus on Labour Exploitation, UK

JYOTI SANGHERA, Office of the High Commissioner for Human Rights,

Switzerland

MARIE SEGRAVE, Monash University, Australia

DARSHAN VIGNESWARAN, University of Amsterdam, The Netherlands;

African Centre for Migration and Society, South Africa

SALLIE YEA, Nanyang Technological University, Singapore

CATHY ZIMMERMAN, London School of Hygiene and Tropical Medicine, UK

The Anti-Trafficking Review is an open access publication distributed under the terms of the Creative Commons Attribution License (CC-BY).

The Anti-Trafficking Review promotes the sharing of information, and we therefore encourage the reproduction and onward dissemination of articles published with us. 


\section{ANTI-TRAFFICKING REVIEW}

Special Issue

FIFTEEN YEARS OF THE UN TRAFFICKING PROTOCOL

The Anti-Trafficking Review (ISSN 2286-7511) is published by the Global Alliance Against Traffic in Women (GAATW), a network of over 100 NGOs worldwide focused on advancing the human rights of migrants and trafficked persons.

The Anti-Trafficking Review promotes a human rights-based approach to anti-trafficking. It explores trafficking in its broader context including gender analyses and intersections with labour and migrant rights. It offers an outlet and space for dialogue between academics, practitioners, trafficked persons and advocates seeking to communicate new ideas and findings to those working for and with trafficked persons.

The Review is primarily an e-journal, published annually. The journal presents rigorously considered, peer-reviewed material in clear English. Each issue relates to an emerging or overlooked theme in the field of anti-trafficking.

Articles contained in the Review represent the views of the respective authors and not necessarily those of the editors, the Editorial Board, the GAATW network or its members. The editorial team reserves the right to edit all articles before publication. 



\section{ANTI-TRAFFICKING REVIEW}

Issue 4, April 2015

Thematic Articles: Fifteen Years of the UN Trafficking Protocol

\section{Editorial}

3 Looking Back, Looking Forward:

The UN Trafficking Protocol at fifteen Jacqueline Bhabha

Two Cheers for the Trafficking Protocol Anne T Gallagher

Protocol at the Crossroads:

Rethinking anti-trafficking law from an Indian labour law perspective Prabha Kotiswaran

56

Purity, Victimhood and Agency:

Fifteen years of the UN Trafficking Protocol Marjan Wijers

80

Was Trafficking in Persons Really Criminalised? Kristiina Kangaspunta

98

Re-evaluating Palermo: The case of Burmese women as Chinese brides

Laura K Hackney

Trafficking in Persons for Ransom and the Need to Expand the Interpretation of Article 3 of the UN Trafficking Protocol Mogos O Brhane 
Debate: 'The Trafficking Protocol has advanced the global movement against human exploitation.'

144 Achievements of the Trafficking Protocol:

Perspectives from the former UN Special

Rapporteur on Trafficking in Persons Joy $N$ Ezeilo

150 The Trafficking Protocol has Advanced the Global Movement against Human Exploitation: The case of the United Kingdom

\section{Caroline Parkes}

156 From Palermo to the Streets of Oslo: Pros and cons of the trafficking framework Synnøve Økland Jahnsen and May-Len Skilbrei

161 Trafficking as a Floating Signifier: The view from Brazil Grupo Davida

167 The Trafficking Protocol and the Anti-Trafficking Framework: Insufficient to address exploitation Kathryn Baer

\section{Interview}

$174 \quad$ Human Trafficking in Brazil: Between crime-based and human rights-based governance Ela Wiecko V. de Castilho 


\section{Looking Back, Looking Forward: The UN Trafficking Protocol at fifteen}

Jacqueline Bhabha

Keywords: Trafficking Protocol, Palermo Protocol, trafficking, human trafficking

Please cite this article as: J Bhabha, 'Looking Back, Looking Forward: The UN Trafficking Protocol at fifteen', Anti-Trafficking Review, issue 4, 2015, pp. 3-12, www.antitraffickingreview.org

Anniversaries provide a pretext for reflection-celebration for national independence days, mourning for war-time massacres. For political reforms and legal innovations, anniversaries warrant a different set of reflections: less predictable or uniform, more sober stock taking and weighing of achievements and failures than affirmation of unequivocal success or defeat. This fourth special issue of the Anti-Trafficking Review embraces the occasion of the fifteenth anniversary of the 2000 United Nations (UN) Protocol to Prevent, Suppress and Punish Trafficking in Persons, Especially Women and Children (hereafter Trafficking Protocol), and evaluates the impact of this landmark instrument of international law on the grave social, political and economic problems it targets. Among the many and varied constituencies concerned with issues of trafficking, from government bodies to international advocacy groups to sex worker collectives, the Trafficking Protocol has attracted considerable attention. It has been widely ratified, its definition of trafficking has been extensively invoked, its criminalisation mandates have been aggressively followed, its victim protection measures have been enthusiastically cited. 
With this high-profile visibility have come controversy and disagreement. Inevitably, evaluation criteria for antitrafficking success vary, opinions on the data evidenced by the empirical track record differ and assessments of intervention efficacy diverge. This divergence of views applies to the impact of the Protocol itself as much as it does to the broader domain of anti-trafficking work. The multifaceted social reality implicated in the phenomenon we label human trafficking is the product of a plethora of factors, among which international legal norms and their consequences (regional and domestic) constitute a small part.

Even the task of disentangling the 'consequences' of legal norms-the impact that ratification of any treaty or protocol has on a country-is anything but straightforward. ${ }^{1}$ Nowhere is this truer than in the trafficking context. Do we have good pre-ratification baseline measures? Do we even agree on the criteria for deciding what counts as success ${ }^{2}-$ are we counting the instances of human exploitation related to trafficking, or the numbers of people who have been trafficked? Are we determining the size of trafficking networks or the profits derived from trafficking, the numbers of arrests, of prosecutions, or of convictions of traffickers? Are we tracking the numbers of people who have been rescued, empowered or protected from the ravages of trafficking, or the numbers of professionals trained to provide appropriate services, or the magnitude of resources available to protect or support trafficked persons? The list is extensive and open-ended.

For contributions to this discussion, see 0 Hathaway, 'Do Human Rights Treaties Make a Difference?', Yale Law Journal, vol. 111, 2002, pp. 1935-2042; J Goldsmith \& E Posner, The Limits of International Law, Oxford University Press, New York, 2005, pp. 107-134; B Simmons, Mobilizing for Human Rights: International Law in Domestic Politics, Cambridge University Press, New York, 2009.

2 A T Gallagher \& R Surtees, 'Measuring the Success of Counter-Trafficking Interventions in the Criminal Justice Sector: Who decides-and how?', AntiTrafficking Review, issue 1, http://www.antitraffickingreview.org/index.php/ atrjournal/article/view/17/19 
For any of the evaluation criteria selected, what is the quality of the empirical data available to measure change over time? Is it comprehensive, reliable, up-to-date? If improvements along any relevant vector are detected, how does one ascertain whether they are caused by adoption of the Protocol as opposed to other factors? All these questions raise serious challenges for anyone confidently embarking on an assessment of the impact of the Protocol a decade and a half after its adoption. But they also highlight the importance of pausing for this moment of reflection. It is clearly imperative that, from our different vantage points, we do our best to dispassionately measure how far we have come, which elements of the Protocol's original intentions have been vindicated, which falsified, which trivialised, which qualified. For such stock taking has the potential to galvanise positive change among key actors. This, at least, is our hope.

When we launched the proposal for a special issue of the Anti-Trafficking Review focused on the fifteenth anniversary of the Trafficking Protocol, we encouraged contributors to reflect on issues related to anti-trafficking work that might usefully contribute to shaping its future. The topics we identified included evidence of harm or benefit resulting from the Protocol's implementation, analysis of the workability and usefulness of the Protocol definition of trafficking as a practical tool, and work on the immigration control impact of the Protocol. We also invited authors to consider the relationship between the anti-trafficking agenda and other human-rights-related agendas such as women, labour, refugee or migrant rights-for example did they think the emphasis on the former had enhanced or crowded out support for the latter? The overarching question-which we used to frame the Debate Section of the issue-was whether the Trafficking Protocol had advanced the global movement against human exploitation.

We are delighted with the response to our call for contributions. As the ensuing pages make clear, we have received a mixed set of offerings, both in terms of subject matter, disciplinary perspective, political stance and geographical location. This is exactly what we hoped for-and we hope our 
readership agrees that it makes for a rich and illuminating contribution to understanding the problems at hand.

Three common themes emerge from the articles. A central one is engagement with the nuanced stock taking we proposed. Several contributors carefully explore the impact of the Trafficking Protocol to offer a considered assessment. A few are unqualifiedly positive. Joy $\mathrm{N}$ Ezeilo, the former UN Special Rapporteur on trafficking in persons, especially women and children, celebrates a milestone international achievement that has, in her view, both accelerated the development of a workable anti-trafficking global framework and at the same time consolidated the international commitment to act on it. She notes the importance of definitional agreement in the Protocol as a basis for transnational cooperation and lauds the emphasis on protection of trafficked persons' human rights, a departure from the more punitive pre-Protocol approach. In a similar vein though from the narrower perspective of the United Kingdom's (UK) policy and practice, Caroline Parkes at The Trafficking Research Project notes the importance of the Trafficking Protocol's impact on modernising and broadening domestic understandings of human exploitation from the UK's archaic embedding within an outmoded slavery model. Though not perfect, she argues that the Protocol's flexible engagement with a range of trafficking situations has spurred States such as the UK to develop legislation (the UK Modern Slavery Bill) that appropriately targets 'the reality of contemporary exploitation, rather than some abstract approximation to it'.

Others are less sanguine in their assessment of the Trafficking Protocol's impact and legacy. Marjan Wijers, an expert who participated in the negotiations leading up to the Protocol, is critical of its focus and argues that it prioritises attention to the coercion involved in the recruitment and transportation aspects of trafficking instead of unconditionally addressing the central human rights violation caused by human trafficking, namely the abusive working conditions of trafficked persons-be they labour- or sexsector related (a distinction Wijers is critical of)-irrespective of the initial induction circumstances. Torture, brutalisation, 
rape, coercion in the daily life of sex workers or undocumented migrants who chose to cross borders to improve their life prospects, she argues, are thus ignored or marginalised. This approach, she notes, diverts the primary preoccupation of anti-trafficking intervention from the protection of vulnerable workers to the policing of State borders. From a single country perspective, Grupo Davida, a conglomerate of academic researchers associated with the Davida prostitutes' rights association in Rio de Janeiro, articulate a similar opinion based on their experience of the Trafficking Protocol's impact on Brazil's anti-trafficking policies. Like Wijers, they note its impact on strengthening migration control policy and its concomitant neglect of some of the most vulnerable and exploited groups, including sex workers, coerced migrant labourers and lesbian, gay, bisexual and transgender individuals. Kathryn Baer at The Trafficking Research Project too from her vantage point in Singapore-a non-signatory country influenced by global anti-trafficking discourse-criticises the impact that growing government emphasis on sanctioning trafficking has had on victim protection. She argues that policies justified as anti-trafficking measures in fact generate and justify raids on irregular migrants and sex worker groups, increasing criminal convictions of vulnerable workers but ignoring issues of victim protection or trafficking prevention. She also notes that a key rights issue confronting vulnerable migrant workers-deceptive recruitment practices that trick them into accepting exploitative labour contracts on false premises-is ignored.

Yet another group of contributors strike a middle ground between these two contrasting perspectives, setting out both gains and detriments that the Protocol seems to have produced. Anne T Gallagher, a leading international expert on anti-trafficking law and policy, carefully sets out the conclusions of her balance sheet. Like Ezeilo, she commends the agenda-setting achievements of the Protocol, the fact that it has generated a road map for dealing with trafficking where none existed. She also notes the beneficial impact of the Protocol's unitary (albeit unwieldy) definition of trafficking as a consensus-building breakthrough that 
provides a basis for global action. The Protocol's generative impact on domestic and regional anti-trafficking developments is also, in her view, a notable plus point, one that several of the country expert contributors in our volume comment on. On the other side of Gallagher's balance sheet are several serious weaknesses. The absence of an effective implementation and enforcement mechanism is perhaps, from a human rights perspective, the most serious. States are afforded great leeway and discretion in the way they implement their protection obligations, with the predictable result that trafficked persons have so far seen little concrete benefit. A related weakness in the Protocol is the extremely low conviction rate for traffickers that has followed its adoption. For a widely ratified instrument promoted as an important law enforcement tool, this is surprising. Expanding on this point, Kristiina Kangaspunta, a prominent expert on trafficking within the UN Office on Drugs and Crime, draws a telling contrast between the number of countries that do not have legislation against trafficking (only 9 out of 173 surveyed by her office), and the $41 \%$ of countries with such legislation who recorded less than ten convictions (and in many cases none at all) in the two-year period between 2010 and 2012. The gap between lawmaking and law enforcement could not be clearer.

A third negative consequence of the Protocol, and one remarked upon by most contributors to this volume, is the collateral damage it has generated. In the process of enforcing anti-trafficking measures, whether through anti-sex worker raids or border checks for irregular migrants, many States have inflicted serious and deleterious human rights impacts on some of their most vulnerable populations. Grupo Davida note the pervasive criminalisation of prostitution migration among Brazilian migrants, a development, they argue, closely related to hasty implementation of the Protocol. Baer criticises the impact that aggressive antitrafficking policies in Singapore has had on vulnerable migrant workers; in a similar vein Prabha Kotiswaran, Senior Lecturer at King's College London, highlights the extent to which the prohibitionist emphasis of the Trafficking Protocol has spurred what she calls 'sexual humanitarianism', 
aggressively removing sex workers from their working environment whether they want this or not, while at the same time ignoring other coercive forms of labour exploitation. She notes critically that in countries such as India the Protocol has failed to challenge, let alone reverse, the underlying vulnerabilities of a broad constituency of marginal workers. It has not insulated these workers from the coercive and abusive pressures of traffickers. On the contrary, by equating sex work and trafficking, she argues, such countries have used the Protocol as an instrument of social control targeting some constituencies of very vulnerable workers. Finally, Synnøve $\emptyset$ kland Jahnsen (PhD candidate, Norwegian Police University College) and May-Len Skilbrei (Professor, University of Oslo) examine the impact of anti-trafficking policies in Norway in the wake of implementation of the Trafficking Protocol and also offer a mixed balance sheet. They acknowledge that the diffusion of the 'trafficking label' has increased the protection opportunities for some vulnerable groups, including those whose vulnerability is related to engagement in sex work or to gender-based oppression. But, they argue, the opposite has been true for other exploited groups, for whom increased surveillance and anti-migration enforcement have exacerbated vulnerability. In this, they concur with other contributors who point critically to the Protocol's prioritisation of criminal justice responses to trafficking over a more preventative and potentially empowering focus on the social and political determinants of vulnerability to trafficking.

I now turn briefly to two other themes in our volume. One centres on the impact of the Protocol's trafficking definition. One of the Protocol's most celebrated legacies, the establishment of a widely adopted unitary definition, has provoked a considerable amount of comment and discussion. Many claim that without this achievement, the energetic focus on anti-trafficking initiatives of the last decade would never have occurred. Wijers highlights the critical importance attached to formulation of a unitary definition by key constituencies working on trafficking-related issues. She describes the lively history of broad-based engagement with the process and gives an account of the contentious and 
adversarial negotiations during the drafting phase that preceded adoption of a final definition. She recalls the heated debate between two groups: one, led by the Coalition Against Trafficking in Women, that considered all prostitution to be a violation of women's human rights and therefore trafficking per se, and another, which included the Global Alliance Against Traffic in Women, that considered coercive and forced labour, rather than sex work per se, to be the target. Eventually, the latter perspective succeeded in excluding sex work per se from the scope of exploitation (except for children), and in embedding the notion that force, coercion or deceit were necessary means. Gallagher notes the powerful impact that adoption of a common definition had on the development of an anti-trafficking normative framework-she describes it as a breakthrough and a necessary precondition for the focused policy work that followed. At the same time she observes that the definition's ambiguity ('exploitation' is not defined; 'abuse of a position of vulnerability' is a murky phrase) has enabled increasingly careless and expansionist applications of the trafficking label. Examples she cites include the sloppy equation of trafficking and 'modern slavery', and the potential for 'mission creep' as actions such as surrogacy or transnational adoption are brought under an anti-trafficking rubric. Kotiswaran also argues that the appearance of a unitary definition has not translated into the reality of a consistent international field of intervention. She too discusses the trafficking definition's lack of clarity and its consequences for domestic anti-trafficking initiatives. Since both the terms 'coercion' and 'exploitation' can be (and have been) construed in very different ways, controversy continues to surround the appropriate scope for anti-trafficking intervention, with considerable variation in the 'legal mediations of the coercion-exploitation balance'. Because domestic anti-trafficking law is a critical site for conceptualising solutions and is the locus with the greatest potential for creative (or repressive) developments in the field of trafficking, Kotiswaran urges focus on domestic contexts as a crucial object of study. India, for example, she argues, has used the Protocol definition to focus on sex worker exceptionalism, neglecting the vast extent of bonded and other 
forms of forced labour that could well also be brought into an anti-trafficking rubric.

Finally, in line with Kotiswaran's plea, over half the authors delve deeply into the Trafficking Protocol's relevance to a particular country or region. This is a particularly important and valuable complement to the more theoretical and transnational discussion, given the critical role of national legislation and domestic enforcement and protection initiatives in the development of policy on the ground. Some contributors track the impact of the Trafficking Protocol on national debates, legislative priorities and funding allocations within their countries-Baer, for example, discusses the development of policy in Singapore and notes the underdevelopment of resources for victim protection and primary protection. Ela Wiecko V. de Castilho (Vice Prosecutor of the Republic, Brazil and Professor at the University of Brasilia), and Grupo Davida present interesting information on the Brazilian case, highlighting the uses to which the Protocol has been applied, and the negative consequences of its 'too hasty' and externally imposed implementation on various vulnerable communities, including Brazilian sex workers migrating for work. These authors also note the persistent deficits in tackling domestic trafficking in Brazil. Laura $\mathrm{K}$ Hackney (Program Associate for the Freeman Spogli Institute for International Studies at Stanford University) presents a detailed case study of bride trafficking across the Sino-Burmese border. One of her most fascinating insights is that there is no clear or predictable distinction in many cases between consensual marriage and human trafficking. Rather, the complex continuum between the two and the changing balance between personal advantage and abusive exploitation as a result of the migration requires a much more nuanced and careful approach than a rigid consent/coercion dichotomy suggests. She concludes that a 'one-size-fits-all criminalisation strategy' is ill advised, and that consideration of economic development factors must feed into the human rights analysis of the brides' circumstances. Like Wijers, she is critical of the Trafficking Protocol's focus on the circumstances of entry rather than on the nature of the labour or marriage relationship. 
Another fascinating case study is provided by Mogos $O$ Brhane, former National Coordinator of Community Courts in Eritrea. He focuses on the new, burgeoning and terrifying phenomenon of trafficking for ransom that characterises much Eritrean, transnational forced migration. The purpose of this form of forced migration, unlike mainstream trafficking, is the securing of ransom monies rather than labour and/or sexual exploitation. Nevertheless, Brhane argues through a careful parsing of the Trafficking Protocol definition that the parallels to debt bondage and forced begging where third party pecuniary extraction is also a central element should persuade us to bring trafficking for ransom in the Horn of Africa firmly within the scope of trafficking definitions as nationally applied, if not within the scope of the Trafficking Protocol itself. Other important case studies are presented by Parkes (tracking the impact of different pieces of UK legislation on trafficking-related conduct) and Jahnsen and Skilbrei (showing how in Norway a prostitution abolitionist agenda has interacted with an anti-migrant agenda to produce both the Sex Purchase Act and the Procurement Act). Together these case studies demonstrate both the very extensive impact of the Trafficking Protocol but also the broad range of consequences and interpretations that it has generated-a far-reaching but mixed legacy.

This volume was conceived as a contribution to both history and advocacy. We hope our readers benefit from both perspectives and use them to deepen their own understandings of the challenges we face moving forward.

Jacqueline Bhabha is FXB Director of Research, Professor of the Practice of Health and Human Rights at the Harvard School of Public Health, the Jeremiah Smith Jr. Lecturer in Law at Harvard Law School, and an Adjunct Lecturer in Public Policy at the Harvard Kennedy School, United States of America. Email: jbhabha@hsph.harvard.edu 
Thematic Articles 


\section{Two Cheers for the Trafficking Protocol}

Anne T Gallagher

\section{Abstract}

The Trafficking Protocol makes an easy target for attack. Its origins lie in an attempt to control a particularly exploitative form of migration that was challenging the ability of States to control their own borders. Its parent instrument is a framework agreement to address transnational organised crime. While paying fleeting attention to the rights of victims, the Protocol, with its emphasis on criminalisation and border protection is nowhere near being a human rights treaty. On top of all that it does not even have a credible enforcement mechanism, allowing States Parties wide latitude in interpreting and applying their obligations. Strangely, these seemingly insurmountable flaws have not stopped the Protocol's emergence as perhaps the single most important development in the fight against human trafficking. Without the Protocol, arguments around definitions would have continued to block the evolution of principles and rules. Without the Protocol it is likely that the human rights system would have continued its shameful tradition of sidelining issues such as forced labour, forced sex, forced marriage and the ritual exploitation of migrant workers through debt. Most critically, the Protocol provided the impetus and template for a series of legal and political developments that, over time, have served to ameliorate some of its greatest weaknesses, including the lack of human rights protections and of a credible oversight mechanism.

Keywords: Trafficking Protocol, human trafficking, antitrafficking, criminal justice

This is an open-access article distributed under the terms of the Creative Commons Attribution License (CC-BY). Under CC-BY license, the public is free to share, adapt, and make commercial use of the work. Users must always give proper attribution to the author(s) and the Anti-Trafficking Review. 
Please cite this article as: A T Gallagher, 'Two Cheers for the Trafficking Protocol', Anti-Trafficking Review, issue 4, 2015, pp. 14-32, www.antitraffickingreview.org

\section{Introduction}

I have spent much of the past fifteen years writing of and around the Trafficking Protocol: ${ }^{1}$ about the drafting process and the substance of its provisions; ${ }^{2}$ about its relationship with other aspects of the international legal framework; ${ }^{3}$ and about the problems of interpretation and application encountered by States Parties. ${ }^{4}$ While criticising its many shortcomings I have also regularly defended the Protocol against attack, including from human rights scholars and advocates unsettled by its criminal justice orientation and offended by the fact that the major contemporary legal instrument to address human exploitation was developed outside the human rights system. ${ }^{5}$

In this article I will seek to weave some of these strands together, incorporating additional insights drawn from experiences working with legislators and practitioners who have frontline responsibility for implementing the Trafficking Protocol's core obligations. As the title suggests, my findings are mixed. On the positive side there is much to applaud.

In full: UN General Assembly, Protocol to Prevent, Suppress and Punish Trafficking in Persons, Especially Women and Children, Supplementing the UN Convention against Transnational Organized Crime, 15 November 2000.

2 A T Gallagher, 'Human Rights and the New UN Protocols on Trafficking and Migrant Smuggling: A Preliminary Analysis', Human Rights Quarterly, vol. 23, 2001, p. 975.

3 A T Gallagher, The International Law of Human Trafficking, Cambridge University Press, New York, 2010; UN Office of the High Commissioner for Human Rights, 'Recommended Principles and Guidelines on Human Rights and Human Trafficking: Commentary', New York and Geneva, 2010.

4 UN Office on Drugs and Crime (UNODC), 'Issue Paper: Abuse of a Position of Vulnerability and other "Means" within the Definition of Trafficking in Persons', UNODC, Vienna, 2012.

5 See for example A T Gallagher, 'Human Rights and Human Trafficking: Quagmire or Firm Ground? A Response to James Hathaway', Virginia Journal of International Law, vol. 49, 2009, p. 789. 
This instrument has done more than any other single legal development of recent times to place the issue of human exploitation firmly on the international political agenda. It has served to crystallise a phenomenon that for too long was left conveniently undefined and under-regulated. It has provided the international community and States with an invaluable-albeit incomplete and imperfect-road map for change.

The single achievement that made all this possible was the incorporation into the Trafficking Protocol of a definition of 'trafficking in persons'. Until that point the term 'trafficking' had not been defined in international law, despite its inclusion in a number of treaties. The reasons are complex, relating principally to differences of opinion concerning the ultimate end result of trafficking; its constitutive acts, and their relative significance; and the relationship between trafficking and related phenomena such as prostitution and irregular migration. The absence of a definition also reflected the marginal place of trafficking within the international human rights system and the associated reluctance of States to tie themselves to specific and detailed rules. As long as the concept of trafficking remained unclear, it was virtually impossible to formulate substantive obligations and to hold States to account for violations. The adoption of an international legal definition of trafficking in persons was a genuine breakthrough because it provided the necessary prerequisite for the elaboration of a meaningful normative framework. Obligations that we now take for granted, for example to criminalise trafficking and to protect victims, would be meaningless without the anchor of an agreed definition. The definition was also critical in forging a common vision between States. Today, the old idea of trafficking as being concerned solely with the cross-border sexual exploitation of women and children has lost all authority. While States continue to prioritise certain forms of trafficking over others, their laws almost uniformly recognise the essence of the Protocol's conception of trafficking: that it can take place within as well as between countries; that it can be used against women, men and children; and that the purposes of trafficking extend to many 
of the ways in which individuals are severely exploited for private gain.

And, on an issue that had long been marginalised by States and the international community, the Trafficking Protocol proved to be a game-changer, triggering unprecedented levels of action. In the several years that followed its adoption, a major regional treaty on the subject was developed $^{6}$ along with important soft law, including, in 2002, the United Nations (UN) 'Recommended Principles and Guidelines on Human Rights and Human Trafficking'. ${ }^{7}$ Intergovernmental bodies outside the UN system, along with civil society groups, became involved in researching the issue and initiating or supporting anti-trafficking efforts. Ratification of the Protocol was extremely rapid, allowing it to enter into force a mere two years after adoption. ${ }^{8}$ States very quickly began implementing its core obligations by introducing new laws and policies aimed at criminalising trafficking as well as, in most cases, providing at least minimal protection for victims. Having been almost completely absent from the Trafficking Protocol's negotiations, and prevaricating in the years that followed, the International Labour Organization (ILO) has come to the fore in recent years: adding its voice to the global movement against exploitation by adopting instruments on domestic servitude ${ }^{9}$ and forced labour $^{10}$ and issuing increasingly authoritative studies of the scope and scale of trafficking-related exploitation. ${ }^{11}$ There

6 Council of Europe, 'Convention on Action Against Trafficking in Human Beings', 16 May 2005.

7 UN High Commissioner for Human Rights, 'Recommended Principles and Guidelines on Human Rights and Human Trafficking', UN Doc. E/2002/68/Add.1, 20 May 2002 (hereinafter UN Trafficking Principles and Guidelines).

8 As of July 2014, the Trafficking Protocol had been ratified or acceded to by 159 States.

9 International Labour Organization, Convention Concerning Decent Work for Domestic Workers (ILO No.189), 16 June 2011.

10 International Labour Conference, 'Text of the Protocol to the Forced Labour Convention', 1930, Provisional Record 9A, 103rd Session, Geneva, 2014.

11 International Labour Office, 'Caught at Sea-Forced Labour and Trafficking in Fisheries, 2013 and Profits and Poverty: The Economics of Forced Labour', ILO, 2013. 
can be no doubt that the nature and pace of developments since 2000 would have been very different without the impetus and foundation provided by the Protocol.

While lauding its considerable impact and achievements, it would be unwise to overlook the challenges and obstacles that the Trafficking Protocol has either generated or contributed to. My concerns are not the usual ones-or at least I draw different conclusions from the weaknesses that others typically ascribe to the Protocol. Its criminal justice focus and feeble human rights protections could have been a disaster but proved not to be fatal, largely because of developments that followed in the wake of the Protocol's adoption in December 2000. The negative impact of the Protocol's weak implementation machinery has been similarly softened by the emergence of external compliance mechanisms. Both these matters are considered further below. I then turn to other aspects of the Protocol's legacy. Of particular concern is the heavy burden of human rights violations that have come to be associated with the Protocol and the kind of response it has encouraged from States. To what extent does the reality of what Global Alliance Against Traffic in Women (GAATW) has termed 'collateral damage'12 cast a shadow on the Protocol's achievements and how can the risks be better managed? Another critical challenge relates to the elusiveness of trafficking itself. Despite widespread acceptance of the Protocol's rather complicated definition, its parameters have proved fluid and continue to be contested. This is causing significant problems at the national level where criminal justice agencies in particular are struggling to draw an appropriate line between the crime of 'trafficking' and other forms of exploitation.

12 GAATW, Collateral Damage: The Impact of Anti-Trafficking Measures on Human Rights Around the World, GAATW, 2007. 
The Criminal Justice Focus and Fragile Human Rights Protections

It is not useful or realistic to lament the Trafficking Protocol's criminal justice focus. Such criticisms are naïve because they fail to appreciate that the alternative-a human rights treaty on trafficking-was never a serious possibility in the first place because it would not have received the necessary level of political support. However, States were prepared to develop an instrument of international cooperation that identified trafficking as a problem of transnational crime requiring a coordinated response and that imposed specific obligations of criminalisation and cross-border collaboration. After considerable prodding, States were also willing to include a few human rights protections as well as a savings clause that guaranteed the Protocol and its parent instrument could not be used to modify existing human rights protections. ${ }^{13}$

While accepting a qualified victory, human rights advocates were nevertheless right to be nervous about the Protocol's sparse and feeble human rights protections. ${ }^{14}$ The failure to clearly specify certain rights, such as the right to immediate protection and support and the right of access to an effective remedy, implied that such rights did not in fact exist. A similar inference could be made of the Protocol's failure to articulate certain critical obligations such as the obligation to proactively identify victims.

The response to this rather dangerous situation was swift and effective. Less than two years after the Protocol's adoption, the UN High Commissioner for Human Rights issued the highly

13 Trafficking Protocol, Article 14.

14 For example, States Parties are required to provide assistance for and protection of trafficked persons '[i]n appropriate cases and to the extent possible under its domestic law' (Article 6(1), 6(2)); to consider implementing a range of measures to provide for the physical and psychological recovery of victims of trafficking (Article 6(3)); to endeavour to provide for the physical safety of trafficking victims within their territory (Article 6(5)); and ensure that domestic law provides victims with the possibility of obtaining compensation (Article 6(6))'. 
influential 'Recommended Principles and Guidelines on Human Rights and Human Trafficking'. While crafting what has come to be known as a 'rights-based approach' to the issue, the UN Trafficking Principles and Guidelines did not seek to present an alternative to the Protocol. Rather, they carefully grafted human rights onto the skeleton that it provided. For example, the Protocol's nod to the special situation of children ${ }^{15}$ is fleshed out with a clear explanation of the rights to which trafficked children are entitled under international law, as well as an affirmation that the 'best interests of the child' must be the primary consideration in any decision regarding children who have been trafficked. ${ }^{16}$ The Protocol's rather vague reference to remedies (national law to provide the possibility of compensation ${ }^{17}$ ) is clarified in accordance with established rules of international law: States are obliged to provide victims of trafficking with access to effective remedies and this requires attention to a range of legal and procedural issues including the right to stay and provision of information and protection. ${ }^{18}$ Even the criminal justice obligations of the Trafficking Protocol, its least ambiguous provisions, were expanded and clarified with reference to the standard of 'due diligence' and the establishment of a now well-recognised connection between victim support and an effective criminal justice response. ${ }^{19}$ The UN Trafficking Principles and Guidelines contained the first-ever acknowledgement of the risk of 'collateral damage' and the need for responses to trafficking to be monitored closely for their negative impact on existing rights and freedoms. ${ }^{20}$ They also articulated, for the first time, the now widely endorsed principle of non-criminalisation of victims in relation to offences committed as a result of being trafficked. ${ }^{21}$

15 Trafficking Protocol, Article 6(4).

${ }^{16}$ UN Trafficking Principles and Guidelines, Principle 10 and Guideline 8.

17 Trafficking Protocol, Article 6(6).

18 UN Trafficking Principles and Guidelines, Principle 17 and Guideline 9.

19 Ibid., Principles 9, 12-16 and Guidelines 5, 6.

20 Ibid., Principle 3, Guidelines 1(7), 3(5).

${ }^{21}$ Ibid., Principle 7. 
Few commentators have appreciated the impact of this instrument on what was to follow. By affirming and extending the Protocol, rather than seeking to displace it, the UN Trafficking Principles and Guidelines provided a way forward that has supported the evolution of a cohesive 'international law of human trafficking' which weaves together human rights and transnational criminal law. ${ }^{22}$ That can be seen most clearly in European law around trafficking. Both the 2005 Council of Europe Convention and the 2011 European Union Directive reiterate the core provisions of the Protocol in relation to criminalisation, cooperation, prevention and victim support, while articulating relevant human rights in far greater detail, frequently incorporating concepts and language first set out in the UN Trafficking Principles and Guidelines. ${ }^{23}$ The international human rights system, regional institutions and courts have continued this unified approach, contributing to clarification of the precise nature and scope of the rights of victims and the corresponding obligations of States, while also affirming obligations of criminalisation, prosecution and prevention. ${ }^{24}$

As a result there is now widespread acceptance that victims of trafficking are indeed the holders of a special set of rights conferred upon them by their status as trafficked persons and that those rights go well beyond the ones recognised in the Protocol. These include: the right to be identified quickly and accurately; the right to immediate protection and

22 While also acknowledging other areas of law, including refugee law and international criminal law.

23 Council of Europe, 'Convention on Action Against Trafficking in Human Beings', 16 May 2005; Directive 2011/36/EU of the European Parliament and of the Council of 5 April 2011 on preventing and combating trafficking in human beings and protecting its victims, and replacing Council Framework Decision 2002/ 629/JHA (2011 EU Trafficking Directive).

24 See, for example, Human Rights Council Resolution 20/1, 5 July 2012, especially at paragraph 4(a) '[States to] ensur[e] that, in order to most effectively protect victims and bring their abusers to justice, national laws criminalize all forms of trafficking in persons in accordance with the provisions of the Protocol to Prevent, Suppress and Punish Trafficking in Persons, Especially Women and Children ...') and paragraph 5 (encouraging States that have not yet done so to ratify the Protocol and 'to take immediate steps to incorporate provisions of the Protocol into domestic legal systems'). 
support; the right to legal information and the opportunity to decide whether and how to cooperate in the prosecution of their exploiters; the right to not be detained; the right to not be prosecuted for offences that relate directly to the fact of having been trafficked; the right to be returned home safely or to benefit from another solution if safe return is not possible; and the right to an effective remedy that reflects the harm committed against them. It is also now widely accepted that certain categories of victims, most particularly children, benefit from additional, status-related rights in recognition of their special vulnerabilities and special needs. In short, no State could (or indeed does) convincingly argue that its human rights obligations in this area are limited to those set out in the Trafficking Protocol.

\section{The Challenge of Weak Implementation Machinery}

Strong and credible international compliance machinery is rightly considered to be an essential aspect of international legal regulation, and trafficking is no exception. Unfortunately, despite its position as the central instrument of legal obligation in this area, the Trafficking Protocol loses out on this front, operating under the very loose oversight of a working group of States Parties attached to the broader Conference of Parties to the UN Convention against Transnational Organized Crime and the Protocols Thereto (UNTOC) that meets annually. ${ }^{25}$ The Working Group does not equate, in any respect, to a human rights treaty body or equivalent compliance body. It does not examine reports from States Parties on implementation of the Protocol. It does not issue recommendations to individual States Parties, engage in a constructive dialogue, or otherwise interact with States Parties in any meaningful way. A further useful distinction is provided by the current (unreported) controversy over

25 'Report of the Conference of the Parties to the United Nations Convention against Transnational Organized Crime on its fourth session, held in Vienna from 8 to 17 October 2008', UN Doc. CTOC/COP/2008/19, 1 December 2008, Decision $4 / 4$ (at 11). 
the question of non-governmental organisation (NGO) participation in its sessions-something that is taken for granted within the human rights system. Some States are strongly supportive of opening its sessions up to outsiders. However others are resisting fiercely. There is also considerable opposition to proposals that the supervisory machinery attached to UNTOC be strengthened. ${ }^{26}$ Among States Parties to the Trafficking Protocol in particular, there appears to be little appetite for another monitoring mechanism in what has become a crowded and contested field.

Within these limitations the Working Group has made some progress, particularly in expanding understanding of the Trafficking Protocol's core provisions and affirming that States Parties' human rights obligations extend well beyond the minimal provisions of the Protocol. For example, it has noted that, with respect to victims, States Parties should '[e]nsure victims are provided with immediate support and protection, irrespective of their involvement in the criminal justice process.' ${ }^{27}$ This recommendation, which goes beyond the strict requirements of the Protocol, makes an important contribution to bringing that instrument in line with emerging international consensus on the need to ensure the provision of immediate protection and support to victims is not made conditional on their cooperation with criminal justice agencies. ${ }^{28}$ Another relates to the contentious issue of non-punishment and non-prosecution for status-related offences. While the Protocol is silent on this point, the Working Group has followed the UN Trafficking Principles and

26 See, for example, 'Report of the Conference of the Parties to the United Nations Convention against Transnational Organized Crime on its fifth session, held in Vienna from 18 to 22 October 2010', UN Doc. CTOC/COP/2010/17, 2010, paragraphs $97-108$.

27 Conference of the Parties to the UNTOC, Working Group on Trafficking in Persons, 'Report on the meeting of the Working Group on Trafficking in Persons held in Vienna on 14 and 15 April 2009', UN Doc. CTOC/COP/WG.4/2009/2, 2009, paragraph 13(c).

28 See, for example 2011 EU Trafficking Directive, Article 11(3). 
Guidelines and European law in recommending that States Parties consider 'not punishing or prosecuting trafficked persons for unlawful acts committed by them as a direct consequence of their situation as trafficked persons or where they were compelled to commit such unlawful acts. ${ }^{29}$ It has affirmed the need for a rights-based approach in relation to several provisions of the Protocol including the requirement that States Parties address trafficking-related demand. ${ }^{30}$ Another substantive and potentially far-reaching achievement of the Working Group relates to its support for a series of studies examining what it termed 'problematic' concepts in the Protocol's definition of trafficking. This work has done much to shed light on the 'practice' of criminal justice responses to trafficking at the national level and has also provided much needed conceptual clarity to States and the international community. ${ }^{31}$

Fortunately, external developments have worked to soften the negative impact of the Protocol's weak compliance machinery. Within the European system for example, the forty-two contracting States to the Council of Europe Convention are subject to a rigorous oversight mechanism that includes country assessment visits. ${ }^{32}$ Contracting States are of course assessed against that instrument and not the Trafficking Protocol. However the correlation between the two is high and the added protections in the former makes its assessment machinery an even more valuable tool from the perspective of human rights. As noted previously, the international human rights system's attention to trafficking

29 Ibid., paragraph 12(b). See also Working Group on Trafficking in Persons, 'Non-punishment and non-prosecution of victims of trafficking in persons: Administrative and judicial approaches to offences committed in the process of such trafficking', UN Doc. CTOC/COP/WG.4/2010/4, 2009.

30 Conference of the Parties to the UNTOC, 'Report on the meeting of the Working Group on Trafficking in Persons held in Vienna from 6 to 8 November 2013', UN Doc. CTOC/COP/WG.4/2013/5, 2013, at paragraph 17.

31 See further the discussion at Part 4, below.

32 Generally on the structure of this monitoring mechanism see A T Gallagher, The International Law of Human Trafficking, above note 3, pp. 473-477. For detailed information including individual country reports see the official anti-trafficking website of the Council of Europe, retrieved 7 January 2015, http:// www.coe.int/t/dghl/monitoring/trafficking/ 
has improved dramatically over the past decade, helped by a growing awareness of a synthesised 'international law of human trafficking'. ${ }^{33}$ The Human Rights Council, ${ }^{34}$ treaty bodies, ${ }^{35}$ the Special Rapporteur on trafficking in persons, especially women and children, ${ }^{36}$ and other mechanisms ${ }^{37}$ regularly draw attention to obligations under the Protocol as well as those that have built on its foundations. The recent adoption of new ILO instruments on domestic servitude and forced labour, both of which reference the Protocol, can be expected to further reinforce implementation of the Protocol by bringing the ILO supervisory bodies into this expanded network of implementation machinery.

The unilateral compliance mechanism established by the United States (US) government can be justifiably criticised on many grounds. ${ }^{38}$ However it too has played a role in reinforcing the core provisions of the Trafficking Protocol; for example in relation to whether States have criminalised trafficking, whether they are prosecuting and appropriately punishing

33 Most clearly set out in the Commentary to the UN Trafficking Principles and Guidelines (see above note 3 ).

34 For example, above note 24.

35 For example, UN Committee against Torture: Concluding Observations: Estonia, UN Doc. CAT/C/EST/CO/5, 2013, paragraph 13; UN Committee on the Rights of the Child, Concluding Observations: Afghanistan, UN Doc. CRC/C/AFG/CO/1, 2011, paragraph 73; UN Committee on the Elimination of Discrimination against Women, Concluding Observations: Saudi Arabia, UN Doc. CEDAW/C/SAU/CO/2, 2008, paragraphs 23-24. See also UN High Commissioner for Refugees, 'Guidelines on International Protection: The application of Article 1(A)(2) of the 1951 Convention and/or 1967 Protocol relating to the Status of Refugees to victims of trafficking and persons at risk of being trafficked', UN Doc. HCR/ GIP/06/077, 2006.

36 For a detailed reflection on the impact of the Trafficking Protocol on the work of the mandate see the Special Rapporteur's '[s]tocktaking exercise on the work of the mandate on its tenth anniversary' contained in 'Report of the Special Rapporteur on Trafficking in Persons, Especially Women and Children, Joy Ngozi Ezeilo', UN Doc. A/HRC/26/37/Add.2, 2014 (hereinafter Special Rapporteur on Trafficking: 2014 Stocktaking Exercise).

37 For example, 'Report of the Special Rapporteur on Torture and Other Cruel, Inhuman or Degrading Treatment or Punishment, Manfred Nowak', UN Doc. A/ $\mathrm{HRC} / 7 / 3$, 2008, paragraphs 56-58.

38 A T Gallagher, 'The trafficking watch list may be flawed, but it's the best measure we have', The Guardian, 2014, retrieved 8 July 2014, http:// www.theguardian.com/global-development/poverty-matters/2014/jun/27/ human-trafficking-watchlist-report 
offenders, and whether they are cooperating with each other to that end. The reports have also evolved over time to place increased emphasis on those underdeveloped aspects of the Protocol that have subsequently been clarified and extended as explained previously. For example, country assessments now routinely consider how the State under review treats victims of trafficking in both law and practice-focusing on issues as diverse as detention of victims in shelters ${ }^{39}$ to protection of trafficked persons who are cooperating in the prosecution of their exploiters. ${ }^{40}$ The reports also address, albeit somewhat unevenly, deeper structural issues-such as public sector corruption-that directly impact on how trafficking happens and how it is responded to. ${ }^{41}$

Finally, it is important to recognise the role of an increasingly vibrant civil society in exposing human trafficking and placing pressure on States and others to respond. Exploitation in the global fishing industry has now been taken up by the US government and international organisations, ${ }^{42}$ but only after researchers and advocates did much of the hard work of documenting the horrific abuses involved. ${ }^{43}$ NGOs such as Verit and Humanity United are conducting in-depth and tightly focused research that would be difficult for public entities to replicate. ${ }^{44}$ One new and abundantly funded NGO has jumped into the fray with its own compliance mechanism, which at

39 See, for example, the Malaysia country report in the US Department of State, Trafficking in Persons Report 2014, p. 260, retrieved 7 January 2015, http:// www.state.gov/j/tip/rls/tiprpt/

40 See, for example, the Ireland, Kazakhstan and Paraguay country reports: ibid., pp. $214,226,310$.

${ }^{41}$ See, for example, the Azerbaijan and Thailand country reports: ibid., pp. 85$87,372-376$.

42 See, for example, the New Zealand and Taiwan country reports: ibid., pp. 291293, 368; and International Labour Conference, 'Caught at Sea'.

43 In relation to trafficking in New Zealand's fishing fleet see, for example, C Stringer, G Simmons \& D Coulston, 'Not in New Zealand's waters, surely? Labour and human rights abuses aboard foreign fishing vessels', New Zealand Asia Institute Working Paper Series, 2011.

44 Verit , 'Risk Analysis of Indicators of Forced Labor and Trafficking in Illegal Gold Mining in Peru', 2013; Verit , 'Forced Labor in the Production of Electronic Goods in Malaysia', 2014. 
this stage principally collates derived data to rank countries from best to worst in a 'Global Slavery Index'. ${ }^{45}$

\section{The Challenge of 'Collateral Damage'}

At the time of the Trafficking Protocol's adoption there was little understanding of how responses to trafficking could seriously compromise human rights. Advocates involved in the negotiation expressed their concerns, particularly in relation to the criminal justice environment within which the Protocol was situated, but had little idea of how things would play out in practice because national responses to trafficking at that point were minimal. By 2002, there was a much better understanding of the nature of this particular challenge and the UN Trafficking Principles and Guidelines asserted strongly that '[a]nti-trafficking measures shall not adversely affect the human rights and dignity of persons, in particular the rights of those who have been trafficked, and of migrants, internally displaced persons, refugees and asylum seekers.' ${ }^{46}$

Unfortunately, the possibility of 'collateral damage' has become a well-documented reality as measures taken in the name of addressing trafficking and related exploitation have been shown to have a highly adverse impact on individual rights and freedoms. Examples include: detention of trafficked persons in immigration or shelter facilities (by NGOs as well as by government service providers); prosecution of trafficked persons for status-related offences including illegal entry, illegal stay and illegal work; denial of exit or entry visas or permits to particular groups on the basis of them being 'at

\footnotetext{
45 Walk Free, 'Global Slavery Index 2014', retrieved 31 January 2015, http:// www.globalslaveryindex.org. For a critique of the methodology and approach used by the authors of the Global Slavery Index see A T Gallagher, 'The Global Slavery Index is Based on Flawed Data-Why does No one Say So?', The Guardian, 28 November 2014, retrieved 31 January 2015, http://www.theguardian.com/ global-development/poverty-matters/2014/nov/28/global-slavery-index-walkfree-human-trafficking-anne-gallagher

46 UN Trafficking Principles and Guidelines, Principle 3.
} 
risk' of trafficking; raids, rescues, and 'crack downs' that do not include full consideration of and protection for the rights of involved individuals; forced repatriation of victims in danger of reprisals or re-trafficking; support and assistance that is made conditional on a trafficked person cooperating with criminal justice agencies; denial of a right to a remedy; and violations of the rights of persons suspected or convicted of involvement in trafficking and related offences, including unfair trials and inappropriate sentencing.

The Protocol's contribution to the problem of 'collateral damage' must be acknowledged. By failing to place the victim at the centre of the anti-trafficking response and failing to specify core rights and obligations it introduced an element of ambiguity that facilitated responses that were not respectful of individual rights and freedoms. The US Department of State Trafficking in Persons Reports must also be held to account on this score. Despite clear indications that US pressure was contributing to inappropriate and even harmful responses, it was only in 2009 that the negative impacts of anti-trafficking interventions were formally acknowledged. While attention to this issue has continued in subsequent reports, coverage is uneven and rarely figures in the country assessments-principally because harm caused by anti-trafficking responses is not part of the formal evaluative criteria. ${ }^{47}$ Fortunately, many other players in the vastly expanded anti-trafficking community are paying increased attention to human rights violations associated with antitrafficking responses. Within the UN's human rights system for example, the Special Rapporteur on trafficking in persons, especially women and children, has made this a constant theme of her work ${ }^{48}$ and several of the treaty bodies have picked up issues of concern to their respective

47 See further discussion in A T Gallagher, 'Improving the Effectiveness of the International Law of Human Trafficking: A vision for the future of the US Trafficking in Persons Reports', Human Rights Review, vol. 12, 2011, p. 381.

48 See Special Rapporteur on Trafficking: 2014 Stocktaking Exercise, above note 35. 
mandates. ${ }^{49}$ But the harms that are occurring in the criminal justice sector in particular, largely prompted by a desire on the part of underperforming States to assert the credibility of their response to the US government, continue to go largely unnoticed and unchallenged.

\section{Where Does Trafficking Begin and End? The Challenge of an Ambiguous Definition}

The development of an international legal definition of trafficking was a great victory but it came at a heavy price. States involved in negotiating the definition did not agree on many points and consensus was only achieved through the adoption of an unwieldy formulation that included a number of vague and undefined terms. Over the years, these compromises have been used to support expansive interpretations of trafficking that seem to go well beyond the intention of the drafters and perhaps even the broader goals of the Protocol. Extreme claims, such as 'all pornography is trafficking' or 'all prostitution is trafficking' are easily discredited through a careful application of the definition. However, other arguments are more difficult to refute. For example, some States have adopted a broad understanding of the term 'abuse of a position of vulnerability' that enables courts to characterise the prostitution or economic exploitation of poor migrants as 'trafficking'. ${ }^{50}$ Rigid adherence to the principle of the irrelevance of consent has been shown to have a similar effect. ${ }^{51}$ The failure of the Protocol to precisely delimit 'exploitation' (the 'purpose' of trafficking) has enabled States to extend the definition to

49 For example, 'Committee against Torture, Concluding Observations: Japan', UN Doc. CAT/C/JPN/CO/2, 2013, paragraph 21; Human Rights Committee, Concluding Observations: Turkey, UN Doc. CCPR/C/TUR/CO/1, 2012, paragraph 15; 'Committee on the Elimination of Discrimination against Women, Concluding Observations: Australia', UN Doc. CEDAW/C/AUL/CO/7, 2010, paragraphs 3031.

50 See UNODC, 'Issue Paper: Abuse of a Position of Vulnerability', above note 4.

51 See UNODC, "Issue Paper: The Concept of "Consent" within the Definition of Trafficking in Persons', vol. 108, no. 4, 2014. 
include practices as diverse as illegal, unethical adoptions; commercial surrogacy; begging; prostitution/pornography; involvement in criminal activities; use in armed conflict or religious rituals; and kidnapping for purposes of extortion or political terrorism..$^{52}$ Ambiguities in the definition have also lent support to the careless and increasingly frequent equation of trafficking with slavery and 'modern slavery' (the latter term unknown to international law).

Of course there are positive aspects to an expanded concept of trafficking. Many of the practices with which trafficking is associated, from forced marriage to debt bondage to forced labour, have long been subject to legal prohibition at both national and international levels. However, international scrutiny has been almost non-existent and States have rarely been called to task for even the worst violations. The abject failure of the international community-including the international human rights system and the ILO-to secure substantial progress on any of these fronts over the past half century should not be forgotten. Recent legal and political developments around trafficking have changed this situation fundamentally, giving previously moribund prohibitions a new lease of life. New laws, institutions and compliance machinery strengthen the capacity of both national and international law to address such practices effectively. Civil society groups are no longer marginal actors. New organisations and new alliances are both creating and sustaining what appears to be an unstoppable momentum for change. It is not unreasonable to conclude that a broadening of the parameters of trafficking to embrace the many ways in which individuals are exploited for private gain-even those that appear to be at the less severe end of the spectrum-will have a similarly positive effect: focusing law, public attention and resources where they are so badly needed.

52 Conference of the Parties to the UNTOC, Working Group on Trafficking in Persons, 'Forms of exploitation not specifically mentioned in the Protocol', UN Doc. CTOC/COP/WG.4/2013/4, 2013. 
But the dangers associated with what one scholar has aptly termed 'the expansionist creep'53 must be openly acknowledged and actively managed. Making all exploitation 'trafficking' (and indeed, making all trafficking 'slavery'a category international law reserves for the most egregious exploitative practices) complicates the task of those who are at the front line of investigating and prosecuting trafficking, presenting particular challenges in countries that lack specialist capacity and robust criminal justice systems. In all countries the expansionist creep risks diluting attention and effort, and potentially deflecting attention from the worst forms of exploitation that are most difficult for States to address. The common equation of prostitution with trafficking provides a case in point: permitting States to claim easy credit for virtually effortless arrests and prosecutions that do little or nothing to address those serious forms of sexual exploitation that the Protocol was intended to challenge. Prosecuting employers for lesser labour exploitations in the name of addressing trafficking is just as questionable. In most countries a raft of penal provisions are available to address such conduct. Why is the blunt instrument of trafficking being favoured over these apparently more appropriate alternatives? It is equally important to question crude international assessment systems that recognise and reward prosecutions for 'trafficking' while ignoring valuable prosecutions for related offences, thereby incentivising States to make everything 'trafficking'.

\section{Conclusion}

Fifteen years ago only a small handful of States specifically prohibited the process by which individuals were moved into and maintained in situations of exploitation at home or abroad. Many of the practices we now associate with trafficking were outlawed in most countries but these laws, like their

53 J Chuang, 'Exploitation Creep and the Unmaking of Human Trafficking Law', American Journal of International Law, vol. 108, 2014. 
international equivalents, were almost never invoked. International scrutiny of State actions with respect to such exploitation was extremely limited and ineffective.

With the benefit of hindsight we can identify the Trafficking Protocol as the trigger and foundation for dramatic and irreversible change. While an imperfect instrument in many respects, the Protocol provided both framework and impetus for the subsequent evolution of a comprehensive 'international law of human trafficking' that articulates, with much greater clarity than was ever previously possible, the obligations of States in relation both to ending impunity for traffickers and providing support, protection and justice for those who have been exploited. This is a singular achievement and one that should not be forgotten as we work to address the many challenges ahead.

Anne T Gallagher is an independent scholar and legal adviser, working with the United Nations, ASEAN and the AustraliaAsia Trafficking in Persons Program.

Email: anne.therese.gallagher@gmail.com 


\section{Protocol at the Crossroads: Rethinking anti-trafficking law from an Indian labour law perspective}

Prabha Kotiswaran

\section{Abstract}

As we approach the fifteenth anniversary of the United Nations Trafficking Protocol, we can discern several phases of its diffusion, materialisation and interpretation in domestic criminal law regimes across the world. Although not exclusively preoccupied with sex work and sex trafficking anymore, the fact remains that the inordinate attention on trafficking in Western industrialised economies is disproportionate to the extent of the problem. Only $7 \%$ of the world's 20.9 million forced labourers are in developed economies while $56 \%$ are in Asia Pacific. Yet in BRIC countries like India, with a substantial majority of the world's trafficked victims and where $90 \%$ of all trafficking is domestic, trafficking has gained policy resonance only relatively recently. Even as India remains an active site for sexual humanitarianism with international and local abolitionist groups actively targeting sex workers, the article argues that less developed countries like India can play a crucial role in reorienting international anti-trafficking law and policy. Towards that goal, this article offers India's bonded, contract and migrant labour laws as a robust labour law model against trafficking in contrast to the criminal justice model propagated by the Trafficking Protocol worldwide.

Keywords: India, bonded labour, contract labour, interstate migrant labour, trafficking

This is an open-access article distributed under the terms of the Creative Commons Attribution License (CC-BY). Under CC-BY license, the public is free to share, adapt, and make commercial use of the work. Users must always give proper attribution to the author(s) and the Anti-Trafficking Review. 
Please cite this article as: P Kotiswaran, 'Protocol at the Crossroads: Rethinking anti-trafficking law from an Indian labour law perspective', Anti-Trafficking Review, issue 4, 2015, pp. 33-55, www.antitraffickingreview.org

\section{Introduction}

On the fifteenth anniversary of the United Nations Protocol to Prevent, Suppress and Punish Trafficking in Persons, especially Women and Children (Trafficking Protocol), this article reassesses the architecture of anti-trafficking law through the lens of transnational legal studies, an emerging field of scholarship mapping the rise of technologies of global governance in response to two decades of globalisation and its dark underside. Like many other transnational legal issues, which have cross-border implications, the anti-trafficking legal field is saturated with legal rules, norms, guidelines, policies, action plans, indicators and reports that derive from overlapping international, regional and domestic legal regimes and corresponding intergovernmental organisations such as the United Nations Office on Drugs and Crime (UNODC) and the International Labour Organization (ILO), to name a few. Increasingly visible is also the work of influential non-state actors like Anti-Slavery International and the Walk Free Foundation which are significantly reshaping anti-trafficking discourse and States' legal conceptualisation of trafficking in terms of modern slavery and forced labour, leading scholars like Janie Chuang to criticise such expansion as 'exploitation creep'. ${ }^{1}$

As crucial as this expansive view of the anti-trafficking legal field is, looking at trafficking purely through the lens of obligations imposed by formal state law, in other words, anti-trafficking law offers us a rather different picture. After

J Chuang, 'Exploitation Creep and the Unmaking of Human Trafficking Law', American Journal of International Law, vol. 108, no. 4, 2014. 
all, transnational criminal law, of which trafficking is an excellent example, refers to 'the indirect suppression by international law through domestic penal law of criminal activities that have actual or potential trans-boundary effects.' 2 In other words, transnational criminal law is fundamentally different from international criminal law, which is 'stricto sensu, consisting of the crimes that provide for individual penal responsibility for violations of international law before an international penal tribunal.' ${ }^{3}$ Therefore, transnational criminal law essentially deals with domestic criminal law where states have a fair degree of freedom in deciding how to respond to their own domestic trafficking problems.

Even as the international anti-trafficking arena is in a constant state of flux and unsettled at various different levels, I argue that at the doctrinal level, domestic antitrafficking law is a far more fertile site for conceptualising creative solutions to address trafficking. In particular, I propose that less developed countries with a vast population of trafficked persons have often pursued a quite different conceptual understanding of the key concepts of trafficking, particularly coercion and exploitation and instated institutional measures to counter trafficking. I will briefly use the example of Indian anti-trafficking law to illustrate this although many others warrant closer inspection, including the Brazilian model. At the level of method, I propose a 'legal realist' research agenda for anti-trafficking lawyers, whereby we not only examine the role of criminal law in countering trafficking but also consider civil legal rules, informal social norms and market practices within specific labour sectors with an eye to being able to assess the unintended economic consequences of trafficking law reform.

2 N Boister, 'Transnational Criminal Law?', European Journal of International Law, vol. 14, 2003, p. 953.

3 Ibid., p. 955. 


\section{Shifts in Global Anti-Trafficking Discourse Over the Past Fifteen Years}

Comprehending shifts in trafficking discourse is essential for appreciating the definitional conundrums of Article 3 of the Trafficking Protocol. Between 2000 and 2008, the Protocol enjoyed phenomenal levels of adoption and ratification by States. Significantly, during this phase, the interpretation of trafficking continued to be hugely influenced by the negotiations leading up to the Protocol, particularly its preoccupation with sex work (or what one might term 'sex work exceptionalism') and the abolitionist policies of the Bush administration. The 'collateral damage' and indeed some would argue, intended damage of the Protocol to the interests of sex workers, migrants, asylum seekers and other groups have been documented in great detail. ${ }^{4}$ During this period, the implementation of anti-trafficking law by many countries was over inclusive because it targeted women engaged in voluntary sex work and was under inclusive because trafficking for purposes other than sex work was effectively ignored. Moreover, as the anti-trafficking movement dispersed across the world, spurred by considerable Western funding, less developed countries in Asia became the theatres of sexual humanitarianism where aggressive raid, rescue and rehabilitation strategies became stock interventions. This journal has documented this phenomenon in detail. While these initiatives continue to fuel the engine of sex work exceptionalism as well as of sex trafficking exceptionalism, they are not the only players anymore. Those promoting sex work exceptionalism have themselves been exposed as evidenced by the cases of Somaly Mam $^{5}$ and Ruchira Gupta. ${ }^{6}$ Further the decentring of sex trafficking within anti-

4 For example, Global Alliance Against Traffic in Women (GAATW), Collateral Damage: The Impact of Anti-Trafficking Measures on Human Rights Around the World, GAATW, 2007, retrieved 14 February 2015, http://www.gaatw.org/ Collateral\%20Damage_Final/singlefile_CollateralDamagefinal.pdf

5 S Marks, 'Somaly Mam: The Holy Saint (and Sinner) of Sex Trafficking', Newsweek, 21 May 2014.

6 N S Jain \& T Suri, 'A Lack of Transparency', The Harvard Crimson, 2 November 2010, retrieved 6 February, 2015 www.thecrimson.com/article/2010/11/2/ apne-aap-women-organization / 
trafficking discourse had commenced in 2009 when the United States (US) Department of State Trafficking in Persons Report referred to trafficking into varied labour sectors rather than focus merely on sex work and sex trafficking. Thus, the UNODC's latest report on global trafficking suggests that more countries now have comprehensive definitions of trafficking than before. ${ }^{7}$ The ILO points to how trafficking for labour exploitation is receiving increased attention after an initial focus on trafficking for sexual exploitation. ${ }^{8}$ Further, the definition of trafficking in many countries covers trafficking for both labour and sexual exploitation. ${ }^{9}$

In addition to changes introduced by States, international organisations have played a significant role in shifting the tone of the agenda on trafficking. There are of course several arms of the United Nations (UN) working on different aspects of the phenomena that constitute trafficking including on slavery and forced labour. The momentum among States on the question of trafficking has energised organisations like the ILO to take stock of its own interventions on forced labour. Thus where the ILO has historically dealt with forced labour exacted by governments, it has in the past decade focused on exploitation in the private sector. In 2014, the International Labour Conference adopted a Protocol to Supplement the ILO's forced labour convention to address trafficking for labour

7 The percentage of countries criminalising only some aspects of trafficking (whether in terms of certain victims or certain forms of exploitation such as sexual exploitation) decreased from $17 \%$ in 2008 to $11 \%$ in 2012, then to $10 \%$ in 2014. UNODC, 'Global Report on Trafficking in Persons 2012', UN publication, 2012, retrieved 6 February 2015, http://www.unodc.org/documents/dataand-analysis/glotip/Trafficking_in_Persons_2012_web.pdf; UNODC, 'Global Report on Trafficking in Persons 2014', p. 51, retrieved 6 February 2015, http: / / www.unodc.org/documents/data-and-analysis/glotip/ GLOTIP_2014_full_report.pdf; correspondingly $85 \%$ of the 173 countries considered by the UNODC criminalise all aspects of trafficking in persons listed in the Trafficking Protocol.

8 ILO, 'Report for Discussion at the Tripartite Meeting of Experts Concerning the Possible Adoption of an ILO Instrument to Supplement the Forced Labour Convention, 1930 (No.29)', ILO, 2013, paragraph 120, retrieved 6 February 2015, http://www.ilo.org/global/standards/WCMS_203982/lang-en/ index.htm

9 Ibid. 
exploitation. ${ }^{10}$ The relationship between trafficking and forced labour however remains murky. A tripartite group of experts that looked into the Forced Labour Convention in detail disagreed on the scope of forced labour in relation to trafficking. The Committee of Experts on the Application of Conventions and Recommendations, the supervisory body entrusted with technical supervision of the application of the ILO Conventions, viewed forced labour as encompassing trafficking. ${ }^{11}$ Others proposed that both concepts were not identical, but shared some areas of overlap. ${ }^{12}$ The Trafficking Protocol itself conceptualises trafficking as covering a range of exploitative labour forms of which forced labour is only one form.

Marginalised groups like sex workers have also had a role to play in challenging the sex work exceptionalism associated with trafficking. That the critique of sex workers' organisations against the conflation of trafficking with sex work is gaining ground was evident most recently in India. A 2013 Presidential Ordinance ${ }^{13}$ ushering in rape law reform, introduced a trafficking offence, which conflated it with prostitution. This was so strongly protested by sex workers' groups that a parliamentary statute replacing the Ordinance modified the trafficking offence to define exploitation in terms of physical and sexual exploitation instead of prostitution. Yet, Section $370 \mathrm{~A}$ of the Indian Penal Code, 1860 (IPC) ${ }^{14}$ criminalises the

10 Protocol to Convention 29-Protocol to the Forced Labour Convention, 1930, Adopted by the Conference at its $103^{\text {rd }}$ Session, Geneva, 11 June 2014, retrieved 6 February 2015, http://www.ilo.org/wcmsp5/groups/public/-ed_norm/relconf/documents/meetingdocument/wcms_248900.pdf

11 ILO, 'Report for Discussion 2013', ILO, p. 57.

12 ILO, 'Report and Conclusions of the Tripartite Meeting of Experts on Forced Labour and Trafficking for Labour Exploitation', paragraphs 92-102, 2013, retrieved 6 February 2015, http://www.ilo.org/gb/GBSessions/GB317/ins/ WCMS_207218/lang-en/index.htm

13 Press Information Bureau, 'Criminal Law (Amendment) Ordinance, 2013', Government of India, retrieved 6 February 2015, pib.nic.in/newsite/ erelease . aspx? relid $=91979$

14 Ministry of Law and Justice, The Criminal Code (Amendment) Act, 2013, Government of India, No. 13 of 2013, retrieved 6 February 2015, http:// indiacode.nic.in/acts-in-pdf/132013.pdf 
use of a trafficked person for sexual exploitation but not other forms of exploitation. Thus, the moral charge that prostitution produces means that it is likely to continue to have a special place for governments in their anti-trafficking policy. As the ILO notes, prosecution rates for trafficking for labour exploitation continue to be low, rather than for trafficking for commercial sexual exploitation. ${ }^{15}$ Moreover, the Swedish model criminalising demand remains popular. However, new opportunities have become available with the current shift from an earlier almost exclusive obsession with sex trafficking to one with an increased focus on labour trafficking and supply chains. The challenge for anti-trafficking law is to now go beyond sexual humanitarianism, or indeed other forms of humanitarianism, to enunciate an agenda that is committed to the fundamental redistribution of resources that reduces the vulnerability of both men and women to trafficking.

\section{The Conceptual Ambiguity/Malleability of Article 3}

The definitional ambivalence and unsettled nature of the definition of trafficking in Article 3 of the Trafficking Protocol is a starting point for envisioning a redistributive agenda vis-à-vis anti-trafficking law. Needless to say, criminal law is not an ideal starting point for such an endeavor until we recognise that criminal law's symbolic power often exceeds its actual enforcement, which in turn opens up regulatory spaces for more distributively-oriented legal regimes such as labour law. I will not rehearse here the deeply contentious (and well documented) debates around the issue of consent or exploitation, particularly, the 'exploitation of the

15 ILO, 'Report for Discussion 2013', paragraph 131. Similarly, the interpretation of certain means of trafficking such as the abuse of position of vulnerability is likely to be influenced by whether it is for purposes of sexual exploitation. See UNODC, "Issue Paper: Abuse of a Position of Vulnerability and Other "Means" within the Definition of Trafficking in Persons', 2012, paragraph 64, retrieved 6 February 2015, http://www.unodc.org/documents/human-trafficking/2012/ UNODC_2012_Issue_Paper_-_Abuse_of_a_Position_of_Vulnerability.pdf 
prostitution of others', ${ }^{16}$ which was extraordinarily influenced by the sex work debates. ${ }^{17}$ In its most general terms, all three elements of the Protocol's definition ${ }^{18}$ of trafficking, the 'actions', the 'means', and the 'purpose', are relatively broad and open-ended. Experts disagree over whether the action element requires cross-border movement or movement of some sort or if merely 'harbouring' is sufficient for purposes of Article 3. Similarly, when it comes to the means element, all the means other than the abuse of position of vulnerability appear to be relatively bounded concepts defined with some precision in domestic legal systems. Even then, there is a high level of fluidity between the various 'means' stipulated in national laws, due, at least in part, to the absence of definitions in the Trafficking Protocol itself. ${ }^{19}$ The term 'abuse of power or of a position of vulnerability' is rather broad, which although not defined in the Protocol itself, according to the travaux préparatoires, ${ }^{20}$ refers to 'any situation in which the person involved has no real and acceptable alternative but to submit to the abuse involved. ${ }^{21}$ In a world economy that is rife with precarious labour, this

16 Ad Hoc Committee on the Elaboration of a Convention Against Transnational Organized Crime, 'Revised Draft Protocol to Prevent, Suppress and Punish Trafficking in Persons, Especially Women and Children, Supplementing the UN Convention Against Transnational Organized Crime', UN Doc. A/AC.254/4/Add.3/ Rev.7, 2000, p. 12.

17 J Chuang, 'Rescuing Trafficking from Ideological Capture: Prostitution Reform and Anti-Trafficking Law and Policy', University of Pennsylvania Law Review, vol. 158, 2010, pp. 1672-1677.

18 "“Trafficking in persons" shall mean the recruitment, transportation, transfer, harbouring or receipt of persons, by means of the threat or use of force or other forms of coercion, of abduction, of fraud, of deception, of the abuse of power or of a position of vulnerability or of the giving or receiving of payments or benefits to achieve the consent of a person having control over another person, for the purpose of exploitation. Exploitation shall include, at a minimum, the exploitation of the prostitution of others or other forms of sexual exploitation, forced labour or services, slavery or practices similar to slavery, servitude or the removal of organs; (b): The consent of a victim of trafficking in persons to the intended exploitation set forth in subparagraph (a) of this article shall be irrelevant where any of the means set forth in subparagraph (a) have been used.' UN General Assembly, 55th Session, Supp. no. 49 at 60, UN Doc. A/55/49, 2000, p. 61. UNODC, 'Issue Paper on Abuse of a Position of Vulnerability', p. 8.

20 Ad Hoc Committee on the Elaboration of a Convention Against Transnational Organized Crime, 2000, paragraph 63.

21 Ibid. 
formulation offers little direction. The ILO's 2009 report, 'The Cost of Coercion', construes it narrowly when it illustrates the concept by offering the example of a worker who is economically so vulnerable that unless he complies with his employer's demands, he is at risk of losing his job. ${ }^{22}$

The purpose of trafficking under the Trafficking Protocol, namely, exploitation, similarly suffers from definitional uncertainties. To begin with, the definition of exploitation received a lot less attention in the Protocol negotiations when compared to the means. Although many of the terms connoting exploitation in Article 3 are defined under international law, they are not defined under the Protocol and the definition of exploitation itself is not exhaustive. ${ }^{23}$ With the scope of the offence of trafficking being up for grabs, the UNODC commissioned three Issue Papers on core concepts central to the definition of trafficking under Article 3, namely 'the abuse of power or of a position of vulnerability', 'consent' and 'exploitation', the first two of which have been published. ${ }^{24}$

Even as definitional debates on trafficking continue without clear resolution, ${ }^{25}$ producing a widespread lack of clarity around the definition of trafficking, ${ }^{26}$ the Trafficking Protocol on the face of it, offers an expansive understanding of both the means of trafficking as well as the purpose for which one is

22 ILO, 'The Cost of Coercion: Global Report Under the Follow-Up to the ILO Declaration on Fundamental Principles and Rights at Work', ILO, 2009, paragraph 35, retrieved 6 February 2015, http://www.ilo.org/declaration/WCMS_106268/ lang-en/index.htm

23 A UN report in fact suggests that it is a minimalist definition allowing for region-specific forms of trafficking to be included and lists such 'other forms of trafficking' such as begging, illegal adoptions and forced marriages. UNODC, 'Global Report on Trafficking in Persons 2012', UN publication, 2012, p. 35.

24 UNODC, 'Issue Paper on The Role of 'Consent' in the Trafficking in Persons Protocol', 2014, retrieved 6 February 2015, www.unodc.org/documents/ human-trafficking/2014/UNODC_2014_Issue_Paper_Consent.pdf

25 ILO, 'Report for Discussion', 2013.

26 UNODC, 'Global Report on Trafficking in Persons 2009', UN publication, 2009, retrieved 6 February 2015, http://www.unodc.org/documents/humantrafficking/Global_Report_on_TIP.pdf 
trafficked, namely, exploitation. Each of these two central legal concepts in the law of trafficking, namely, the means and purpose, both span a continuum of possibilities. The means or coercion can range from legally recognisable and fairly narrowly construed notions of coercion, deception, fraud, and abduction (termed as 'strong coercion' for ease of reference ${ }^{27}$ ) to the capacious, outlier concept of the abuse of a position of vulnerability (weak coercion). Similarly, while Article 3 points to specific labour conditions that constitute exploitation and are recognised and understood under international law (strong exploitation), this list of labour conditions is not exhaustive and could well include a range of working conditions that are best described as precarious, exploitative, and normatively reprehensible (weak exploitation).

A narrow construction of the offence of trafficking might entail means of entry such as coercion understood in terms of violence, deception or fraud (strong coercion) resulting in slavery (strong exploitation). A paradigmatic example would be the trafficking episode etched in our minds through repeated iterations by the media, namely, of the young woman who is offered a well-paying job as a nanny but is duped into doing sex work in a foreign country against her will and under threat of physical and sexual violence for no pay. A broader construction of the offence of trafficking, in contrast, may penalise the recruitment of a victim by abuse of the position of vulnerability (weak coercion) resulting in precarious work with less than minimum-wage pay (weak exploitation). An example would be of a Netherlands case where antitrafficking law was invoked against a restaurant owner who employed undocumented migrant workers (who begged him for a job) working for far less than the Dutch minimum wage. ${ }^{28}$ Moreover, there is no necessary correlation between a

27 The terms 'strong' and 'weak' are not used to qualify the quality or quantity of the means of trafficking but simply to indicate the levels of relative legal certainty or legal malleability around them.

28 UNODC, 'Issue Paper on Abuse of a Position of Vulnerability', pp. 38-39. 
coercive means of entry and an exploitative purpose. ${ }^{29}$ In other words, coerced entry into a labour sector can exist without exploitation, while exploitation can occur without coerced entry. To illustrate, a domestic worker entering the United Kingdom (UK) legally could well be paid far less than the minimum wage in a household that she works in and thus be exploited. A female migrant duped into sex work on the other hand, may well earn a lot more than she would have ever earned in her previous employment and therefore not be exploited; exploitation being understood here in purely economic terms. This incredible malleability of the definition of trafficking means that states ${ }^{30}$ tailor the offence according to their need and political, ethical and normative desire. As countries increasingly ratify the Trafficking Protocol, their domestic legal mediations of the coercionexploitation balance vary quite dramatically.

More generally, based on this analysis, we could conceptualise anti-trafficking law in terms of a pyramid of trafficking offences with trafficking episodes involving strong coercion and strong exploitation forming a narrow sliver at the top of the pyramid, while the base is occupied by instances characterised by weak coercion in relation to the means and weak exploitation in relation to the purpose. ${ }^{31}$ In the context of transnational labour markets, intermediate categories of trafficking might include scenarios characterised by strong coercion (e.g. deception into a certain line of work) and weak exploitation (e.g. pay below minimum wage) and weak

29 J Bhabha, 'Trafficking, Smuggling, and Human Rights', Migration Information Source, 2005, retrieved 6 February 2015, http://www.migrationinformation. org / feature/display.cfm?ID=294

30 International organisations also operationalise the definition in ways that are narrower than Article 3 would suggest. See P Kotiswaran, 'Beyond Sexual Humanitarianism: A Postcolonial Approach to Anti-Trafficking Law', University of California Irvine Law Review, 2014, pp. 353-405; ILO, 'Operational Indicators of Trafficking in Human Beings: Results from a Delphi Survey Implemented by the ILO and the European Commission', ILO, 2009, retrieved 6 February 2015, http: / / www.ilo.org/wcmsp5/groups/public/@ed_norm/@declaration/ documents/publication/wcms_105023.pdf

31 The clarity and certainty around a narrow definition of trafficking might result in a higher rate of prosecution. Alternatively, a broader definition of trafficking might result in greater prosecutorial discretion thus bringing down the rate of prosecution. 
coercion (e.g. abuse of position of vulnerability) and strong exploitation (e.g. debt bondage). There are two additional dimensions along which anti-trafficking law operates. The first is the legality of the means of entry, and the second is the legality of the sector in which trafficked labour is carried out. One can thus visualise at least sixteen scenarios based on these four factors that would implicate anti-trafficking law, only a minute fraction of which anti-trafficking law targets in reality. Further, over the life of a trafficking episode, there is considerable fluidity between statuses. A migrant may start out by migrating legally, but given the complete lack of protection within the formal sector (particularly in certain migrant worker contexts) and high levels of abuse, deploy the strategy of 'absconding' to shift into an undocumented immigration status or work in an illegal sector.

Viewed this way, it is not hard to understand why some states have focused unduly on targeting prostitution through anti-trafficking law. Sex work is highly stigmatised and on the surface looks to tick the boxes of both coercion and exploitation per se, the reasoning being that who but a coerced person would want to do sex work, and how can sex work be anything other than exploitative? Yet anti-trafficking law is not always used against instances involving strong coercion and strong exploitation at the top of the antitrafficking pyramid. The preoccupation of many Western states with border control means that there is an inordinate emphasis on the legality of the means of entry and the sector migrants work in-the assumption is that such migrants are not exploited. Thus a Filipino migrant worker ostensibly recruited to do factory work in the United Arab Emirates, but who ends up cleaning septic tanks on an American army base in Iraq, which he is not allowed to leave, ${ }^{32}$ is subject to both strong coercion and strong exploitation but is likely to fall off the radar screen of anti-trafficking law in the host state. Migrants legally entering labour markets through the spectrum of strong or weak means of coercion for varied levels of exploitation do not fare better either.

32 P Mahdavi, Gridlock: Labor, Migration, and Human Trafficking in Dubai, Stanford University Press, Stanford, 2011, pp. 18, 27; 97-101. 


\section{Domestic Mediations of Coercion/Exploitation: The Indian Example}

There is a deep paradox in contemporary anti-trafficking law and discourse. The inordinate attention on trafficking in Western industrialised economies is disproportionate to the extent of the problem. Only 7\% of the world's 20.9 million forced labourers are in developed economies while $56 \%$ are in Asia Pacific. ${ }^{33}$ Yet countries like India have a substantial majority of the world's trafficked victims and $90 \%$ of all trafficking is domestic. ${ }^{34}$ For instance, according to the ILO, forced labour, one of the forms of exploitation listed in Article 3, is to be found largely in Asia and the Pacific. Consider debt bondage and roughly 84 to $88 \%$ of the world's 20.5 million bonded labourers are in South Asia. ${ }^{35}$ Indeed, it is this very visibility of long-standing labour problems that has caused these emerging economies to engage in sex work and sex trafficking exceptionalism. ${ }^{36}$ Of late however, countries like Brazil are playing a key role in reimagining antitrafficking law; Brazil was actively involved in the discussions based on which the expert committee report recommended standard setting to the Governing Body of the ILO, ${ }^{37}$ which recently adopted a Protocol and Recommendation supplementing the Forced Labour Convention, 1930 (No. 29). ${ }^{38}$

Countries like Brazil and India also have sophisticated domestic legal regimes meant to target trafficking without

33 ILO, 'Profits and Poverty: The Economics of Forced Labour, ILO, 2014, p. 7, retrieved 2 March 2015, www.ilo.org/wcmsp5/groups/public/-ed_norm/declaration/documents/publication/wcms_243391.pdf

34 US Department of State, Trafficking in Persons Report 2014, retrieved 6 February 2015, http://www.state.gov/documents/organization/226846.pdf

35 S Kara, Bonded Labor Tackling the System of Slavery in South Asia, Columbia University Press, New York, 2012, p. 3.

36 ILO, 'Report for Discussion 2013', paragraph 120. Interestingly, trafficking in these jurisdictions is defined as trafficking only for sexual exploitation rather than labour exploitation. This has only recently changed in India.

37 ILO, 'Report and Conclusions of the Tripartite Meeting of Experts', ILO, 2013, paragraphs $92-102$.

38 ILO, 'Decision on the Second Item on the Agenda: Agenda of the International Labour Conference', ILO, 2013, retrieved 6 February 2015, http://www.ilo.org/ $\mathrm{gb} /$ decisions/GB317-decision/WCMS_208157/lang-en/index.htm 
exclusively relying on the criminal justice system. Trafficking in India has historically been associated with sex trafficking and sex work, and therefore with women. This understanding punctuated the Indian government's legislative interventions both in 2005 and more recently in 2013. However, prior to this, in the 1970s, the postcolonial state sought to address the deplorable conditions of bonded labour, forced migration and migrant labour that we would today identify as trafficking through a radically different mediation of the relationship between coercion and exploitation. I describe the Indian anti-trafficking legal regime in more detail elsewhere ${ }^{39}$ but deal here with the Bonded Labour System (Abolition) Act, 1976, as amended by the Bonded Labour System (Abolition) Amendment Act, 1985 (BLSAA), the Contract Labour (Regulation and Abolition) Act, 1970, as amended by the Contract Labour (Regulation and Abolition) Amendment Act No.14 of 1986 (CLRAA), ${ }^{40}$ and the Inter-State Migrant Workmen Act (Regulation of Employment and Conditions of Service) Act, 1979 (ISMWA). ${ }^{41}$ My goal is to first highlight the resolutely domestic legal iterations of transnational anti-trafficking law, and second to showcase alternate legal conceptualisations of the core aspects of the trafficking offence, namely, coercion and exploitation and the institutional mechanisms deployed against trafficking.

The BLSAA is a social legislation that abolishes intergenerational bondage ${ }^{42}$ backed up by the force of the criminal law, whereas

39 P Kotiswaran, 'Beyond Sexual Humanitarianism: A post colonial approach to antitrafficking law', University of California Irvine Law Review, 2014, pp. 353-405.

40 The Contract Labour (Regulation and Abolition) Act, No. 37 of 1970, India Code, retrieved 6 February 2015, http://indiacode.nic.in (search by Act Year).

${ }^{41}$ The Inter-State Migrant Workmen (Regulation of Employment and Conditions of Service) Act, 1979, No. 30 of 1979, India Code, retrieved 6 February 2015, http://indiacode.nic.in (search by Act Year).

42 The statement of objects and reasons to the legislation clearly indicates that it is aimed towards the abolition of a system existent in many parts of the country where 'several generations work under bondage for the repayment of a small sum which had been taken by some remote ancestor.' The Bonded Labour System (Abolition) Act, No. 19 of 1976, India Code (1976), retrieved 6 February 2015, http://www.childlineindia.org.in/CP-CR-Downloads/ Bonded\%20Labour\%20System\%20\%28Abolition\%29\%20Act $\% 201976 \% 20$ and $\% 20$ Rules.pdf 
the CLRAA and ISMWA fall within the province of labour law. Together, they form an interlocking system consisting of both criminal and labour laws aimed at targeting trafficking. The BLSAA essentially abolishes the 'bonded labour system', which is defined as a system of forced/partly forced labour whereby a debtor enters, or is presumed to have entered, into an agreement with a creditor under which, in exchange for economic consideration, or in pursuance of any customary or social obligation, he is required to work under certain conditions. Although terms like 'forced labour' and 'partly forced labour' are not defined, the working conditions that they entail include where the debtor renders his own labour or that of his family without wages or with the payment of nominal wages, gives up his freedom to sell his labour or the products of his labour, gives up his right to sell his property and gives up his freedom to move. 'Nominal wages' are defined being below the minimum wage or what is normally paid for the same or similar labour in that locality. The statute not only deals with bonded labour as a customary practice facilitated by the caste system, but also with supposedly voluntary agreements made under the force of circumstance whereby a debtor agrees to extremely harsh and ordinarily unacceptable working conditions amounting to forced labour. Transportation of the labourer is not essential for him to be considered bonded. A 1985 amendment extended the reach of the BLSAA so that any contract labourer or interstate migrant labourer working under the conditions listed in Section 2(g)(v) would be assumed to be working under the bonded labour system.

The BLSAA outlaws bonded labour and prohibits and penalises both existing and future bonded labour. All bonded labourers are set free and, by law, their obligation to pay back the debt is extinguished. The Act has several elaborate deeming provisions in relation to existing and future legal action arising from the debt. These provisions hint at a victim-centred anti-trafficking law. Creditors accepting any repayment for an extinguished debt can face imprisonment and fines. Offenses are cognisable and bailable, and civil courts have no jurisdiction under the Act. Local district magistrates and subordinate officers ensure the Act's implementation and the 
rehabilitation of bonded labourers. Vigilance committees with representatives of the state, the affected community, social workers, rural development institutions, and credit institutions are to assist the executive in this, while also defending suits against freed bonded labourers. Where the committee or labourer asserts the existence of a debt, bonded labour is presumed and the creditor has to prove otherwise.

The CLRAA and the ISMWA, deal with contract labour and migrant labour respectively. The statutory interpretive materials accompanying the BLSAA, CLRAA and ISMWA do not distinguish between these labour forms too sharply. These labour forms occupy a choice-coercion spectrum, with bonded labour at one end, ostensibly 'free' labour at the other with contract labour and migrant labour falling somewhere in between. Although CLRAA targets labour practices in the formal sector, courts have very much viewed it as a social legislation for the welfare of labourers; empirical studies confirm high levels of informality with the largest proportion of contract labourers working in the construction industry where contractors themselves are small operators. ${ }^{43}$ The government can, under the CLRAA, prohibit contract labour once certain conditions are satisfied but recognising, that pending the abolition of contract labour, minimum working conditions need to be ensured, the CLRAA imposes obligations on recruiters of contract labourers and intermediaries in the employer-employee relationship with a backstop to the principal employer. Central and state-level advisory boards and inspectors enforce the law, which penalises offending parties. Given the inadequacy of the CLRAA to deal with such abuse, the ISMWA was passed to protect the interests of an unorganised migrant labour force, often recruited by contractors for out-of-State work in large construction projects with little pay for work under extremely poor conditions. The ISMWA is similar to the CLRAA in many respects and several obligations are imposed on contractors, failing which, employers become liable for these. Salient for purposes

43 B Tulpule, 'ILO Initiative on Contract Labour', Economic and Political Weekly, 30 August 1997, at L-21, L-22. 
of conceptualising anti-trafficking law is the persistent role of intermediaries in all three labour forms, which explains the pragmatic imposition of obligations on them rather than their criminalisation under the CLRAA and ISMWA.

The three statutes are also key for offering an alternate conceptualisation of coercion and exploitation. In landmark judgments of the 1980s, the Indian Supreme Court interpreted force for purposes of forced labour prohibited by Article 23 of the Indian Constitution to include not only physical force, or force exerted through a legal provision, but also, 'any factor which deprives a person of a choice of alternatives and compels him to adopt one particular course of action'. ${ }^{44}$ This includes situations where the labourer was suffering from hunger or starvation or utter grinding poverty such that he or she accepted work remunerated with less than the minimum wage. Thus any labour remunerated at less than the minimum wage would be considered to be forced labour under the Constitution. Further, since a forced labourer is likely to have received an advance on his earnings to live off, the court directed that a presumption be raised as to his bonded labour status when a forced labourer was found to have received an advance. ${ }^{45}$ It was in response to this interpretation that the Indian parliament amended the BLSAA in 1985 so that any contract labourer or ISMW working in forced labour would be considered to be a bonded labourer.

The three legislations taken together have been poorly enforced. As Siddharth Kara observes, ${ }^{46}$ prosecutions for bonded labour are rare for several reasons including corruption, ${ }^{47}$ an indifferent bureaucracy, the inability of government officials and vigilance committees to identify bonded labourers and social tolerance of exploitative

44 People's Union for Democratic Rights v Union of India, A.I.R. 1982 S.C. 1473, at 1490.

45 Bandhua Mukti Morcha v Union of India, (1984) 2 S.C.R. 67, 78 (India).

46 S Kara, pp. 39, 42.

47 Kara also speaks of his interview of one bonded labourer who did not even bother with rehabilitation as these schemes were fraught with corruption. Ibid., p. 202. 
practices. ${ }^{48}$ To illustrate, of the 231 prosecutions that were launched under the BLSAA since 1996-1997, only six had been decided and even those cases had resulted in acquittal. ${ }^{49} \mathrm{Also}$, rehabilitation is virtually nonexistent or withheld for unreasonably long periods of time.

Despite this dire enforcement, I read these laws as domestic anti-trafficking law to show how they conceptualise force, not merely in terms of physical and legal force, but in structural terms, that is, background economic conditions including poverty, in other words, 'weak coercion'. The determinative factor then is whether the recruitment results in exploitation. Section 2(g)(v) of the BLSAA sets an objective threshold for such exploitation including the payment of anything less than the minimum wage, thus targeting 'weak exploitation'.${ }^{50}$ Unlike contemporary anti-trafficking laws which privilege coerced entry into trafficking over exploitation, ${ }^{51}$ the BLSAA, CLRAA and ISMWA de-emphasise the means of trafficking and privilege the purpose of trafficking, namely, exploitation. Given their focus, these laws deploy a combination of criminal and labour law mechanisms to target trafficking instead of solely relying on criminal law, which is a fraught option considering the abuse-generating role of the Indian police.

Despite, or some would argue because of, this legislative backdrop, the offence of trafficking under Section 370 of the Criminal Law (Amendment) Act, 2013, criminalises

48 Ibid., p. 201.

49 Ibid., p. 205.

50 For likely objections to this approach see Kotiswaran, pp. 391-395; these include whether a domestic legal regime could be transposed to the international level, whether Indian anti-trafficking laws are not meant to address the uniqueness of Indian labour conditions such as intergenerational debt bondage, whether emphasising exploitation and expanding its remit might not further entrench a politics of abolition, and whether a broader focus on the exploitation of both men and women might not obscure specific gendered harms that female migrants are subject to.

51 This is more likely to be true for developed countries like the UK and USA. Unless of course sex work is involved in which case, it is inevitably considered to be exploitative per se. 
trafficking along the lines of Article 3 but drops one of the means of trafficking, namely, the abuse of power or of a position of vulnerability. The forms of exploitation under Section 370 also omit reference to forced labour. Section 370A further criminalises anyone engaging a trafficked minor or adult, but only for purposes of sexual exploitation, ignoring the use of trafficked persons in myriad sectors of the Indian economy, including brick kilns, rice mills, farms, embroidery workshops, mines, stone quarries, homes and carpet factories. Although the 2013 amendment has consciously chosen to depart from the Article 3 definition of trafficking given the expansive judicial pronouncements on forced labour and bonded labour, those pronouncements continue to be good law. The striking omissions on the part of parliament could reflect the lack of political will more than anything else. The Indian domestic regime is however instructive for contemporary anti-trafficking discourse on three counts-their desire to counter a larger sliver of labour conditions falling within the anti-trafficking pyramid through a broad interpretation of coercion and a clear-cut baseline for exploitation (namely the minimum wage); the multiple institutional pathways of criminal justice, labour law and administrative law to counter trafficking and the pragmatic imposition of obligations on intermediaries in addition to principal employers to ensure decent conditions of work.

\section{Going Forward: A research agenda for anti-trafficking lawyers and activists}

I have suggested so far that domestic legal negotiations of the conceptual elements of the definition of trafficking, namely, coercion and exploitation can help elaborate a redistributive function for anti-trafficking law. However even a renewed focus on the full range of exploitative conditions in several labour sectors does not ensure that we can always identify a bright line concept (such as the minimum wage) for deciding on the boundaries of anti-trafficking law and the attendant regulatory choice between criminal law and/or labour law. This is particularly true for highly stigmatised sectors of 
work such as sex work where its assimilation into the world of legitimate work has always been contested. It is also true for the informal economy where the employment relationship is hard to identify or where the work involves the provision of services or for hybrid work sectors like manufacturing, which partake of the formal economy but become increasingly informal down the complex, transnational supply chain.

Abstract theorising on exploitation does not translate very well when concretely applied to the sectors I have listed. To illustrate, according to Wilkinson, ${ }^{52}$ exploitation could be measured in terms of the three alternate situations to being exploited. These include (1) the pre-interactive baseline (the outcome had the parties to the transaction never met); (2) the closest possible world baseline (the outcome had the exploited person entered into the same kind of transaction with someone other than the exploiter); and (3) the normative baseline (the outcome that is normatively desired for the exploited person). Given the precarious conditions of labour today, workers are invariably above the pre-interactive baseline whether they resort to work out of dire poverty or 'dull economic compulsion'. ${ }^{53}$ The challenge for anti-trafficking scholars then is to reduce the gap between the closest possible world baseline and the normative baseline. However for this, some basic understanding of the political economy of these labour sectors is necessary. In addition, anti-trafficking scholars, especially lawyers would need to approach anti-trafficking provisions through a legal realist lens. In other words, rather than bemoan the ineffectiveness of criminal sanctions against trafficking, lawyers might assess the myriad sets of civil rules (immigration, emigration, housing, labour, contract), informal social norms, market practices and attempts at self-regulation operating at the international, regional,

52 V Munro, 'Exploring Exploitation: Trafficking in Sex, Work and Sex Work' in V Munro \& M Della Giusta (eds.), Demanding Sex: Critical Reflections on the Regulation of Prostitution, Routledge, London, 2008, p.85.

53 J O'Connell Davidson, 'The Rights and Wrongs of Prostitution', Hypatia, vol. 7, issue 2, 2002, pp. 84, 94. 
domestic and local levels that often structure the political economies of varied labour sectors. Viewed this way, the regulatory profiles of sectors such as domestic work, sex work, sexual entertainment, janitorial work, factory workmigration corridors would vary quite significantly. While I am not suggesting a depoliticising move that narrowly engages with sector-specific responses to what are endemically poor labour conditions, lawmakers do need to recognise the complex legal pluralist space of labour markets. This calls for legal ethnographic research.

Importantly also, lawyers and activists need to appreciate the unintended consequences of any form of regulatory intervention or rule change, even if ostensibly beneficial. Protective measures can in fact end up having perverse consequences in that the number of jobs available in the host State might reduce as a result. ${ }^{54}$ As the work of Rhacel Parreñas on Filipina migrant hostesses in Japan demonstrates, an elaborate labyrinth of obligations imposed both in the Philippines and in Japan on recruiters, agencies and employers has only resulted in hostesses being indentured. Her work also illustrates that these labour sectors are quite sensitive to any regulatory changes. Thus, when the Japanese government introduced more stringent requirements for entertainer visas, ${ }^{55}$ ostensibly to professionalise hostessing by increasing the training period (but really to improve its Tier 2 Watch List categorisation in the US Trafficking in Persons rankings), the numbers of Filipina migrant hostesses fell from 80,000 in 2004 to 8,000 in $2005 .{ }^{56}$ This translated into more debt for the migrant workers, increasing their vulnerability to trafficking. ${ }^{57}$ If, on the other hand, one were to reduce

54 D McKenzie, C Theoharides \& D Yang, Distortions in the International Migrant Labor Market: Evidence from Filipino Migration and Wage Responses to Destination Country Economic Shocks, Centre for Research and Analysis of Migration, 2012, retrieved 6 February 2015, http:// www.cream-migration. org/publ_uploads/CDP_09_12.pdf

55 R S Parreñas, Illicit Flirtations: Labor, Migration and Sex Trafficking in Tokyo, Stanford University Press, Stanford, 2011, pp. 51-55, 172-73.

56 Ibid., 147.

57 Ibid., 173. 
their qualification requirements to reduce debt levels among Filipina hostesses through their reduced dependency on talent managers, ${ }^{58}$ the resultant increased supply of hostesses may well lower wages in the host state. We thus need to continue to explore the interface between the law and economy, especially the precise interaction between social norms driven by the economic logic of the market and formal state law to assess the most effective regulatory strategies to counter trafficking.

\section{Conclusion}

As we mark the fifteenth anniversary of the Trafficking Protocol, the challenges of using a prohibitionist international law to target a highly complex and fluid phenomenon like trafficking, which is itself embedded in global flows of people and products, are becoming apparent. I have argued in this article that the structure of transnational criminal law requires us to zero in on domestic legal regimes against trafficking, where conceptual and institutional innovations are most likely to materialise. I have also proposed actively expanding the narrow focus of current anti-trafficking efforts away from the top of the pyramid of anti-trafficking law, which targets scenarios involving strong coercion and strong exploitation, and instead pushing downwards towards the range of other trafficking scenarios. The momentum around trafficking issues will not only help re-envision international anti-trafficking law, but will also offer an opportunity to invigorate the enforcement of domestic labour laws against trafficking, which have been rendered dormant with the onslaught of neoliberal economic reforms. Similarly, fostering plurality in the regulatory mechanism such that labour law is at the centre, coupled with the highly selective use of criminal law penalties, informed in turn by a fine-grained understanding of the political economy and legal topography

58 Ibid., 177. 
of labour markets is likely to be more effective. A deeper understanding of the economics driving labour markets and the highly counter intuitive effects of legal responses to forced migration and exploitative working conditions in labour markets $^{59}$ is crucial.

Fifteen years after the adoption of the Trafficking Protocol, it is this immense opportunity that we can mobilise.

Prabha Kotiswaran is Senior Lecturer at the Dickson Poon School of Law, King's College London, United Kingdom.

Email: Prabha.kotiswaran@kcl.ac.uk

59 For an excellent example of such analysis of the brick markets in Afghanistan, which employ bonded labour, ILO, 'Buried in Bricks: A Rapid Assessment of Bonded Labour in Brick Kilns in Afghanistan', ILO, 2011, retrieved 6 February 2015, http://www.ilo.org/wcmsp5/groups/public/@asia/@ro-bangkok/documents/ publication/wcms_172672.pdf 


\section{Purity, Victimhood and Agency: Fifteen years of the UN Trafficking Protocol}

Marjan Wijers

\section{Abstract}

When the women's movement reverted back to the nineteenth-century Victorian concept of 'trafficking in women' to address abuses of migrant women in the sex industry, it unwittingly adopted not only a highly morally biased conceptdividing women into innocent victims in need of rescue and guilty ones who can be abused with impunity-but also one with racist and nationalistic overtones. Despite efforts to counter these flaws, this inheritance continues to define the debate on trafficking today, exemplified by the distinction made by the United Nations Trafficking Protocol between so-called 'sexual exploitation' and 'labour exploitation' and its focus on the aspects of recruitment and movement. As a result, its implementation in the last fifteen years has led to a range of oppressive measures against sex workers and migrants in the name of combating trafficking. The focus on the purity and victimhood of women, coupled with the protection of national borders, not only impedes any serious effort to address the exploitation of human beings under forced labour and slavery-like conditions, but actually causes harm. The call of the anti-trafficking movement for a human rights-based approach does not necessarily solve these fundamental problems, as it tends to restrict itself to protecting the rights of trafficked persons, while neglecting or even denying the human rights of sex workers and migrants.

Keywords: Trafficking Protocol, sex workers' rights, anti-trafficking, human rights, migrant women 
Please cite this article as: $M$ Wijers, 'Purity, Victimhood and Agency: Fifteen years of the UN Trafficking Protocol', Anti-Trafficking Review, issue 4, 2015, pp. 56-79, www. antitraffickingreview.org

\section{Introduction}

This article argues that from a human rights perspective the concept of trafficking, and consequently the anti-trafficking framework, is fundamentally problematic. It discusses the debate on the definition of trafficking during the negotiations on the United Nations (UN) Trafficking Protocol ${ }^{1}$ and the position of the two main non-governmental organisation (NGO) lobby blocs. After placing this debate in its historical context, the paper evaluates the extent to which the Protocol has solved the old problems attached to the anti-trafficking framework. Major problems that remain fifteen years after the Protocol negotiations include the conflation of trafficking and sex work and the focus on (trans border) movement rather than on the actual forced labour and slavery-like exploitation of human beings. The paper concludes with remarks on implications for the antitrafficking movement.

\section{The Making of the UN Trafficking Protocol}

One of the most hotly debated issues during negotiations on the Trafficking Protocol concerned the definition of trafficking. This is not surprising as, until then, one of the fundamental problems in combating 'trafficking' had been the lack of international consensus on a definition and thus on exactly which practices should be combated.

During the fifteen years preceding the Protocol, trafficking had been framed in several, sometimes conflicting, ways. Six

In full: United Nations Protocol to Prevent, Suppress and Punish Trafficking in Persons, Especially Women and Children, supplementing the United Nations Convention Against Transnational Organized Crime. 
main approaches can be distinguished. In the moral approachbased upon the traditional definition of trafficking wherein trafficking is inherently linked to prostitution-prostitution itself is seen as the problem. Women in prostitution are either victims who need to be rescued or deviants who must be reformed and/or punished. Corresponding strategies aim at the (further) criminalisation of prostitution. This approach was mainly put forward by States but also by some NGOs. Connected to the moral approach is the definition of trafficking as a threat to public health and order that should be controlled by strict regulation of prostitution through different forms of State control. However, two other approaches, primarily employed by States, had become increasingly dominant: trafficking as an issue of illegal or 'unorderly' migration demanding more restrictive immigration policies, and trafficking as a problem of (organised) crime to be solved with heavier punishments, better international police cooperation and more effective prosecution of perpetrators. Relatively new was a human rights approach, mostly advocated by NGOs and defining trafficking as a violation of women's human rights for which States could be held accountable. However, within this approach two different currents existed: the first defining prostitution as such as a violation of women's human rights, bringing us back to the moral approach. The second holding that not prostitution itself, but the conditions of coercion, abuse and deceit constitute a violation of human rights. Building on the latter type of human rights approach, sex workers' rights organisations and a number of anti-trafficking organisations started to challenge the traditional approaches, advocating the decriminalisation of sex work and the sex industry as a preliminary condition for the protection of the human rights of the women involved. Within this labour approach the concept of trafficking is expanded to include the exploitation of women's work in informal labour sectors, such as domestic work. ${ }^{2}$

2 M Wijers \& L Lap-Chew, Trafficking in Women, Forced Labour and Slavery-like Practices in Marriage, Domestic Labour and Prostitution, Utrecht/Bangkok: Foundation Against Trafficking in Women/GAATW (revised edition), 1999, pp. 189-210; $M$ Wijers, 'European Union Policies on Trafficking in Women' in $M$ Rossilli (ed.), Gender Policies in the European Union, Peter Lang, New York, 2000, pp. 217-226. 
The different approaches make clear that, depending on the conceptualisation of trafficking, different solutions are drafted, each with its own interests attached. This made the definition of trafficking a highly contested issue during the Protocol negotiations and a major lobbying goal for participating NGOs. Underlying the debates were (and are) two diametrically opposed views on sex work. As discussed above, one view sees all prostitution as trafficking, considering prostitution in and of itself a violation of women's human rights and consequently seeking to include all sex work in the definition of trafficking. The other view sees sex work as legitimate work, holding that forced labour in all industries, including the sex industry, should be addressed. In this view, it is the conditions of abuse that violate human rights, no matter in which industry. It thus makes a clear distinction between sex work, defined as consensual sex between adults, and trafficking, defined by coercion and deceit. $^{3}$

These two views were represented by two opposing NGO lobbying blocs: the International Human Rights Network and the Human Rights Caucus. The International Human Rights Network consisted of anti-trafficking and abolitionist ${ }^{4}$ groups, led by the Coalition Against Trafficking in Women (CATW). ${ }^{5}$ The Human Rights Caucus was made up of human rights, anti-trafficking and sex workers' rights organisations and activists, led by the International Human Rights Law Group (IHRLG) and the Global Alliance Against Traffic in Women

3 M Ditmore \& $M$ Wijers, 'The Negotiations on the UN Protocol on Trafficking in Persons. Moving the focus from morality to actual conditions', Nemesis, 2003, p. 79.

4 'Abolitionist' in this context means the abolition of prostitution, referring to the historical movement for the abolishment of slavery. Abolitionist groups are also at times referred to as radical feminist groups.

5 Members of the CATW-led network included CATW North America, Asia Pacific, Africa, Latin America and Australia, Equality Now (USA), the International Abolitionist Federation, Women's Front (Norway), and the European Women's Lobby. 
(GAATW). ${ }^{6}$ The latter alliance, for the first time, brought together human rights, anti-trafficking and sex workers' rights movements in a joint lobby. In particular, the combination of anti-trafficking and sex workers' rights groups was radical, bridging the historical gap between the two caused by the persistent conflation of 'trafficking' and 'prostitution' and the abuse of anti-trafficking measures to police and punish female (migrant) sex workers and restrict their freedom of movement. ${ }^{7}$ As per the Global Network of Sex Work Projects statement on the Protocol in 1999:

Historically, anti-trafficking measures have been more concerned with protecting women's purity than with ensuring the human rights of those in the sex industry. This approach limits the protection afforded by these instruments to those who can prove that they did not consent to work in the sex industry. It also ignores the abusive conditions within the sex industry often facilitated by national laws that place (migrant) sex workers outside of the range of rights granted to others as citizens and workers. ${ }^{8}$

Feminist NGO networks and State delegations alike were deeply divided over the issue of prostitution. As noted by Doezema, many State delegations used the negotiations as an opportunity to denounce the evils of prostitution, while others (fewer in number) argued that focusing on prostitution detracted from efforts to come to an agreement

6 The following organisations were part of the Human Rights Caucus: International Human Rights Law Group (IHRLG, USA), Global Alliance Against Traffic in Women (GAATW), Foundation Against Trafficking in Women (STV, the Netherlands), Asian Women's Human Rights Council (AWHRC, Philippines, India), La Strada (Poland, Ukraine, Czech Republic), Fundación Esperanza (Colombia, Netherlands, Spain), Ban-Ying (Germany), Foundation for Women (Thailand), KOK-NGO Network Against Trafficking in Women (Germany), Women's Consortium of Nigeria, Women, Law and Development in Africa (Nigeria), and sex workers' rights activists from the Global Network of Sex Work Projects (NSWP).

7 M Ditmore \& $M$ Wijers, pp. 80-81.

8 NSWP, 'Commentary on the Draft Protocol To Combat International Trafficking In Women And Children Supplementary To The Draft Convention On Transnational Organized Crime', (A/AC.254/4/add.3), NSWP, retrieved 28 February 2015, http://nswp.gn.apc.org/es/node/505 
on trafficking. ${ }^{9}$ The lobbying efforts of the Human Rights Caucus focused on a broad and inclusive definition, addressing all trafficking into forced labour, slavery and servitude, irrespective of the nature of the work, the services provided or the gender of the trafficked person. This definition excluded voluntary, non-coercive sex work. Additionally, the Caucus worked to include human rights protections for trafficked persons, regardless of their willingness to act as witnesses in prosecutions of their traffickers. Finally, an important aim was the inclusion of a non-discrimination clause to ensure that trafficked persons would not be subject to discriminatory treatment in law or in practice. ${ }^{10}$

While the Caucus recognised sex work as work, the second bloc, the International Human Rights Network, lobbied to include all prostitution in the definition of trafficking, irrespective of conditions of consent or force, with little or no interest in expanding the definition to address other forms of trafficking and forced labour. This position goes back to the early treaties on trafficking, in particular the 1949 Convention for the Suppression of the Traffic in Persons and of the Exploitation of the Prostitution of Others, as the next section shows.

\section{Back to History ${ }^{11}$}

The first treaties on trafficking-or 'white slavery' as it was called then-stem from the early twentieth century. They define 'trafficking' as the compulsive procurement of women and girls 'for immoral purposes', originally only across

\footnotetext{
9 J Doezema, 'Now you see her, now you don't: Sex workers at the UN Trafficking Protocol Negotiation', Social and Legal Studies, vol. 14, issue 1, 2005, p. 62, retrieved 25 February 2015, http://sls.sagepub.com/content/14/1/61

${ }_{10} M$ Ditmore \& $M$ Wijers, p. 81.

11 See for an extensive description of the historical development of the concept of trafficking: Wijers \& Lap-Chew, 1999.
} 
borders, later also within national borders. ${ }^{12}$ The dominant concern was the protection of 'innocent' women and girls from being lured into brothels, thus 'distinguish[ing] the innocent woman who found herself in the sex industry as a result of abduction or deceit, from the ordinary prostitute. ${ }^{13}$ Coercive conditions inside brothels were explicitly not addressed, and instead considered 'a question of internal legislation', as the closing statement of the 1910 International Convention for the Suppression of the White Slave Traffic states.

In later treaties, in particular the 1949 Convention for the Suppression of the Traffic in Persons and of the Exploitation of the Prostitution of Others, trafficking became linked to the exploitation of prostitution, and coercion as defining element was abandoned. Declaring prostitution 'incompatible with the dignity and worth of the human person', the 1949 Convention obliges States to criminalise all forms of procurement and exploitation for the purpose of prostitution, with or without consent of the woman involved. The prostitute herself, however, was not to be penalised as she was seen as a passive victim in need of protection, if necessary against her will. Although addressed in two separate articles, 'trafficking' and 'exploitation of prostitution' are mentioned in the same breath. ${ }^{14}$ Illustrative are various national laws that followed the Convention, such as the Indian Immoral Traffic (Prevention) Act, which targets the exploitation of prostitution rather than 'trafficking' ${ }^{15}$

12 International Agreement for the Suppression of the White Slave Traffic, 1904; International Convention for the Suppression of the White Slave Traffic, 1910; International Convention for the Suppression of the Traffic in Women and Children, 1921; International Convention for the Suppression of the Traffic in Women, 1933. Whereas the 1904 Agreement only addresses the compulsive procurement of women for immoral purposes abroad, the 1910 Convention broadens the scope to include the traffic in women within national boundaries. The 1933 Convention importantly includes boys ("traffic in children of both sexes'). The 1933 Convention removed the requirement of constraint, but solely in regard to the international traffic in women.

$13 \mathrm{~J}$ Bindman \& J Doezema, 'Redefining Prostitution as Sex Work on the International Agenda', Anti-Slavery International and NSWP, 1997, p. 2.

${ }^{14} M$ Wijers \& L Lap-Chew, pp. 25-26.

15 M Wijers \& L Lap-Chew, p. 148; GAATW, Collateral Damage: The Impact of AntiTrafficking Measures on Human Rights Around the World, GAATW, Bangkok, 2007, p. 116. 
As stated by Bravo, this preoccupation with prostitution continues today, despite the recognition of other exploitative purposes:

The spectre of involuntary sex and of despoilment of innocent white maidens seized the world's attention in the late 1800's and early 1900's. Overtones of that appalled, fascinated, and condemnatory prurience continue to pervade public and institutional perceptions of the traffic in human beings in the early twenty-first century. ${ }^{16}$

From the first treaties, and later in the 1980s as trafficking debates re-emerged following a period of silence, the concern about 'trafficking' was mixed with concerns about the morality of women as well as about national borders. A recurring theme is the issue of consent.

\section{Free vs Forced Prostitution: The issue of coercion and consent $^{17}$}

Whereas coercion had been abandoned in the 1949 Convention, in the years before the Trafficking Protocol discussions began, a number of definitions, e.g. in the 1994 UN Resolution on Traffic in Women and Girls, tried to reintroduce coercion or force as a crucial element of trafficking. ${ }^{18}$

Although this reintroduction had the potential to give some room for disentangling trafficking from an equation with all prostitution, the question as to what exactly coercion and consent refer to remained a permanent source of confusion. Debates on this also impacted the Protocol as is explored later in this paper.

${ }^{16} \mathrm{~K}$ E Bravo, 'Exploring the Analogy Between Modern Trafficking in Humans and the Trans-Atlantic Slave Trade', Boston University International Law Journal, vol. 25, no. 2, 2007, pp. 207-221.

17 See for a more fundamental discussion of the forced/voluntary dichotomy and the issue of consent: J Doezema.

18 Resolution 49/166 of the General Assembly of the UN (UN Doc/A/Res/49/166), adopted December 1994. 
Relatively clear is the viewpoint in which 'coercion' or 'force' is interpreted as referring to both the process of recruitment and the conditions of work. 'Forced prostitution' in this interpretation is the equivalent of 'forced labour in prostitution'.

A second interpretation of the coercion/consent dichotomy, as per the early twentieth century treaties, is that coercion and consent refer to the process of recruitment only. 'Forced' in this interpretation merely addresses the way a woman came to be a prostitute: as a result of her own decision or forced by others. Once a woman works in prostitution, the conditions under which she works-be they good or exploitativeare not considered relevant. 'Coercion' or 'force' defined in this way excludes women who consciously make the decision to work in the sex industry, but who are subject to force and abuse in the course of their work. The abuses she undergoes are considered to be the consequences of her willingness to be a prostitute.

A third view is that the institution of prostitution itself is a violation of human rights, akin to slavery. Within this view, any distinction which refers to the consent or will of the woman concerned is irrelevant, as no person, even an adult, is believed to be able to give genuine consent to engage in prostitution. The conditions of recruitment or work-whether forced or free-are not relevant as prostitution is believed to be 'forced' per definition. ${ }^{19}$ It follows that anyone involved in assisting a woman move from one place to another to engage in sex work is a trafficker. ${ }^{20}$ In addition, it is difficult to see how prostitutes can be respected if their work is viewed as inherently degrading. ${ }^{21}$

19 M Wijers \& L Lap-Chew, pp. 37-38, 223.

20 J Doezema, p. 67.

21 Illustrative is the characterisation of prostitutes by a member of CATW as 'empty holes surrounded by flesh, waiting for a masculine deposit of sperm', during the NGO consultation with UN/inter governmental organisations on Trafficking in Persons, Prostitution and the Global Sex industry: 'Trafficking and the Global Sex Industry: The need for a human rights framework', 1999, Palais des Nations, Geneva (quoted in J Doezema, p. 74). 


\section{Trafficking vs Illegal Migration}

During the 1990s the historical focus on (cross-border) recruitment and transportation re-emerged leading to a range of repressive immigration measures, especially by industrialised Western countries. For example, at a European conference on trafficking coorganised by the European Commission and the International Organization on Migration in 1996, an overwhelming number of documents prepared by governments and international organisations were titled 'trafficking in migrants' or 'trafficking in aliens' and predominantly addressed illegal migration, aiming to 'prevent the entry of possible victims'.22

Measures to combat trafficking varied from tightening up visa policies, closer supervision of international marriages and the criminalisation of third parties who facilitate illegal entry or stay (and sometimes of the migrant her or himself). Some countries, like the United Kingdom (UK), explicitly excluded (alleged) prostitutes from legal immigration to address trafficking. ${ }^{23}$ Yet, 'destination' countries are not alone in seeking to combat trafficking by obstructing migration, especially of young women. Bangladesh, for example, issued a ban on migration for low- and semi-skilled women, arguing that 'these women [...] have low moral standards and can easily be seduced to be engaged in immoral activities', ${ }^{24}$ while Hungary confiscated the passports of alleged prostitutes in order to prevent them from crossing borders. ${ }^{25}$ These types of restrictions are combined with 'awareness raising' campaigns in countries of origin, warning women and girls of the dangers of trafficking, which they say are inherent in migration. ${ }^{26}$

22 European Commission, 'Report of the Conference on Trafficking in Women', (CAB./183/96-en), Vienna, Brussels, 1996.

${ }^{23}$ M Wijers \& L Lap-Chew, p. 198. See also a study on biases of immigration officers in Australia and Thailand, J Ham, M Segrave and S Pickering, 'In the Eyes of the Beholder: Border enforcement, suspect travellers and trafficking victims,' Anti-Trafficking Review, issue 2, 2013.

24 S Sobhan, Women Labour Migration, the case of Bangladesh, Bangladesh, 1992.

25 M Ditmore \& $M$ Wijers, p. 81.

${ }^{26}$ S Ghosh, 'Anti-Trafficking and its Discontents: Women's migrations and work in an Indian borderland, Gender, Place \& Culture, 2014. 


\section{Key Points of the Debate on the Trafficking Protocol}

From the historical roots of the anti-trafficking framework a number of problematic dominant themes were carried into the Protocol negotiations, notably: the focus on recruitment and transport, rather than on abusive or coercive conditions of work, coupled with concerns about protection of national borders; the preoccupation with the innocence, read: the morality, of the women concerned; the conflation of trafficking and prostitution; and the reduction of women to passive victims without regard to conditions of coercion or consent.

Concepts of women's agency-i.e. whether women can actually choose to work in the sex industry-permeated all other discussions. A crucial term was 'consent':

States, supported by the CATW-network, argued that the definition must include wording on consent that indicated that a person could never consent to prostitution. Other states argued that as force and coercion had already been agreed as the key elements of trafficking, a statement on consent would be redundant. As one delegate put it [...] 'by definition, no one can consent to abuse or coercion'. ${ }^{27}$

Whereas the International Human Rights Network was in favour of restricting the Protocol to the trafficking in women and children, leaving men out of the equation entirely, and advocated the inclusion of language like 'with or without consent', the Human Rights Caucus advocated that the Protocol address trafficking for all types of work or services for both women and men, while removing any mention of prostitution from the international definition of trafficking. The Caucus also advocated the use of the term 'trafficked persons', rather than 'victims', as the latter term tends to reduce the identity of, in particular, women to that of a passive victim rather than recognising them as persons with

27 J Doezema, p. 79. 
agency, decision-making abilities and rights. In the same vein, the Caucus argued that the singling out and linkage of women and children as targets of the Protocol was problematic in that it often entails treating women as children, denying them the right to have control over their own bodies and lives. ${ }^{28}$

\section{Successes and Failures}

The final definition in the UN Trafficking Protocol is a political compromise. Compared to the old definitions, the Trafficking Protocol signifies a step forward. The use of coercion, abuse and deceit are a key element of trafficking; the Protocol broadens the definition to include all forms of forced labour and slavery-like practices into which people-of any gendercan be trafficked, whether within or across borders; and, for the first time, the definition links trafficking with forced labour and slavery-like practices, thus bringing into play international conventions and agreements on forced labour.

Moreover, the Trafficking Protocol makes a clear distinction between trafficking and prostitution. Although it explicitly mentions the exploitation of the prostitution of others and other forms of sexual exploitation as one of the forms of exploitation, this type of exploitation must be combined with one of the deceptive or coercive 'means' listed in the definition to classify as trafficking. The terms 'exploitation of the prostitution of others' and 'sexual exploitation' were intentionally left undefined, leaving the question of how to address prostitution in their domestic laws to the discretion of individual States. ${ }^{29}$

Less successful were the efforts of the Caucus to include human rights protections for trafficked persons. Whereas all law enforcement provisions are mandatory, including those on strengthening border controls, the provisions on

28 M Ditmore \& $M$ Wijers, p. 82.

29 See Interpretative Notes (A/55/383/Add.1/Addendum). 
protection and assistance of trafficked persons are largely discretionary. A major cause for this failure was the deep and entrenched divide between the two NGO blocs, which made any concerted lobby almost impossible, even on issues on which one may have expected they agreed. ${ }^{30}$

\section{Old Problems in a New Coat}

\section{'Sexual exploitation' vs 'labour exploitation'}

In practice, in the post-Protocol years, the old problems have continued to reappear, though in a new coat. Firstly, the Protocol's text has been interpreted in a way in which 'sexual exploitation' is singled out as separate from what now is called 'labour exploitation', i.e. forced labour, slavery, slaverylike practices and servitude in other industries. This is problematic for a number of reasons.

Apart from the fact that this implies that sex work cannot be labour, the separation of sexual exploitation from forced labour falsely suggests that forced labour cannot exist in the sex industry, consequently depriving sex workers of protection against the practice. This is one of the reasons why sex workers perceive the trafficking framework as unhelpful in the protection of their human rights. In this context it should be noted that the International Labour Organization (ILO) Committee of Experts has always dealt with forced prostitution as a form of forced labour. As stated by the 2007 International Labour Conference:

While a certain distinction has been drawn in the above definition between trafficking for forced labour or services and trafficking for sexual exploitation, this should not lead to a conclusion that coercive sexual exploitation does not amount to forced labour or services, particularly in the context of human trafficking. ${ }^{31}$

$30 \mathrm{~J}$ Ditmore \& $M$ Wijers, pp. 85-86.

31 ILO, 'Eradication of Forced Labour', ILO, 2007, p. 42. 
In this sense, the Protocol is a step backwards rather than forwards. Oppositely, the distinction does not recognise that sexual exploitation can take place in any labour sector.

Moreover, despite the distinction the Protocol makes between trafficking and sex work, in practice the singling out of 'sex trafficking' has reinforced the historical obsession with prostitution and fed into the old conflation of sex work and trafficking, more so since the terms sexual exploitation and exploitation of prostitution are left undefined.

The distinction between 'sexual exploitation' and 'labour exploitation' also gives rise to diametrically opposed strategies in combating trafficking in the sex industry and other industries. ${ }^{32}$ In the latter case, strategies focus on strengthening rights of migrant workers and enforcing labour standards to combat abusive practices, e.g. by the ILO. Conversely, in the case of trafficking in the sex industry, the further criminalisation of prostitution is advocated, thus leaving sex workers with fewer instead of more rights. This is reinforced by the call on States in Article 9(5) of the Protocol to take measures to 'discourage the demand that fosters all forms of exploitation, especially of women and children, that leads to trafficking'. This paved the way for 'end demand' campaigns, which call for the criminalisation of clients of sex workers under the heading of combating trafficking. It, moreover, paves the way for excluding sex work from measures to address forced labour in other industries, such as those contained in the 2014 ILO recommendation for the suppression of forced labour. ${ }^{33}$

32 See further problematising of this in the Australian context in F Simmons \& $\mathrm{F}$ David, 'The Road to Effective Remedies: Pragmatic reasons for treating cases of "sex trafficking" in the Australian sex industry as a form of "labour trafficking"', Anti-Trafficking Review, issue 1, 2012.

33 ILO, 'R203-Forced Labour (Supplementary Measures) Recommendation', no. 203, 2014, retrieved 5 March 2015, http://www.ilo.org/dyn/normlex/en/ $\mathrm{f} ? \mathrm{p}=$ NORMLEXPUB:12100:0::NO::P12100_INSTRUMENT_ID:3174688 


\section{Movement vs Forced Labour and Slavery-Like Exploitation as the Crucial Element}

A second, but connected, fundamental problem is the focus on the way people arrive in a situation of forced labour or slavery-like exploitation. Attention on the movement elements of trafficking has taken focus away from its forced labour and slavery-like outcomes:

[...] the Trafficking Protocol does not equate 'exploitation' [...] with trafficking, but is concerned only with prohibiting forms of dealing which facilitate or lead to exploitation. There is, in consequence, no obligation flowing from the Trafficking Protocol to do anything about the condition of being exploited, much less to provide a remedy to exploited persons. ${ }^{34}$

The focus on (cross-border) movement has not only provided States a justification to pursue a border control agenda under the guise of combating trafficking. ${ }^{35}$ It also unjustifiably privileges a small subgroup of persons-i.e. those who arrived in a situation of forced labour through trafficking-while marginalising those who find themselves in forced labour or slavery-like situations but who do not meet the definition of trafficking.

In practice, the focus on movement often leads to discriminatory measures which deprive some people from exercising their freedom of movement and their right to a livelihood, because they might be trafficked, while excluding others who actually have been subjected to forced labour, slavery-like practices or servitude from protection or support

34 J C Hathaway, 'The Quagmire of "Human Trafficking”, Virginia Journal of International Law, vol. 49, issue 1, 2008-2009, p. 10.

35 M Lee, 'Human Trafficking and Border Control in the Global South' in K S Aas \& $M$ Bosworth (eds.), The Borders of Punishment: Migration, citizenship and social exclusion, Oxford University Press, 2013; B Anderson, 'Where's the Harm in That? Immigration enforcement, trafficking, and the protection of migrants' rights،, American Behavioral Scientist, vol. 56, issue 9, 2012, pp. 1241-1257. Also for instance: BBC, 'UK “won't take Calais migrants"', BBC News, 22 Sept 2009. 
because they do not fall under the trafficking definition. There is no reason why one category of victims of forced labour and slavery-like practices should have access to assistance and protection and other categories not, simply because of the way they arrived in that situation.

From a human rights perspective, the primary concern is to stop exploitation of people under forced labour or slavery-like conditions, no matter how people arrive in such situations and whether it concerns a victim of trafficking, a smuggled person, an illegal migrant or a lawful resident.

The logical way forward-at least from a human rights point of view-would be to focus policy interventions on the forced labour and slavery-like outcomes of trafficking, rather than on the means of trafficking. Importantly, this would shift the debate from morality ${ }^{36}$ to actual working conditions.

\section{Collateral Damage}

Since the adoption of the Trafficking Protocol in 2000, efforts to stop trafficking have mushroomed globally. While one may hope that this at least has led to some progress in the area of protection and assistance of victims, the Protocol has done little to address the old problems as above.

Notwithstanding the distinction the Protocol makes between trafficking and sex work, anti-trafficking measures increasingly target sex workers and sex work as such. Neither has it changed the emphasis of most governments on control and restriction of migration, instead of on protecting migrants against abuse and exploitation. ${ }^{37}$

\footnotetext{
36 See for instance: R Weitzer, 'Moral Crusade Against Prostitution', Society, vol. 43, issue 3, 2006, pp. 33-38.

37 See for instance: GAATW, 'Collateral Damage'.
} 
Moreover, rather than safeguard the human rights of people who have been trafficked, the priority of governments has been to prosecute and punish traffickers, as per their commitments in the Protocol. Even when the need for assistance and protection of victims is recognised, most countries make access to assistance and protection of trafficked persons conditional on their cooperation with law enforcement officials, only to pack them off home when they are not useful anymore. ${ }^{38}$ In many cases, trafficked persons are detained and deported without protection against reprisals from traffickers and without redress for unpaid wages and compensation for the damages they suffered. ${ }^{39}$ Sometimes trafficked persons are, in the name of protection or rehabilitation, confined in public or private shelters under conditions no different from detention. ${ }^{40}$ In other cases, as this section shows, trafficked persons are prosecuted for being complicit in offences they committed as a result of their being trafficked. Usually this is prostitution, either in the country where they were identified or upon arrival at home, but it can also be a migration offense.

In the name of combating trafficking, Sweden, Northern Ireland and an increasing number of other European countries have criminalised clients of sex workers, based on the logic that if there is no 'demand', there is no prostitution. And, if there is no prostitution, there is no trafficking for prostitution. Reports from sex workers and researchers indicate that, while there is nothing to support the claim that prostitution in Sweden has decreased since the

38 See: GAATW, 'Collateral Damage'; S Copić \& B Simeunović-Patić, 'Victims of Human Trafficking: Meeting Victims' Needs?' in J Winterdyk, B Perrin \& P Reichel (eds.) Human Trafficking: Exploring the International Nature, Concerns, and Complexities, CRC Press, London, 2011.

39 B Anderson; K H Heinrich, 'Ten Years After the Palermo Protocol: Where are protections for human trafficking?', Human Rights Brief, vol. 18, issue 1, 2010. S Plambech, "Between "Victims" and "Criminals": Rescue, deportation, and everyday violence among Nigerian migrants', Social Politics, vol. 21, issue 3, 2014.

40 A T Gallagher \& E Pearson, 'Detention of Trafficked Persons in Shelters: A legal and policy analysis', 2008, retrieved 27 Feb 2015, http://ssrn.com/ abstract $=1239745$ 
country established the law on criminalisation of clients of sex workers in 1999, violence against sex workers has increased, in particular against those working on the streets. Stigma and social exclusion of sex workers have also increased, leaving them more isolated and vulnerable. In addition, criminalising clients has not only made it more difficult for sex workers to work independently but also increased unsafe sex practices, as police use condoms as evidence of prostitution. ${ }^{41}$ And in the name of combating trafficking, the European Women's Lobby is campaigning for a 'prostitutionfree Europe', in essence denying sex workers the very right to exist. ${ }^{42}$

The distinction between 'innocent' and 'guilty' victims persists and is one of the major obstacles to combating trafficking, as it denies sex workers protection against abuse. When sex workers do find themselves in a trafficking situation, they have to prove they are 'innocent'. The Protocol states clearly that 'consent' cannot be used as a legal defence once the use of one of the coercive or deceptive means has been proved. ${ }^{43}$ However, in practice trafficked

41 A Jordan, 'The Swedish Law To Criminalize Clients: A Failed Experiment In Social Engineering', Center For Human Rights and Humanitarian Law, 2012, retrieved 25 February 2015, http://www.nswp.org/sites/nswp.org/files/Issue-Paper4\%5B1\%5D_0.pdf; S Thing, P Jakobsson \& A Renland, 'When purchase of sex is a crime: About new legal measures and its impact on harm reduction among sex workers in Sweden and Norway', presented at International Harm Reduction Association's 22nd International Conference, Beirut, Lebanon, 3-7 April 2011; S Dodillet \& P Östergren, 'The Swedish Sex Purchase Act: Claimed success and documented effects', Conference paper presented at the international workshop 'Decriminalizing Prostitution and Beyond: Practical experiences and challenges', The Hague, 3-4 March 2011; J Juosmanen, 'Attitudes and Perceptions about Legislation Prohibiting the Purchase of Sexual Services in Sweden', European Journal of Social Work, 2011, pp. 1-17; C Holmström, 'Report on the Effects of the Swedish Ban Against Sex Purchase' [original name in Swedish], Swedish Association for Sexuality Education, 2015.

42 European Women's Lobby, 'Together for a Europe Free from Prostitution', retrieved 27 February 2015, http://www.womenlobby.orgspip.php?rubrique187 \&lang=en

${ }^{43}$ Article 3(b) of the Protocol explicitly states that the consent of a victim of trafficking in persons to the intended exploitation is irrelevant where any of the coercive or deceptive means listed in the definition are used. A person can thus consent to be smuggled, to migrate or to work as a domestic worker, sex worker or any other work, but this does not imply that the person consented to the exploitation. On the issue of consent also see: UNODC, 'The Role of Consent in the Trafficking in Persons Protocol', Issue Paper, UNODC, 2014. 
persons are having to prove that they did not consent to prostitution in order to be considered a 'real' victim. ${ }^{44,45}$ As noted by the European Expert Group in its report:

The effect is that in many cases, instead of the offender standing trial, it is the victim who has to prove her 'innocence', thus shifting the focus from the acts of the trafficker to the morality of the victim. ${ }^{46}$

The distinction between 'good' women who deserve protection and 'bad' women who forfeited their right to protection against abuse sends two messages. The first one is that sex workers can be abused with impunity. ${ }^{47}$ The second is that the right of women to be protected against violence and abuse is determined by their sexual purity or 'honour'. This is not only harmful for sex workers, but for all women.

In Romania, for instance, forcing 'innocent' women into prostitution is a crime. The same acts, however, will be qualified as 'pandering' when the victim is a sex worker. In the first case the victim is entitled to protection and support; in the second she is seen as co-perpetrator and prosecuted and punished. ${ }^{48}$ Similarly, in Albania the articles in the Criminal

${ }^{44}$ M Ticktin, Casualties of Care: Immigration and the Politics of Humanitarianism in France, University of California Press, Berkeley, 2011; C M Jacobsen \& M-L Skilbrei, 'Reproachable Victims'? Representations and Self-representations of Russian Women Involved in Transnational Prostitution, Ethnos: Journal of Anthropology, vol. 75, issue 2, 2010, pp. 190-212. On images of 'real' victims, see: T G Blanchette, A P Silva \& A R Bento, 'The Myth of Maria and The Imagining of Sexual Trafficking in Brazil', Dialectical Anthropology, vol. 37, no. 2, 2013, pp. $195-227$.

45 A similar reasoning in regard to trafficking for, e.g., domestic labour would imply that if a person consented to work as a domestic worker or did so before, it would exclude that person from being recognised as a victim of trafficking for domestic labour.

46 Experts Group on Trafficking in Human Beings, 'Report of the European Experts Group on Trafficking in Human Beings', European Commission, 2004, p. 51, retrieved 5 March 2015, http://lastradainternational.org/doc-center/1049/ report-of-the-experts-group-on-trafficking-in-human-beings

47 J O' Connell Davidson, 'Will the Real Sex Slave Please Stand up?', Feminist Review, no. 83, 2006, pp. 4-22.

48 Pro Refugio/Adpare, 'Legal Analysis of the Rights of Trafficked Persons', Association Pro Refugi, Bucharest, 2013, p. 19. 
Code on trafficking and aggravated forms of exploitation of prostitution overlap. Depending on whether the crime is qualified as trafficking or as exploitation of prostitution, the victim will either be entitled to assistance or be prosecuted and punished. ${ }^{49}$

Conversely, Bulgaria and Mexico deleted the requirement of coercion in the UN definition of trafficking, putting adult women on the same level as children, for whom coercion is not applicable in the Protocol. ${ }^{50}$ Although 'pimping', including consensual partner relationships of sex workers, has always been criminalised in Mexico, the new anti-trafficking law now defines what was formerly 'pimping' as 'trafficking' with much harsher sanctions. This law effectively criminalises as 'traffickers' all people who associate with sex workers, including colleagues, partners, adult children, cleaners, barmen etc., while defining all sex workers as 'victims'. At the same time the law criminalises clients. The effect has been a massive increase in raids on brothels, leading to the arrest and detention of sex workers, who consequently have the choice to either declare themselves to be a 'victim' and betray their colleagues, partners and other associates as 'traffickers', or refuse to do so and themselves be prosecuted and imprisoned. At the same time the rights of those who actually became victims of trafficking and exploitation are disregarded. ${ }^{51}$

In India the police still uses the Immoral Trafficking (Prevention) Act to carry out so-called raid and rescue operations, leading to the arbitrary arrest and detention of sex workers, confiscation of their property, forced rehabilitation and the deportation of undocumented migrant

49 Centre for Legal and Civil Initiatives (CLCl), 'Promotion of the rights of trafficked persons in Albania. Legal analysis of the current situation in regard to the rights of victims of trafficking', CLCl, Tirana, to be published in 2015.

50 Animus Association, 'Promotion of the Rights of Trafficked Persons in Bulgaria', Animus Association, Sofia, 2013; Rights4Change, Report Right Guide Training Mexico, Utrecht: Rights4Change, 2013.

51 Rights4Change; personal interviews with the Colectivo contra la Trata de Personas, 2015. 
sex workers, both trafficked and non-trafficked. ${ }^{52}$ The same goes for Thailand, as described by Empower in their report on the impact of anti-trafficking measures on sex workers' rights. ${ }^{53}$

Although the problem of needing to prove innocence is particularly visible and began in relation to the sex industry, it has spread in relevance to all trafficked undocumented migrants who may be perceived to lack the necessary 'innocent victim' status, as they may have consented to illegal border crossing, smuggling or working in exploitative conditions. ${ }^{54}$

For many years now, anti-trafficking, sex workers' rights and migrants' rights organisations have argued that antitrafficking policies can do and do significant harm and have collected evidence to prove this. GAATW's Collateral Damage report, for instance, documents a wide range of examples of how anti-trafficking policies negatively affect the people they are supposed to benefit. As stated in the report, the evidence available also suggests that it is especially marginalised groups, such as sex workers, migrants, refugees and asylum seekers, who suffer the negative consequences. ${ }^{55}$ It is difficult to avoid the conclusion that the anti-trafficking framework is inherently and irreparably flawed-being overly focused on women's sexual purity and national borders and therefore the wrong instrument to further human rights.

52 R Manjoo, 'Report of the Special Rapporteur on violence against women, its causes and consequences', Human Rights Council, $26^{\text {th }}$ session, A/HRC/26/38/ Add.1, 2014.

53 Empower Foundation, 'Hit and Run: The impact of anti-trafficking policy and practice on sex workers' human rights in Thailand', Empower University Press, Nonthaburi, 2012, retrieved 14 June 2013, http://www.empowerfoundation.org/sexy_file/ Hit\%20and\%20Run\%20\%20RATSW\%20Eng\%20online.pdf

54 Experts Group on Trafficking in Human Beings, p. 51.

55 GAATW, Collateral Damage: The Impact of Anti-Trafficking Measures on Human Rights Around the World, GAATW, Bangkok, 2007. 


\section{A Human Rights Approach}

In the years following the Protocol's adoption, there have been increasing calls for a human rights approach to trafficking. However, the question is whether this solves the fundamental problems in the anti-trafficking framework and will help to reduce the collateral damage of anti-trafficking measures. In practice, those who advocate for a human rights approach tend to exclusively focus on the rights of trafficked persons, while ignoring the concerns of other people affected by anti-trafficking laws and policies, as well as basic human rights principles, such as participation, empowerment and non-discrimination.

In 2002, the then UN High Commissioner for Human Rights, Mary Robinson, issued a set of 'Recommended Principles and Guidelines on Human Rights and Human Trafficking'. These stress that:

...anti-trafficking measures should not adversely affect the human rights and dignity of persons, in particular the rights of those who have been trafficked and of migrants, internally displaced persons, refugees and asylum seekers.

While this was, at the time, a brave and important thing to say, significantly sex workers are not mentioned, though they are clearly among the groups that suffer most from anti-trafficking measures. The 2010 'Commentary on the Recommended Principles and Guidelines', while stressing the importance of monitoring the impact of anti-trafficking measures to ensure that they do not interfere with established rights, also ignores sex workers when listing the groups whose rights in particular should be taken into account. ${ }^{56}$

56 Office of the High Commissioner on Human Rights, 'Recommended Principles and Guidelines on Human Rights and Human Trafficking: Commentary', 2010. 
If this makes anything clear it is that human rights are a highly contested area, as they have always been. A human rights approach touches upon strong interests of States. This is clear in the case of migration and crime control, but as much applies to the control of female sexuality, as the debates on, for example, reproductive rights show. Contestations about human rights, as we have seen, touch upon deep ingrained ideas about gender roles, the value of men's work and women's work, female and male sexuality, sex work and concepts of sexual purity of women and their entitlement-or lack of entitlement-to protection from violence and abuse.

\section{What Does this Mean for the Anti-Trafficking Movement?}

This does not mean that we should denounce the human rights-based approach or that this is not a valid framework. On the contrary we need to look at what policies and practices do uphold rights de facto, and we need to change or deprioritise those that do not. As this paper argues we firmly need to move away from the focus on how people get into a situation of forced labour or slavery-like exploitation and extend our concern about the protection of human rights to all people who are subjected to these abuses. A first step would be to demand that the protections afforded to trafficking victims-however minimal they may be-are extended to all people subjected to forced labour, slavery or slavery-like practices. In fact, this is precisely what States are already obliged to do under the relevant conventions.

It also means that we should not only be concerned about the human rights of trafficked persons, but also about the impact of anti-trafficking policies and measures on the human rights of other groups affected by them, in particular sex workers, migrants and refugees. With regard to the first, there is a lot to learn from the sex workers' rights movement. It is up to the anti-trafficking movement to listen. Lack of awareness is no excuse: the body of research 
on the negative human rights impacts of anti-trafficking measures is ever growing. ${ }^{57}$ The same goes for the impact on the rights of migrants and refugees. ${ }^{58}$

Furthermore, as a basic principle, groups affected by trafficking and anti-trafficking measures must be involved in the design, implementation, monitoring and evaluation of anti-trafficking measures. Their participation is key.

Lastly, it means that we should refuse to accept the distinction between people (usually women) who deserve protection and those who do not. This implies opposing the distinction between 'sexual exploitation' and 'forced labour' and its implicit gender bias. Forced labour is forced labour, no matter in which industry it takes place.

Marjan Wijers works as an independent researcher, consultant and trainer and has published on trafficking, sex work and human rights. She is co-founder of Rights4Change, which specialises in development and application of human rights impact assessment tools. She has worked at the Dutch Foundation against Trafficking in Women, the Clara Wichmann Institute, the Dutch Expert Centre on Women and Law, and the Verwey-Jonker Institute. She has wide experience in providing support to victims of trafficking, as well as in policy development and advocacy. She was actively involved in the NGO lobby around the UN Trafficking Protocol as part of the Human Rights Caucus, a coalition of anti-trafficking, human rights and sex workers rights organisations. She also was one of the organisers of the first European sex workers conference in Brussels in 2005. From 2003-2007 she was President of the Experts Group on Trafficking in Human Beings, established by the European Commission.

57 See other citations in this paper, but also Empower Foundation; A Ahmed \& $M$ Seshu, "We have the right not to be 'rescued'...": When Anti-Trafficking Programmes Undermine the Health and Well-Being of Sex Workers', AntiTrafficking Review, issue 1, 2012; M Ditmore, 'The Use of Raids to Fight Trafficking in Persons', Sex Workers Project, New York, 2009.

${ }^{58}$ See for example J C Hathaway; B Anderson. 


\section{Was Trafficking in Persons Really Criminalised?}

Kristiina Kangaspunta

\section{Abstract}

This paper examines the successes and setbacks in the criminal justice response to trafficking in persons. While today, the majority of countries have passed specific legislation criminalising human trafficking in response to the United Nations Protocol to Prevent, Suppress and Punish Trafficking in Persons, Especially Women and Children, there are still very few convictions of trafficking. Using currently available knowledge, this paper discusses four possible reasons for low conviction rates. Further, the paper suggests that due to the heavy dependency on victim testimonies when prosecuting trafficking in persons crimes, members of criminal organisations that are easily identifiable by victims may face criminal charges more frequently than other members of the criminal group, particularly those in positions of greater responsibility who profit the most from the criminal activities. In this context, the exceptionally high number of women among convicted offenders is explored.

Keywords: trafficking in persons, criminal justice framework, legislation, convictions, Nigerian organised crime, female traffickers

Please cite this article as: K Kangaspunta, 'Was Trafficking in Persons Really Criminalised?', Anti-Trafficking Review, issue 4, 2015, pp. 80-97, www.antitraffickingreview.org 
Fifteen years ago, when the first anti-human trafficking initiatives were launched by international organisations, we practitioners would hear comments like: 'why is the United Nations (UN) interested in prostitution?' or 'these so-called victims left the country voluntarily, it is their own fault', which showed the ignorance and lack of understanding of the nature of trafficking in persons at that time. Since then, awareness of human trafficking has increased vastly and the professionalism in dealing with the issue has improved in most countries. However, there are still many open issues with regard to preventing and combating trafficking crimes. For instance, has the increasing awareness and professionalism also translated into success in addressing cases of trafficking in persons? Are we currently more efficient in detecting trafficking cases, protecting victims' rights and preventing people from being victimised? Have anti-trafficking activities had negative impacts on some people? And have we reached a point where we can say that we are properly sanctioning the commission of trafficking offences in a way that takes into account the gravity of these crimes? This article will attempt to respond in particular to the last question based on the knowledge that we have today regarding criminal justice responses. While recognising that the criminal justice response must be accompanied by a larger effort to prevent trafficking and assist victims, this article focuses on successes and problems in this particular field. At the current time, a large majority of countries in the world have established a criminal justice framework to deal with trafficking in persons, and therefore it is useful to discuss whether this framework has been successfully used to respond to trafficking.

The adoption of the Trafficking Protocol ${ }^{1}$ in 2000 and its entry into force in 2003 demonstrated the political will of the international community to address trafficking in persons.

Protocol to Prevent, Suppress and Punish Trafficking in Persons, Especially Women and Children, supplementing the UN Convention against Transnational Organized Crime, retrieved 5 March 2015, http://www. unodc.org/documents/treaties/UNTOC/Publications/TOC\%20Convention/ TOCebook-e.pdf 
States Parties of the Protocol are obliged to criminalise trafficking, either as a single offence or a combination of offences. $^{2}$ The provision obligating States to criminalise trafficking in persons directly references the internationally agreed-upon definition of trafficking presented in Article 3 of the Protocol ${ }^{3} \mathrm{creating}$ a standard for criminalisation.

Yet, the Trafficking Protocol has been criticised because it emphasises the law enforcement response over the protection and support of victims' rights $^{4}$ (e.g. while this argumentation usually cannot be denied, it should be kept in mind that the Trafficking Protocol supplements the UN Convention against Transnational Organized Crime, which is of course, a crime treaty, with the main objective being the improvement of international cooperation mechanisms to prevent and combat transnational organised crime. Ratification of the Convention is a pre-condition to ratify the Trafficking Protocol, which roots the Protocol in the criminal law framework. Obviously, this framework has had an impact not only on victims and offenders as operators in the criminal justice system, but has also shaped the policies closely related

2 United Nations Office on Drugs and Crime (UNODC), 'Legislative Guides for the Implementation of the United Nations Convention against Transnational Organized Crime and the Protocols thereto', UN, New York, 2004, p. 267.

3 'Trafficking in persons' shall mean the recruitment, transportation, transfer, harbouring or receipt of persons, by means of the threat or use of force or other forms of coercion, of abduction, of fraud, of deception, of the abuse of power or of a position of vulnerability or of the giving or receiving of payments or benefits to achieve the consent of a person having control over another person, for the purpose of exploitation. Exploitation shall include, at a minimum, the exploitation of the prostitution of others or other forms of sexual exploitation, forced labour or services, slavery or practices similar to slavery, servitude or the removal of organs.

4 A T Gallagher, The International Law of Human Trafficking, Cambridge University Press, New York, 2010; R Piotrowicz, 'The UNHCR's Guidelines on Human Trafficking', International Journal of Refugee Law, vol. 20, issue 2, 2008, pp. 242-252; L Shoaps, 'Room For Improvement: Palermo Protocol and the Trafficking Victims Protection Act', Lewis \& Clark Law Review, vol. 17, no. 3, 2013; J Todres, 'Widening Our Lens: Incorporating Essential Perspectives in the Fight Against Human Trafficking', Michigan Journal of International Law, vol. 33, Georgia State University College of Law, Legal Studies Research Paper No. 2011-29, 2011, pp. 53-76, retrieved 5 March 2015, http:// papers.ssrn.com/sol3/papers.cfm?abstract_id=1958164\#\# 
to trafficking such as migration and prostitution policies. ${ }^{5}$ Treaties elaborated subsequent to the Protocol, such as the Council of Europe Convention on Action against Trafficking in Human Beings, ${ }^{6}$ do not have the same sort of connection to the criminal justice framework, which makes it possible for them to operate primarily in the human rights or other frameworks.

\section{Legislation}

The Trafficking Protocol entered into force in 2003. Before that, many countries either had partial legislation that addressed only some forms of trafficking in persons or some victims, or did not have any legislation at all. Particularly male victims were absent from trafficking definitions and often only sexual exploitation was criminalised. Encouraged by the Protocol, the number of countries that introduced the crime of trafficking in persons into their penal code increased sharply after 2003 as shown in Figure 1.

Currently, ${ }^{7}$ only nine countries (out of the 173 countries that were analysed by UN Office on Drugs and Crime's (UNODC) 2014 'Global Report on Trafficking in Persons' do not have any specific legislation against trafficking in persons and 146 countries criminalise all aspects of trafficking in persons as explicitly listed in the Trafficking Protocol. When the population size of those countries that do not have special legislation or only have partial legislation against trafficking in persons is reviewed, we can see that about one-third of the world's population, consisting of around two billion people, live in a situation where trafficking is not criminalised as

GAATW, Collateral Damage: The Impact of Anti-Trafficking Measures on Human Rights Around the World, GAATW, Bangkok, 2007.

6 Council of Europe Convention on Action against Trafficking in Human Beings, retrieved 5 March 2015, http://conventions.coe.int/Treaty/en/Treaties/ $\mathrm{Html} / 197 . \mathrm{htm}$

7 As of August 2014. 
required by the Trafficking Protocol. ${ }^{8}$ This situation combined with a very low number of convictions makes trafficking in persons a crime of vast impunity.

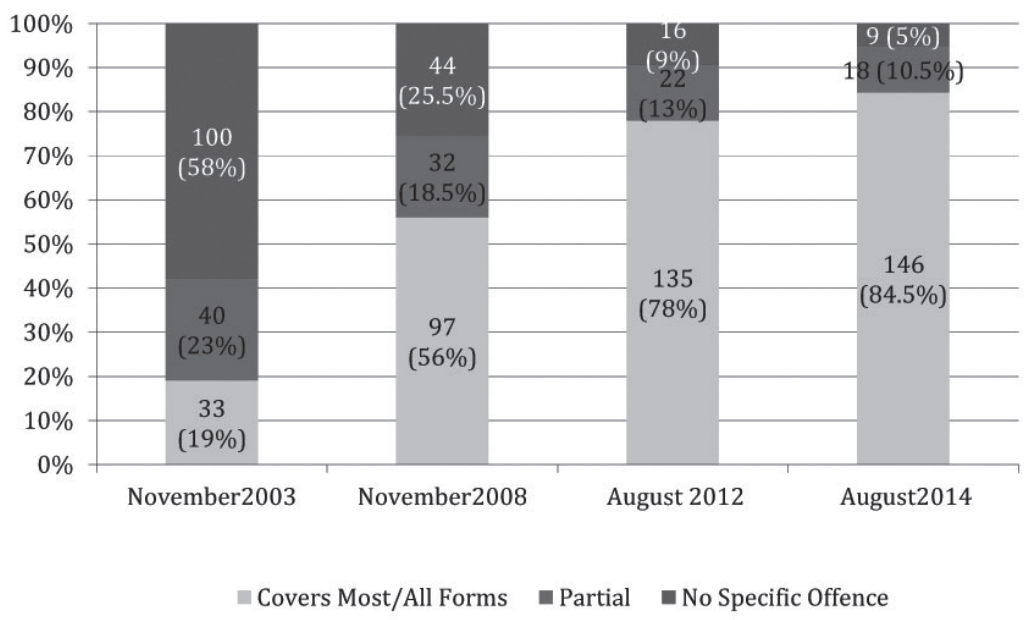

Figure 1. Criminalisation of trafficking in persons with a specific offence, share and number of countries, 2003-2014

Source: UNODC 2014

In some countries, the use of non-specific criminal offences to prosecute cases of trafficking in persons is possible, including those against sexual violence, pimping, kidnapping, smuggling of migrants or others. However, for States Parties of the Trafficking Protocol in particular, there are serious drawbacks to using a non-specific criminal offence to address trafficking in persons. For instance, if trafficking legislation is in compliance with international treaty obligations, it will include the protection and assistance measures specifically designed for victims of trafficking in persons. Non-specific

8 UNODC, 'Global Report on Trafficking in Persons 2014', United Nations publication, 2014, pp. 51-52. 
criminal offences will most likely not have any such provisions. As a result, the use of non-specific legislation will lead to a situation in which trafficking victims may not have proper access to support and protection services that are specifically developed for them. There are also other serious drawbacks to not using trafficking specific legislation based on the Trafficking Protocol, such as not having a basis to extradite suspects, to use mutual legal assistance to gather evidence, to confiscate proceeds of crime and to prosecute organised crime groups for money laundering.

At the regional level, the countries of North and Central America as well as Europe and Central Asia currently have legislation that is in compliance with the Trafficking Protocol and criminalises most or all forms of trafficking. Five countries in the Caribbean and South America lack specific legislation or have partial legislation against trafficking in persons. The situation is similar in South Asia, East Asia and the Pacific where four countries have either not criminalised human trafficking or have criminalised it only partially. The situation is most worrying in Sub-Saharan Africa where fourteen countries have no or partial legislation on trafficking in persons. In North Africa and Middle East, there are three countries that have not criminalised trafficking in persons. ${ }^{9}$

Criminalisation of trafficking in persons has been an important step for many countries to demonstrate that trafficking will not be accepted. It also brings human trafficking into the official criminal justice system, necessitating an allocation of resources to investigate the crime as well as prosecute, convict and sanction the traffickers. In many countries, the importance of a victim's rights-centered approach has been acknowledged in the development of policies, and criminal justice responses have been complemented by victim protection and support schemes. However, implementation of these schemes has proven to be difficult and victims in many countries still may not have

9 UNODC 2014. 
access to appropriate protection and support measures. ${ }^{10}$ Hopefully, limited resources combined with increasing needs will not force countries to choose between enforcing the legislation and protecting and assisting the victims.

\section{Convictions}

The Trafficking Protocol clearly created a push for new, more comprehensive legislation addressing trafficking in persons. However, legislation remains a rather symbolic act against trafficking in persons, only signifying a moral standard against the crime, unless it is implemented. The real intolerance against human trafficking should be demonstrated by holding criminals liable to sanctions that take into account the gravity of human trafficking offences combined with proper compensation to victims of trafficking.

Unlike the great push to enact legislation against trafficking in persons after the entry into force of the Protocol, conviction records have remained stubbornly low since 2003. In fact, in $60-77 \%$ of countries, there were no major changes in this number between 2003 and 2012. On the contrary, the share of countries that recorded an increasing number of convictions went down from $21 \%$ to $13 \%$ in the same period. Currently, $41 \%$ of countries have not had any convictions or have recorded less than 10 convictions between 2010-2012, even though these countries have legislation criminalising trafficking in persons. In the period from 2007-2010, 39\% and in 2003-2007, 36\% reported none or less than 10 convictions. ${ }^{11}$ On the other hand, $16 \%$ of countries reported more than 50 convictions from 2010-2012. This number was $18 \%$ in $2007-2010 .{ }^{12}$

10 M McAdam, 'Who's Who at the Border? A rights-based approach to identifying human trafficking at international borders', Anti-Trafficking Review, issue 2, 2013, pp. 33-49; S Plambech, "Between "Victims" and "Criminals": Rescue, Deportation, and Everyday Violence Among Nigerian Migrants', Social Politics, vol. 21, no. 3, 2014.

11 UNODC, 'Global Report on Trafficking in Persons 2012', United Nations publication, 2012; UNODC/UN Global Initiative to Fight Human Trafficking (UN.GIFT), 'Global Report on Trafficking in Person 2009', UNODC, 2009, p. 40.

12 UNODC 2014, p.13. 
Number of convictions recorded per year, share of countries, 2010-2012

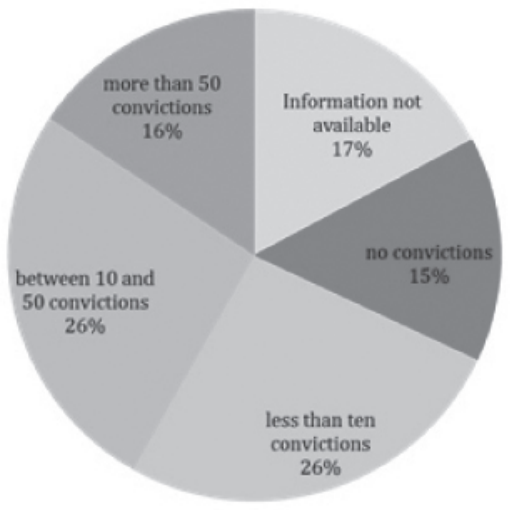

Source: UNODC elaboration on national data.

In order to study regional conviction capacities, it is useful to compare convictions with the population size, since in very populous countries the number of convicted offenders tends to be higher. In Europe and Central Asia, the ratio of trafficking in persons convictions per 100,000 population is around 0.3 which is higher than in other regions where this ratio remains around $0.1 .^{13}$ Comparing conviction rates with other crimes emphasises the low rates in trafficking in persons cases. For example, the average number of persons convicted for completed intentional homicides per 100,000 population in Europe in 2011 was 1.2, for assault (bodily injury) it was 74, for rape, it was 1.5. Among crimes connected to transnational organised crime, the number of persons convicted for money laundering per 100,000 population in Europe in 2011 was 0.7 , for corruption it was 1.9 and for drug trafficking it was 21. ${ }^{14}$ These European

13 UNODC 2014, p. 54.

14 M Aebi, G Akdeniz, G Barclay, C Campistol, S Caneppele, B Gruszczyñska, S Harrendorf, M Heiskanen, V Hysi, J Jehle, A Jokinen, A Kensey, M Killias, C Lewis, E Savona, P Smith, R órisdóttir, 'European Sourcebook of Crime and Criminal Justice Statistics 2014', Fifth edition, European Institute for Crime Prevention and Control affiliated with the United Nations (HEUNI) Publication Series No. 80, Helsinki, 2014. 
figures show that trafficking in persons convictions seem to be very low even when compared with other serious crimes such as homicide or similarly hidden crimes such as rape.

There could be several reasons for the low number of convictions. First, it could be argued that the low number of convictions reflects a low level of instances of crime. Indeed, comparing the number of convictions to the number of detected victims demonstrates that often countries that report no or few convictions also identify very few victims. However, there are indications that often low conviction levels do not reflect the actual domestic human trafficking scenario. In this regard, around one-third of countries with no or few convictions identify significant numbers of victims. ${ }^{15}$ This shows that in many countries, the identification of victims does not lead to increased convictions and the conviction numbers do not reflect the trafficking in persons situation in these countries. As a result, it can be determined that, in many countries, low convictions of traffickers do not correlate to actual incidences of the offence; particularly, since trafficking in persons is often very hidden.

A second reason for low levels of convictions is the previously mentioned hidden nature of trafficking in persons. Human trafficking is largely a crime which does not easily come to the attention of the police, border control officers, health authorities, labour inspectors, embassy personnel, service providers or other persons who potentially could come into contact with human trafficking. Victims can be reluctant to report their traffickers due to control, intimidation, threats of violence and fear of being punished and deported to their origin country. Victim self-identification is difficult because of the complex nature of human trafficking. In some cases, trafficking victims may see little benefit in dealing with authorities and service providers that may infringe their human rights or even harm them. ${ }^{16}$ Even when victims are

UNODC 2014, p. 54.

16 GAATW. 
identified, they might be reluctant to cooperate with criminal justice authorities because of lack of trust, fear of being deported or prosecuted for related criminal activity, fear of being stigmatised, or for other reasons.

For several years, trafficking in women for sexual exploitation dominated the discussions on human trafficking so that trafficking for other forms of exploitation such as forced labour, begging, petty crime, organ removal and child soldiers received limited attention. This was also reflected in the identification of cases. ${ }^{17}$ However, the situation has changed in recent years. While in 2006, $21 \%$ of detected victims were trafficked for other purposes than sexual exploitation, ${ }^{18}$ in 2011, the share was $47 \% .^{19}$

In addition, authorities often have difficulties identifying perpetrators, particularly without the cooperation of victims, since proactive investigations relying on methods other than victim testimonies are seldom used. ${ }^{20}$ Therefore, the crime that is not seen cannot be prosecuted. The hidden nature of human trafficking makes an accurate estimate of the number of victims very challenging and when this is not known, it is very difficult to assess the level of convictions when compared to the estimated severity of trafficking.

However, some empirical studies have shed light on the prevalence of trafficking in persons. Based on his study on trafficking of migrant workers in San Diego county, Sheldon Zhang $^{21}$ estimates that there could be as many as 2.472

17 K Kangaspunta, 'Collecting Data on Human Trafficking: Availability, Reliability and Comparability of Trafficking Data' in E Savona and S Stefanizzi, Measuring Human Trafficking, Complexities and Pitfalls, Springer, New York, 2007.

18 UNODC/UN.GIFT, p. 50.

19 UNODC 2014, p. 33.

20 A Farrell, 'Improving Law Enforcement Identification and Response to Human Trafficking' in J Winterdyk, B Perrin, P Reichel (eds.), Human Trafficking: Exploring the International Nature, Concerns, and Complexities, CRC Press, Boca Raton, FL, 2012; A T Gallagher \& P Holmes, 'Developing an Effective Criminal Justice Response to Human Trafficking. Lessons From the Front Line', International Criminal Justice Review, vol. 18, no. 3, 2008, pp. 318-343.

21 S Zhang, 'Trafficking of Migrant Laborers in San Diego County: Looking for a hidden population', San Diego State University, San Diego, CA, 2012. 
million trafficking victims among undocumented Mexican migrants in the United States of America. Another study on trafficking in persons in Ukraine based on three different surveys concludes that in the three-to-five-year period under review, 22,000 to at least 36,000 Ukrainian citizens per year had been exploited abroad. ${ }^{22}$ At the same time, the data received by UNODC from Member States shows that the number of victims known to the authorities rarely reaches 1,000 per year in any country. ${ }^{23}$ These estimates from different countries clearly indicate that only a limited number of trafficking victims are identified and most human trafficking cases remain hidden. Based on these findings, we can safely assume that there are many trafficking in persons cases and traffickers that are not known to the authorities and thus cannot be prosecuted, all resulting in low levels of convictions. This is also related to the lack of capacity and prioritisation to address trafficking in persons crimes.

A third possible reason for low conviction rates is the limited capacity of national criminal justice practitioners to investigate and prosecute human trafficking cases. Courts can also suffer from lack of capacity to sanction traffickers properly. Limited capacity could be a result of many factors. Police officers and prosecutors may not be trained to identify trafficking in persons cases. Trafficking in persons crimes are often very complex offences that require intensive efforts to investigate and prosecute. ${ }^{24}$ This might lead to a situation where trafficking in persons cases are prosecuted and convicted to a lesser extent than other offences which are easier to investigate and require fewer resources. In some cases, the criminal justice system is reluctant to devote resources to investigate human trafficking cases which are not immediately visible to the citizens and which are not seen

22 D Ball \& R Hampton, Estimating the Extent of Human Trafficking from Ukraine, University of Nebraska-Lincoln, 2009, retrieved 28 January 2015, http:// digitalcommons.unl.edu/humtraffconf/25/

23 UNODC 2014.

24 A Herz, 'Human Trafficking and Police Investigations' in J Winterdyk, B Perrin, P Reichel (eds.), Human Trafficking: Exploring the International Nature, Concerns, and Complexities, CRC Press, Boca Raton, 2012. 
happening in the local community, leading citizens to believe that the crime does not concern them. This often means that there are no pressures on authorities to take action. ${ }^{25}$

The capacity of the criminal justice system can also be evaluated by the percentage of suspected traffickers who are convicted. ${ }^{26}$ At the global level, out of 100 persons suspected of trafficking in persons, 45 suspects are prosecuted and 24 are convicted in the first instance. Of all those who are prosecuted for human trafficking, $55 \%$ are convicted. ${ }^{27}$

\section{2 \\ Operating traffickers and trafficking networks}
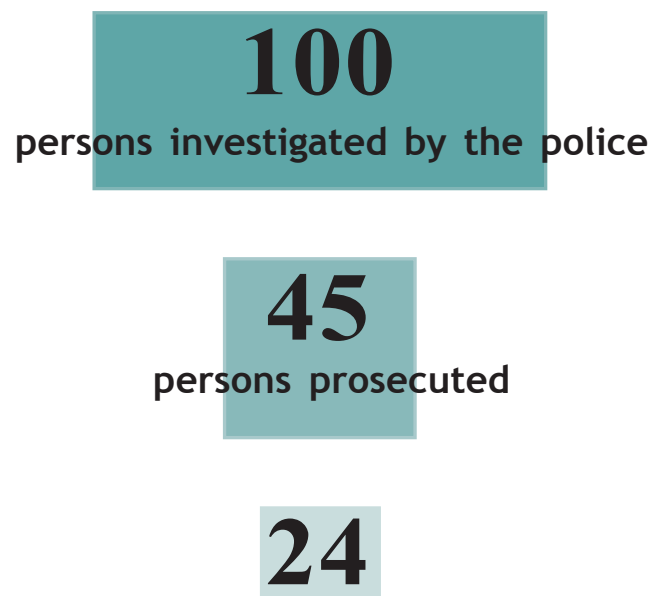

persons convicted in first instance

Figure 3. Probability of first-instance conviction for persons investigated for trafficking in persons

Source: UNODC 2014

25 Farrell, p.196.

26 This loss of cases or filtering out of cases during the criminal justice process is called attrition (see Aebi et al., 2014, p. 154).

27 UNODC 2014, p. 55. 
There are, however, some regional differences in these attrition figures. In Western and Central Europe, around 30\% of suspects and around 50\% of those prosecuted are convicted in the first instance. Other regions in Asia, Americas and Africa present lower ratios. ${ }^{28}$ In order to review the efficiency of the criminal justice system in convicting suspected offenders of trafficking in persons cases, the figures can be compared with other crimes. Based on the UNODC Crime Trend Survey, which collects data globally on crimes in general, on average $60 \%$ of suspects are convicted. ${ }^{29}$ For homicide at the global level, for every 100 persons suspected, 44 are convicted. ${ }^{30}$ Compared to these figures, the efficiency of the criminal justice system to process trafficking in persons crimes and convict suspected offenders is relatively low, which might reflect the complex nature of human trafficking offences, the difficulty in collecting evidence needed for successful prosecution and/or lack of resources within the criminal justice systems. ${ }^{31}$ All this is naturally reflected in the low conviction numbers.

The fourth reason for low conviction figures is corruption. At present, there is only scattered evidence on the relationship between corruption and trafficking in persons showing the strong linkage between these two issues. ${ }^{32} \mathrm{~A}$ study in Brazil on corruption and trafficking in persons shows that $71 \%$ of all examined cases of domestic and international trafficking in and from Brazil had a linkage with corruption. ${ }^{33}$ The role of organised and structural corruption in human trafficking is

28 UNODC 2014.

29 S Harrendorf, M Heiskanen, S Malby (eds.), 'International Statistics on Crime and Justice', HEUNI Publication Series 64, 2010, p. 92.

30 UNODC, 'Global Study on Homicide 2013', United Nations publication, 2014, p. 93.

31 M Wade, 'Prosecution of Trafficking in Human Beings Cases' in J Winterdyk, B Perrin, P L Reichel (eds.), Human Trafficking: Exploring the International Nature, Concerns, and Complexities, CRC Press, Boca Raton, 2012.

32 L Holmes, 'Human Trafficking and Corruption: Triple Victimisation?' in Cornelius Friesendorf (ed.), Strategies Against Human Trafficking: The Role of the Security Sector, National Defence Academy and Austrian Ministry of Defence and Sports, DCAF, 2009, pp. 87-99.

33 A Cirineo \& S Studnicka, 'Corruption and Human Trafficking in Brazil: Findings from a Multi-Modal Approach', European Journal of Criminology, vol. 7, no. 1, 2010, pp. 29-43. 
presented in a study on Southern and Eastern European trafficking networks. ${ }^{34}$ Even ten years ago, experts and practitioners interviewed in the Czech Republic estimated that up to $30 \%$ of trafficking cases involved a hidden element of corruption. ${ }^{35}$ The role of corruption in trafficking for forced labour has been illustrated in a paper on the global supply chain. ${ }^{36}$ However, this linkage is not visible in the convictions since public officials and private actors are scarcely prosecuted or charged for their complicity in cases of human trafficking. A study in Finland demonstrates that legal practitioners and other authorities can benefit from trafficking-related activities; however, it is very difficult to prosecute these cases. ${ }^{37}$ The UNODC Human Trafficking Case Law Database, which contains more than 1,000 cases from nearly ninety countries, includes only nine cases where corruption is present. ${ }^{38}$ Corruption can have an impact on convictions in several ways. Police officers may purposefully ignore signs of trafficking or they may even enable it. They may warn criminals of raids or protect them after the raid. Government officials may attempt to draft legislation that hinders efficient responses and protects traffickers or blocks investigation, prosecution and conviction. ${ }^{39}$

34 J Leman \& S Janssens, 'The Albanian and Post-Soviet Business of Trafficking Women for Prostitution. Structural Development and Financial Modus Operandi', European Journal of Criminology, vol. 5 (4), 2008, pp. 433-451.

35 I Trávníèková, Trafficking in Women: The Czech Republic Perspective, Institute for Criminology and Social Prevention (IKSP), Prague, 2004, p. 10.

36 Verité, 'Corruption \& Labor Trafficking in Global Supply Chains', 2013, retrieved 28 January 2015, http://www.verite.org/sites/default/files/images/ WhitePaperCorruptionLaborTrafficking.pdf

37 M Viuhko \& A Jokinen, Human Trafficking and Organised Crime. Trafficking for sexual exploitation and organised procuring in Finland, Publication Series No. 62, HEUNI, 2009.

38 UNODC Case Law Database, retrieved 28 January 2015, http://www.unodc.org/ cld/index.jspx

39 K Kangaspunta, 'Trafficking in persons and its links to corruption', presentation at the Asia-Pacific Economic Cooperation Pathfinder Dialogue on Combating Corruption and Illicit Trade across the Asia-Pacific Region: A Shared Partnership for Protecting National Assets, Human Capital and Natural Resources, Bangkok, Thailand, 2013. 


\section{Who is Punished?}

Even when there are convictions related to trafficking in persons cases, the persons that are convicted might not be the heads of the criminal group or those who make the biggest profits. Based on an evaluation of cases included in the UNODC Human Trafficking Case Law Database involving an organised crime component, it could be concluded that most offenders were identified by the victims. Also, other research shows that there is a heavy dependency on victim testimonies when prosecuting trafficking in persons crimes, some prosecutors even refuse to go to trial without the victim's testimony. ${ }^{40}$ This could lead to a situation where only those known to the victim, particularly recruiters, are prosecuted and convicted. The analysis of the data on assisted victims show that half of the recruiters are known to the victims as friends, relatives, business contacts or other acquaintances. ${ }^{41}$ Emphasising victims' testimonies in the investigation and prosecution of trafficking crimes can result in the nonidentification of members of the organised criminal groups, particularly the heads of these groups, who, at the end of the day, will be able to continue their criminal associations and activities. The endurance of the trafficking of Nigerian victims by Nigerian criminal groups to Europe for sexual exploitation illustrates this situation.

Nigerian organised criminal networks, which are structured around a highly hierarchical system, are mainly behind the trafficking of Nigerian victims. ${ }^{42}$ However, Nigerian

40 A Farrell, J McDevitt, R Pfeffer, S Fahy, C Owens, M Dank \& W Adams 'Identifying Challenges to Improve the FRA (2009) Child Trafficking in the European UnionChallenges, perspectives and good practices', European Union Agency for Fundamental Rights, 2012, p. 8.

${ }^{41}$ IOM, 'IOM Counter Trafficking Database. Counter Trafficking (CTM)-Return and Assistance', IOM, 2009, unpublished material.

42 Federal Centre for the Analysis of Migration Flows, the Protection of Fundamental Rights of Foreigners and the Fight against Human Trafficking, 'Annual Report on human trafficking 2013. Building Bridges', Brussels, Belgium, 2014; UN Interregional Crime and Justice Research Institute (UNICRI), 'Trafficking of Nigerian Girls in Italy', UNICRI, Turin, 2010; J Carling, 'Migration, Human Smuggling and Trafficking from Nigeria to Europe', IOM, 2006; UNODC 2014. 
organised crime groups do not always directly engage in the recruitment and exploitation of victims, but rather tax and control the activities within a certain territory. ${ }^{43}$ In this case, victims might not ever come into contact with the higher levels of management of the criminal organisation, and therefore would be unable to identify them or present evidence of their involvement. Another reason for low conviction rates of Nigerian offenders may be related to the closed structure of the trafficking network which is rigidly hierarchical and self-contained and in which victims are controlled both physically and mentally through a ritualistic practice. ${ }^{44}$ This often means that victims are very reluctant to reveal their experiences to outsiders and to testify against their traffickers. Since securing a conviction in many countries is highly dependent on victim testimony, Nigerian traffickers are difficult to prosecute. Criminal justice statistics in Europe support this theory, as among all non-European suspects, Nigerian traffickers made up the largest group between $2010-2012,{ }^{45}$ but the conviction rates were only around $3 \%$ of the total number. At the same time, $10 \%$ of the total number of detected victims were from Nigeria. ${ }^{46}$

The percentage of women offenders convicted for trafficking in persons is globally around $30 \%$. The share is higher than in other crimes where around $10-15 \%$ of convicted offenders are women. ${ }^{47}$ The share of female offenders is particularly high, above $50 \%$ in some countries of Eastern Europe and Central Asia and above $70 \%$ in the Southern Caucasus. ${ }^{48}$ One possible reason for such high figures is the focus on prosecuting recruiters, who are often women, and who in some cases might be forced to recruit victims, thereby

43 UNODC 2014, p. 57.

44 UNICRI; Federal Centre for the Analysis of Migration Flows, the Protection of Fundamental Rights of Foreigners and the Fight against Human Trafficking.

45 European Union, 'Trafficking in Human Beings', 2014 edition, Eurostat Statistical working Papers, 2014.

46 Based on the information UNODC has received from Member States.

47 UNODC 2014, p. 27.

48 UNODC 2014. 
becoming themselves victims of trafficking. ${ }^{49}$ A study on trafficking in persons in Finland involving mainly women victims trafficked from former Soviet Union countries shows that female traffickers are involved in the recruitment of other women, organising practical matters and coaching newly recruited women. Some female victims who were in a situation of debt bondage were actually forced to recruit other women in order to pay back their debts. ${ }^{50}$ Another study on trafficking networks operating in Italy in the late 1990s showed that female members of the criminal organisation were often used for activities most visible to victims such as recruitment, collecting money from clients, controlling victims and escorting them. ${ }^{51}$ It seems that the high share of convicted women may actually not reflect the exceptionally high participation of women in human trafficking crimes but rather the strategic placement of women by organised crime groups in more public realms of activity.

\section{Conclusions}

Since 2003, when the Trafficking Protocol entered into force, there has been a clear increase in the criminalisation of trafficking in persons, at least when measured by the number of countries with a specific offence against trafficking in persons. However, successful criminalisation requires more than the adoption of a legislation. The implementation and enforcement of the legislation has been weak in many countries and the number of convictions continues to be very low. The situation has not improved since 2003 even though increasing amounts of countries have more comprehensive legislation, as required by the Protocol. The reasons for the lack of success in the criminal justice response are probably related to the complicated and hidden nature of trafficking

49 Information received from local experts.

50 M Viuhko \& A Jokinen, p. 80.

51 E Ciconte, The Trafficking Flows and Routes of Eastern Europe, WEST-Women East Smuggling Trafficking, Ravenna, 2005. 
in persons which makes the crime difficult to address with current legislation and prosecution efforts. Investigation is time consuming and many countries do not have the resources for successful prosecutions. And those who do have many competing priorities in their domestic anti-crime agendas. A proper criminal justice response would require a focused effort to find the offenders and victims, combined with resources which would make the specialisation possible. This would hopefully lead to real criminalisation, sanctioning in particular those criminals who profit most from the exploitation of others. Without the successful implementation of legislation, trafficking in persons will remain only partially criminalised.

Kristiina Kangaspunta is heading the preparation of the 'Global Report on Trafficking in Persons' at the United Nations Office on Drugs and Crime (UNODC) in Vienna, Austria. The biannual Global Report has been published in 2012 and 2014 presenting the global and regional human trafficking trends and patterns. Previously, she was the Deputy Director of the United Nations Interregional Crime and Justice Research Institute (UNICRI) leading the Research Programme of the Institute in Turin, Italy. Before UNICRI, she worked with UNODC as the Chief of the Anti-Human Trafficking Unit. She moved to UNODC from the Ministry of Justice of Finland where she worked at the European Institute for Crime Prevention and Control, affiliated with the United Nations (HEUNI). 


\title{
Re-evaluating Palermo: The case of Burmese women as Chinese brides ${ }^{1}$
}

\author{
Laura K Hackney
}

\section{Abstract}

The definition of human trafficking as set in the Trafficking Protocol (also known as the Palermo Protocol) functionally centres most of the response to the phenomenon in the criminal justice system. This occludes many of the sociopolitical determinants of vulnerability that leads to trafficking. It also discourages any real debate about the various forms of oppression and even structural violence that act as catalysts to the human trafficking market. The Trafficking Protocol, and a vast number of international organisations, nongovernmental organisations and governments, focuses on statistics of prosecution rates, arrests, victim typology and organised crime. I use the example of bride trafficking along the Sino-Burmese border to illustrate the complications and, in certain instances, harm that befall an anti-trafficking regime that does not use a wider lens of migration, agency, development and gender equality to address the factors leading to exploitation.

\footnotetext{
I would like to thank the Center for East Asian Studies and the Center on Democracy, Development and the Rule of Law at Stanford University, United States of America. Workshops and some of the interviews were conducted under the auspices of the Stanford China Center at Peking University, China, and gracious support was given by Dr Kimberly Singer Babiarz and Dr Helen Stacy.
} 
Keywords: Burma, China, bride trafficking, trafficking for marriage, borders, Palermo, migrant rights, Trafficking Protocol

Please cite this article as: L K Hackney, 'Re-evaluating Palermo: The case of Burmese women as Chinese brides', Anti-Trafficking Review, issue 4, 2015, pp. 98-119, www.antitraffickingreview.org

\section{Introduction}

Within the past two decades, the densely populated region of Yunnan province, China and mainland Southeast Asia (commonly referred to as the Mekong River Region) has been characterised as a major 'hot spot' for human trafficking. ${ }^{2}$ In 2000, the United Nations Protocol to Prevent, Suppress and Punish Trafficking in Persons, Especially Women and Children (Trafficking Protocol) created an international standard for governments to pass national legislation on human trafficking and set the parametres of how acts now considered the crime of human trafficking constitute a global crime. In 2008, the People's Republic of China responded to the growing international concerns of human trafficking within and across its borders by establishing a National Action Plan. Burma, Thailand and Lao People's Democratic Republic (Laos) also developed national legislation along with bilateral Memorandums of Understanding aimed at combating different forms of cross-border human trafficking. Responding to the Trafficking Protocol (also known as the Palermo Protocol) with national legislation or action plans has become the norm in countries around the world.

G Bonanno, 'Development Dynamics in the Greater Mekong Sub-Region: TransBoundary Routes of Human Insecurity', GMSARN International Journal, vol. 6, 2012, pp. 97-104; K Chalk, 'Taking the Journey Together: A United Response to Trafficking in the Mekong Region', World Vision International, 2006; W van Schendel, L Lyons \& M Ford, Labour Migration and Human Trafficking in Southeast Asia: Critical perspectives, Routledge, London, 2012. 
Since the Chinese government launched its 2008 National Plan of Action on Combating Trafficking in Women and Children, the Chinese marriage market has been scrutinised for its connections to human trafficking activities. Instances of transnational marriage, mail-order brides and commercial networks of marriage migration are becoming more prevalent throughout this region and the world. ${ }^{3}$ China's sex-ratio imbalance at birth and resulting gender imbalance has created a demand for brides that outstrips China's domestic populations. Additionally, across the border in Burma, extreme poverty, land grabs and military conflicts have made livelihoods unsustainable for many women in Burma. These factors have expanded the market for marriage transactions across the border even though Burma has ratified the Trafficking Protocol and institutionalised an Anti-Trafficking Police Task Force.

Though the Trafficking Protocol does not explicitly mention forced marriage or bride trafficking in its definition of human trafficking, the term 'slavery-like practices' incorporates the many forms of domestic or gendered exploitation that the drafters intended to constitute as human trafficking. ${ }^{4}$ Scholars and activists are eager to identify, classify and target forced marriage as bride trafficking in Asia. Governments such as those in China and Burma are being pressured to increase the prosecution rates of bride trafficking offenses and maintain positive reputations abroad, especially under the influence of the United States Department of State Trafficking in Persons Report. This creates a focus on policing borders, raids, arrests and criminal enterprises linked to forced marriages. This emphasis on criminality, catalysed by the Trafficking Protocol,

W Yang \& M Lu, Asian Cross-Border Marriage Migration: Demographic Patterns and Social Issues, Amsterdam University Press, Amsterdam, 2010.

4 This was at the behest of the Special Rapporteur on violence against women, its causes and consequences, found in the supra notes of the Protocol. D MacLean, 'Commercial Marriage Trafficking: Uncovering a Growing New Form of Transnational Human Trafficking and Shaping International Law to Respond', UC Davis Journal of International Law and Policy, 2012, p. 15. 
is complicated by marriage practices within China and the complex and historical connections between cross-border ethnic groups. The 'means, force, and exploitation' factors found in the Trafficking Protocol do not always align with the situations of brides and migratory marriage, and marriage transactions today exist on a continuum that cannot be easily divided between human trafficking and consensual marriage.

Rather than define a clear distinction between consensual marriage and bride trafficking, I instead observe the structural factors within Chinese society that have altered its age-old marriage market and border relations. The border of Yunnan province and Burma has a history of being a transit point for trade (both licit and illicit), and thus, the main site for addressing the issue. Along the Yunnan-Burma border, Chinese men usurp Yunnan's historical trade and kinship networks in search of wives. Many of these men are utilising the ties ethnic minority groups have across borders, and creating demand in the market for arranging marriage transactions. Deciding to procure a wife, by any means possible, is the result of marriage market shifts in China and the blurring of the lines between cross-border marriages and traditional matchmaking industries.

How can the Protocol's influence on national legislation and grassroots effort be adapted to account for China's historical marriage practices, the new causes for increased demands for brides, and the evolving marriage market in China and along China's border with Burma? It is clearly the case that some women from Burma are deceived and forced to marry Chinese men against their will. However, my research shows that many of these same women, when given options, chose to remain in their Chinese marriages. This is just one example. Other women choose to be sold to Chinese men, and others return home to Burma after the birth of their first child. Criminal prosecutions do not address the vulnerabilities of the poor or the difficulties facing migrants who travel from Burma in China. Marriage values and practices that cross national borders are responses to larger social, demographic and economic changes occurring in both countries. Broader issues of immigration policy, economic development and 
women's agency, I argue, need to be incorporated into the current anti-human trafficking regime.

The process of criminalising marriage transactions as bride trafficking is a starting point to launch a deeper study into the complexities and root causes of the cross-border exchange of people between China and Burma. This process reflects many of the values of the international institutions and treatises, but these global, one-size-fits-all responses do not always serve the people they are meant to help.

\section{Outside the Scope of the Trafficking Protocol}

According to United Nations (UN) statistics, the natural sex ratio at birth is 104 males to every 100 females. ${ }^{5}$ Over the past three decades, Azerbaijan, Armenia, China, India and South Korea have experienced exponential disparities in this birth ratio. In 1982, the Chinese national average was 108.5 males per 100 females. This has increased to an average of 118 males per 100 females in $2012 .{ }^{6}$ A wide range of reports, including those from official Chinese government bureaus, estimate that around 22 to 30 million Chinese men will be unable to find wives by 2025-2030. ${ }^{7}$ In China today, marriage is a nearly universal practice. According to China sociologists James Lee and Wang Feng: 'the proportion of Chinese women who have not married by age 30 has remained consistent at $1 \%$ for the last three hundred years.' ${ }^{8}$ Over $10 \%$ of the population will not be able to secure traditional marriages or

Ibid.

6 S Greenhalgh, 'Patriarchal Demographics? China's Sex Ratio Reconsidered', Population and Development Review 38, 2012, p. 133.

7 N He, 'Brides and Prejudice in China', China Daily, 23 August 2010, retrieved 5 February 2015, https://www.chinadaily.com.cn/china/2010-08/23/ content_11186841.htm; T Hesketh \& J Min Min, 'The Effects of Artificial Gender Imbalance', European Molecular Biology Organization Report, vol. 13, issue 6, 2012, p. 488.

8 Comparatively, $15 \%$ of Western women have not married by this age. J Z Lee \& W Feng, One Quarter of Humanity: Malthusian Mythology and Chinese Realities, 1700-2000, Harvard University Press, Cambridge, 1999, p. 67. 
long-term partnership in their lifetime. These men are called guangun, 'bare branches' in Chinese, because of their inability to produce a child and continue the family lineage. Chinese demographers Wei Xing Zhu and Li Lu estimate that 'China will see very high and steadily worsening sex ratios in the reproductive age group for the next two decades'.

More and more Chinese women are migrating to larger urban centres for economic opportunities and better marriage prospects. Migrant networks in cities and online domestic websites are creating spaces for migrant women to meet urban men. For example, many cities now have legal services for domestic matchmaking of migrants that are organised by the Committee of Matchmaking Service Industries in Beijing. ${ }^{10} \mathrm{~A}$ marriage to a man with an urban hukou ${ }^{11}$ means that a woman is able to re-register her new status and receive the better medical, housing and education services for her children. ${ }^{12}$ This trend intensifies the problems caused by the sex ratio imbalance. In most provinces, even if women were to stay in rural areas, there would still be an imbalance between the genders. The resulting 'marriage squeeze' has produced challenges and pressures on the marriage market, and this is especially salient in rural and impoverished areas.

Many of these impoverished rural communities are in provinces that do not offer the robust social services and protection programmes that many wealthier provinces on

Z W Xing, L Lu \& T Hesketh, 'China's Excess Males, Sex Selective Abortion, and One Child Policy: Analysis of Data from 2005 National Intercensus Survey', BMJ, 2009, p. 6.

10 L Wu, 'China Releases Chinese Marriage Situation Survey Report 2011', All China Women's Federation, 2012, retrieved 5 February 2015, http://www.women ofchina.cn/html/womenofchina/report/136873-1.htm

11 Hukou is the Chinese name for the record used in China's household registration system. This record documents where a person is born and lives, who their family is, and where they are able to access state resources.

12 C Fan \& $Y$ Huang, 'Waves of Rural Brides: Female Marriage Migration in China', 1998; Y Sun, Corruption and Market in Contemporary China, Cornell University Press, Ithaca, New York, 2004; T Lin, S Short \& L Hui, 'Shuangchongwailaizhe de sheng huo, nvxinghun yin yi min de sheng huojing li fen $x i$ ' ('The life of double outsiders, an analysis of the experience of women marriage migrants'), She huixue Yan jiu (Sociology Research), vol. 104, no. 2, 2003, pp. 7583. 
China's east coast are able to offer. ${ }^{13}$ Without a safety net, these men often are forced to remain dependents in their family homes. Entire villages in China are being labelled 'bare branch villages' when up to $20 \%$ of the population consists of unmarried men. ${ }^{14}$

The bride price has again fluctuated to reflect this dearth of women. Current estimates put the bride price for Han Chinese women between '12,300-41,000 RMB (c. USD $1,500-5,000)$ '. ${ }^{15}$ Though this number can vary based on location or income level, it has, on average, increased dramatically since the pre-1978 era. In addition to this bride price, Chinese men are often not even considered by women for marriage if they do not have a whole suite of material assets. ${ }^{16}$ This is a major economic burden for many men, and it is almost inconceivable for China's most poor.

The marriage strategy that is gaining far greater traction across China is the deployment of international markets for finding brides. International marriage commodification in East and Southeast Asia is not new, but it is a growing trend in many countries. More developed countries such as Japan and South Korea have created sophisticated marriage business models that bring women from Cambodia, the Philippines, Taiwan and Vietnam, to marry domestic men. Since 1990, over 20,000 women from overseas have arrived in Japan to become spouses. ${ }^{17}$ Some international marriages still rely on

13 R Kaur, 'Mapping the Adverse Consequences of Sex Selection and Gender Imbalance in India and China', Economic and Political Weekly, XLVIII, 2013, p. 39; E Sharygin, A Ebenstein, \& M das Gupta, 'Implications of China's Future Bride Shortage for the Geographical Distribution and Social Protection Needs of Never-Married Men', Population Studies, vol. 67, issue 1, 2012, pp. 39-59.

${ }_{14} Q$ Jiang \& J J Sanchez-Barricarte, 'Socio-Demographic Risks and Challenges of Bare-Branch Villages in China', Asian Social Work and Policy Review, vol. 7, issue 2, 2013, p. 104.

$15 \mathrm{H}$ Peters, 'Heaven is High and the Emperor is Far Away: Beijing Certainties Encounter Yunnan Ambiguities', Conference paper: The Human Rights Challenge of Globalization in Asia-Pacific-US, The Trafficking in Persons, Especially Women and Children in Honolulu, Hawaii, 2002.

16 Personal interview with Zhang Youlan in Kunming, China, 15 November 2013.

17 H Wang \& S Chang, 'The Commodification of International Marriages: Crossborder Marriage Business in Taiwan and Viet Nam' International Migration, vol. 40, issue 6, 2002, p. 94. 
personal connections between kinship groups or migrant groups. Other international marriages rely on agencies (both illegal and legal), tools such as the internet and media ${ }^{18}$, and well-connected networks of brokers. In these marriages, both parties can be aware of the specifics of the arrangements, or the man's financial situation, living conditions or physical attributes are hidden until the arrival of the woman. ${ }^{19}$ Families with sons who have physical disabilities are often reliant on these markets. In almost all reported cases of international marriage transactions, the woman is the one to migrate to a country or region with higher levels of economic development. These potential economic benefits make international marriage the choice for many women, despite the risks.

\section{Marriage Markets at the Yunnan-Burma Border}

For Chinese men, harnessing the historical trade relations between Yunnan and Burma and the vulnerability of Burmese $^{20}$ populations across the border is a practical means to expand the marriage market. A decade ago, most of the international marriages spanning the Yunnan-Burma border were local and taking place within particular ethnic groups. These marriages had similar traditions of bride prices and 'go-betweens' to arrange the meeting of new couples, but rarely did the transaction take place over long distances. Now, men and their families from all of China's provinces have the option to travel to Yunnan or to arrange cross-border transactions to find a wife. ${ }^{21}$ Chinese gender researcher Zhang Jiayu recounted a conversation with a party official

18 D Belanger, K Thu Hong \& T Giang Linh, 'Transnational Marriages between Vietnamese Women and Asian Men in Vietnamese Online Media', Journal of Vietnamese Studies, vol. 8, no. 2, 2013, pp. 81-114.

19 G Jones, 'International Marriage in Asia: What do we know, and what do we need to know?', Asia Research Institute (ARI) Working Paper No. 174, ARI, 2012, p. 14.

20 Note here that 'Burmese' does not mean ethnically 'Burman' but includes any person or ethnic group living inside Burma.

21 Personal interview with researcher at the Yunnan Academy of Social Sciences in Beijing, China, 21 March 2013. 
stating: 'Under the open and reform policy, if men cannot get brides in China, they can find them in other countries'. ${ }^{22}$ These practices, as Zhang illustrates, are making their way to Chinese policymakers. Yunnan's economic development and trade relations have given Chinese men the option to seek brides from Burma. Men gain access to markets in towns such as Ruili and Jinghong, and negotiate with those who have connections across the border.

Bride price, in this context, is a fee that the man must pay to arrange the procurement of a woman, her transportation and, depending on the situation, her documentation. This documentation is the only addition to what is considered included in the traditional bride price. Currently in Yunnan, international marriages are legal once the bride produces documentation from her home country to prove her 'single' status. A new husband is able to register his new wife at the local Bureau of Civil Affairs and pay a fee for any child produced in the marriage. ${ }^{23}$ According to China's UN Inter-Agency Project on Human Trafficking (UNIAP) office, many Burmese women do not have documentation or even national identification cards. ${ }^{24}$ Some marriages are not documented and those women remain illegal immigrants within Yunnan or other provinces, but others rely on forged documentation or connections that their brokers can provide.

Chinese men, through the use of brokers, pay less than one-fourth of the bride price of Chinese women (both Han and ethnic minority women) for a woman from Burma. ${ }^{25}$

22 J Zhang, 'Imbalanced Sex Ratio at Birth and Women's Human Rights in China: A Rights Analysis and Comparative Implications', Master of Arts Thesis, Chinese University of Hong Kong, 2010, p. 38.

23 Personal interview with staff member UNIAP-China, in Beijing, China, 14 October 2013.

24 Interviews for this study were conducted with key informants such as local and domestic NGOs working on human trafficking in both China and Burma. The author also conducted fieldwork in the city of Ruili, China, and surrounding villages in Yunnan province by using informal interview and participant and non-participant observation. Future fieldwork and qualitative data gathering is currently being planned by the author.

25 H Peters. 
In one common case, a Chinese man bought a bride and her documentation from northern Shan state for only CNY 1,200 (USD 185). ${ }^{26}$ Burmese women are among the cheapest international brides in China because of their economic status and relatively lower physical desirability. The average annual income in 2011 for Burmese families, according to the UN Children's Fund (UNICEF), was less than USD 735. ${ }^{27}$ Comparatively, China's average income per capita in 2011 was USD 4,930 and, in the United States of America, this number was at USD 48,450. ${ }^{28}$ Though regional differences within Burma can create variation in these specific numbers, approximately $75 \%$ of the population lives below the poverty line. ${ }^{29}$ Once considered world-class through the mid-1900's, Burma's schools, hospitals and other vital infrastructure are considered unfit by most international standards today. In 2013, government expenditures on health and education combined consisted of $2.3 \%$ of the national budget, but the spending on military and defence was $20.86 \%$ of the national budget. ${ }^{30}$

Villages with large populations of Burmese brides in China are sometimes referred to as 'black villages' because of Burmese

26 Palaung Women's Association, 'Stolen Lives: Human Trafficking from Palaung areas of Burma to China', Palaung Women's Association, Chiang Mai, Thailand, 2011, p.22.

27 UNICEF, 'Statistics: Republic of Myanmar', UNICEF, 2011, retrieved 27 February 2015, http://www.unicef.org/infobycountry/myanmar_statistics.html

28 UNICEF, 'Statistics: China' UNICEF, 2011, retrieved 27 February 2015, http:// www.unicef.org/infobycountry/china_statistics.html; UNICEF, 'Statistics: United States' UNICEF, 2011, retrieved 27 February 2015, http:// www.unicef.org/infobycountry/usa_statistics.html

29 Burmese Women's Union, 'Caught Between Two Hells: The Report Highlights the Situation of Women Migrant Workers in Thailand and China', Burmese Women's Union, 2007, p.7.

30 Kachin Women's Association of Thailand, 'Driven Away: Trafficking of Kachin Women on the China-Burma Border', Kachin Women's Association of Thailand, 2005, p.15; K H Mon, 'UNICEF Tells Govt to Increase Education, Health Spending', Irrawaddy News, 7 November 2013, retrieved 27 February 2015, http://www.irrawaddy.org/ un/unicef-tells-govt-increase-education-health-spending.html; N Aye, 'Military Spending Challenged in Parliament', Democratic Voice of Burma News, 19 February 2013, retrieved 27 February 2015, http://www.dvb.no/news/military-spendingchallenged-in-parliament/26476 
women's darker skin. ${ }^{31}$ The international marriage market, across China and most of East Asia, currently operates through a hierarchy based on the perceived advantageous attributes of women's home country. For women from Burma, this generally places them at the bottom of the market after Vietnam, Cambodia and Thailand. The bride price, along with the trade networks along the border, make this region one of the most sought-after for international brides for 'bare branches', who otherwise have no prospects for marriage.

\section{Applying the Protocol to Burmese Women}

Anti-trafficking responses from the Chinese and Burmese governments mirror the ideals propagated by the Trafficking Protocol. Burmese brides in Yunnan are labelled as 'trafficking victims' and become the targets of the Chinese police force's rescue and repatriation campaigns. In reality, despite how they entered China, Burmese women who have passed through the Chinese marriage market often vacillate between 'victim' and 'agent' in their new Chinese context. International and domestic efforts to end human trafficking in the region do not take into account the vast range of circumstances facing Burmese women in China. Instead, she is identified by both countries as a victim of human trafficking. If this victim is fortunate, according to the anti-trafficking regime, she is rescued and saved by the Chinese police and then safely returned to her home in Burma. Accounts from police raids and rescues are harrowing and describe torturous conditions suffered by women at the hands of their husbands, his family and the people responsible for bringing them across the border. After consulting local anthropologists in the region, non-governmental organisation

31 'Henan nongcunnannubilieshitiao, miandianfunujiarudangdi' ('Demographic imbalance between male and female in rural areas of Henan Province, Burmese Women married illegally into the local villages'), WangyiXinwen, 16 June 2006, retrieved 27 February 2015, http://news.163.com/06/0616/ 10/2J004A760001124J.htm 
(NGO) workers, local government and police, reports from Burmese organisations based in the region, and interviews from Burmese women who had returned from China, I found that these exploitative situations do occur, but that this type of victimology overshadows many of the other experiences of Burmese women. More importantly, both the Chinese and Burmese governments rely on criminal interdiction to satisfy commitments to the international community under the Trafficking Protocol mandate, instead of reforming institutions and systems that make these women vulnerable in both Burma and China.

Under the China National Action Plan on Combating Trafficking in Women and Children (2008-2012), the Chinese government identified child abduction, forced marriage and trafficking into the sex industry as the crimes that would be pursued by the criminal justice system at the national and provincial levels. During the early 2000s, the Chinese government added eight articles to the Chinese Criminal Penal Code, all of which address issues termed 'trafficking in persons'. ${ }^{32}$ The powerful Ministry of Public Security coordinated these reforms and established a consortium of thirty-four other ministries and bureaus to work on human trafficking. On 8 February 2010, China signed and ratified the Trafficking Protocol. By 2013, the government put forward China's Action Plan Against Human Trafficking (2013-2020) that added labour trafficking, forced begging, child performance, and organised theft to the list of human trafficking crimes. ${ }^{33}$ Despite these inclusions, the Chinese government continues to mainly focus on child abductions and bride trafficking, due to international concerns. In 2010, the Chinese government also made it illegal for matchmaking services and agencies to

32 These include $234 \mathrm{~A}, 240,241,242,244,262,276 \mathrm{~A}$, and 358. Text and description available at: http://www.asianlii.org/cn/legis/cen/laws/clotproc361/ retrieved 5 February 2015.

33 中国反对拐卖人口行动计划 General Office of the States Council, no. 9, 2 March 2013, retrieved 27 February 2015, http://www.gov.cn/zwgk/2013-03/08/ content_2349019.htm 
include foreign clients. ${ }^{34}$ Domestic Chinese marriage agencies continue to flourish but cross-border agencies have been legally conflated with bride trafficking.

In implementing the Action Plans, the Ministry of Public Security uses 'strike-hard' (hard-hitting) campaign ${ }^{35}$ policies to target traffickers. These campaigns, similar to anti-drug campaigns, are short-lived and expensive, both in terms of financial expenditures and human capital. The Chinese government is able to defer reforms to economic or immigration policy by pursuing these campaigns despite their dismals success rates. According to Chinese sociologist Gracie Ming Zhao: 'One consequence of such a style is during a specific strike-hard campaign period, the criminals of a targeted activity are likely to face a more severe punishment than in a normal period...but most offenders learn to take advantage of it.' ${ }^{36}$ The offenders coordinate their own actions based on the timings between raids. However, the hard-hitting campaigns against bride trafficking are highly publicised in the national media. High-profile celebrities have made documentaries that follow local police forces conducting raids on trafficking rings and returning brides to their home countries. ${ }^{37}$ Pictures of Burmese women in the company of Chinese police officials flood websites, news outlets and China's microblogs (such as the popular Twitter-like website, Weibo) without concern for the privacy of the victims. On the other hand, other types of exploitation in labour industries are censored by the government and not included in these raids. Despite quarrels over human rights issues between China and Western powers, China continues to strive to fit the international mould when it

34 K L Huang, 'Illegal Chinese Cross-Border Matchmakers Flourish as Demand Grows', South China Morning Post,12 November 2013, retrieved 5 February 2015, http:/ /www.scmp.com/print/news/china-insider/article/1354390/illegal-chinesecross-border-matchmakers-flourish-demand-grows

35 The term 'strike-hard campaign' is the Chinese expression.

${ }^{36}$ G Z Ming, 'Trafficking of women for marriage in China: Policy and practice', Criminology and Criminal Justice, vol. 3, no. 1, 2003, p. 95.

37 W Yates, 'Human Traffic: China', MTV Exit Production, Beijing, China, retrieved 5 February 2015, http://mtvexit.org/humantrafficen/\#learn 
comes to anti-trafficking efforts. China wants its system of criminal interdiction against human trafficking to be considered up to international and Trafficking Protocol-driven standards.

Burma passed its National Anti-Trafficking Legislation in 2005, and at the same time joined China in signing a bilateral Memorandum of Understanding to organise responses to cross-border trafficking of people. ${ }^{38}$ China and Burma are part of the consortium of countries in East and Southeast Asia that recognise the universal criminality of human trafficking and the need for international cooperation. Six of these countries, Burma, Cambodia, China, Laos, Thailand and Vietnam, have formed a ministerial policy coordination group called the Coordinated Mekong Ministerial Initiative Against Trafficking, or COMMIT. ${ }^{39}$ In Burma, under two similar National Plans of Action for Combating Trafficking (20072011 and 2012-2016), the Ministry of Home Affairs established the Central Body for Suppression of Trafficking in Persons. This Central Body's main function is the creation of a new branch of the Burmese police force that will act as a widereaching Anti-Trafficking Task Force network system that has also established internal Task Force units and Border Liaison Offices with Thailand and China.

The Burmese Anti-Trafficking Police regularly releases reports on the types of cases investigated by their border liaison offices and taskforces. In 2012, they prosecuted 120 cases, of which $79 \%$ were identified as forced marriage from Burma into China. ${ }^{40}$ Government-run shelters for trafficking victims

38 The Union of Myanmar, The State and Peace Development Council, Anti-Trafficking in Persons Law, 15 September 2005, retrieved 5 February 2015, http:// www.hsph.harvard.edu/population/trafficking/myanmar.traf.05.pdf; The Memorandum of Understanding between the Government of the Union of Myanmar and the Government of the People's Republic of China on Strengthening the Cooperation on Combating Human Trafficking, signed 11 November 2009, retrieved 5 February 2015, http://www.notip.org.cn/Userlmages/00001039.pdf

39 COMMIT, retrieved 5 February 2015, http://www.no-trafficking.org/ commit.html

40 Ministry of Home Affairs, 'Myanmar Five-Year National Plan of Action to Combating Human Trafficking 2012 Annual Progress Report', Government of the Republic of Myanmar, 2013, p. 32. 
have been established in Mandalay and Myawaddy, and they also provide counselling and job training for those repatriated from China or Thailand. ${ }^{41}$ The Burmese police work with NGOs Save the Children and World Vision to run educational campaigns and shelter programmes, and with other international groups like Australian Aid to supply specialised police training. Civil society groups in Burma are currently trying to pass a new Association Registration Law that would decrease regulations for the formation of domestic NGOs. The current Law Relating to Forming Organizations (No. 6/ 88 ) only registers organisations with direct ties to the government, and as a consequence, most Burmese antitrafficking organisations have had to operate out of other countries such as Thailand. ${ }^{42}$

Despite these efforts, the anti-trafficking regime in Burma is still focused on criminal prosecutions and high-profile interactions with other countries and international organisations. According to Julia Matrip, head of the Kachin Woman's Association in Thailand: 'the regime is mainly involved in pleasing the international community rather than actually dealing with the problem. ${ }^{\prime 3}$ Representatives of the Shan Women's Association argue that the previously mentioned 120 human trafficking prosecutions in 2012 correlated with the 120 arrests made on these charges. ${ }^{44}$ The $100 \%$ prosecution rate in Burma raises suspicion over the Burmese government's claims of having a fair and transparent criminal justice system. Questions also remain regarding the Burmese police force's investigation and arrest procedures. In addition to targeting traffickers, new immigration barriers are being

41 Ibid.

42 P Vierze, "Civil Society and MPs Draft "Progressive" Association Registration Law', Irrawaddy News, 21 October 2013, retrieved 5 February 2015, http:// www. irrawaddy.org/burma/csos-mps-draft-progressive-associationregistration-law.html

${ }^{43}$ A Ellgee, 'Human trafficking increases on Sino-Burma border', Irawaddy News, 26 March 2010, retrieved 5 February 2015, http://www2.irrawaddy.org/ article.php?art_id=18124\&page $=2$

44 Personal interview with the Shan Women's Association in Chiang Mai, Thailand, 23 August 2013. 
implemented to protect women from threats of being 1 trafficked. Women are being detained and questioned at border checkpoints. The Burmese Women's Union argues that imprisoning female migrants for trying to leave the country will not help end exploitation. ${ }^{45}$ Their main point is that these arrests can be factored into the Burmese government's efforts at fighting human trafficking, but do not serve or improve the lives of the women seeking employment. Structural problems of poverty, corruption and civil conflict, especially in the northern Shan and Kachin states, are not being calculated into human trafficking responses by the current government. The Burmese anti-trafficking regime is winning accolades on the international stage, but on the ground the situation for most of these women is not improving.

Burmese women migrate to China for many reasons, including the pursuit of economic opportunities in China, flight from civil conflict in Burma or a combination of both. Women migrate to save their families from starvation, pay off debts or afford basic necessities. For the past fifty years, the civil wars between the government's army, the Tatmadaw, and various allied ethnic group militias have created another type of migrant: the refugee from civil conflict. In the Kachin and Shan areas in northern Burma, fighting has been a constant feature of daily life for fifty years. The Kachin Women's Association of Thailand and the Palaung Women's Association (a group located in northwest Shan state) report that in hundreds of cases Burmese women accept job offers in China, but then find themselves sold to Chinese men. ${ }^{46}$ Recruitment for a job that turns into marriage involves kinship ties or connections between social circles. In the past four years, there has been an increase in the use of websites (including Facebook), mobile phone messaging and public job advertisements to recruit Burmese women for sale across the

45 Personal interview with the Burmese Women's Union in Chiang Mai, Thailand, 23 August 2013.

46 Kachin Women's Association of Thailand, 'Pushed to the Brink: Conflict and human trafficking on the Kachin-China border', Kachin Women's Association of Thailand, 2013. 
border. Some recruiters openly advertise for brides in Burma. One website simply stated: 'Contact me if you or your friends want to get married in China. ${ }^{47}$ Women are seizing these opportunities and passing across the border with relative ease, aided by recruiters and their web of contacts throughout China.

The situations Burmese brides find themselves in whilst in China are as varied as the number of Burmese brides in China themselves. The cases of women suffering abuse (physical and mental) or trafficking into other industries (such as sex or labour) at the hands of their Chinese husbands are often the only ones reported by international NGOs or the Burmese government. Other scenarios also exist. Upon arriving in China, many Burmese brides stay married for precisely the factors that drove them to migrate in the first place. In this case, she is able to fashion better economic conditions for herself and achieve her own personal hypergamy within her new social group or community. Burmese brides have also been documented working outside the home and sending remittances to their families across the border. ${ }^{48}$

Burmese women are not protected under the same laws protecting the rights Chinese citizens, and they can be forced to leave the country against their will. A Burmese bride is currently unable to be eligible for a hukou, and thus, cannot travel freely, work legally or access important health services. She also cannot vote in village elections or seek legal help in the event that her husband is abusive. Most of these constraints, it should be noted, affect Burmese women back home as well. The system of issuing Burmese national

${ }^{47}$ Z Mann, 'Police Close Chinese Marriage-Fixing Agency on Burma-China Border,' Irrawaddy News, 22 November 2013, retrieved 5 February 2015, http:// www. irrawaddy.org/china/police-close-chinese-marriage-fixing-agency-burmachina-border.html

48 K Kha, 'Ruili Working Condition Tough on Burmese Women', Mizzima News, 25 August 2013, retrieved 5 February 2015, www.mizzima.com/news/regional/ 6652-ruili-working-conditions-tough-on-burmese-women?tmpl=component \&print=1\&page= 
identification cards is plagued with corruption and discrimination along ethnic lines. ${ }^{49}$ Even if women in Burma can access hospitals, for example, the quality of the hospital is abysmal, especially when compared to those in China.

Furthermore, a child can drastically alter the factors influencing a Burmese woman's decision to remain in China. Any child produced in the marriage between a Chinese national and a Burmese woman has the full rights of a Chinese citizen. ${ }^{50}$ Her child will be able to have a free education, a hukou registration card and access to social services from the government. Aside from these benefits, many women choose not to leave with their children and return home to Burma. Even some of the women who do go back to Burma after having a child in China will ultimately return the latter because the Chinese family wants to be with her child. Over time, I was not surprised to learn that many of these Burmese women do not view themselves as having been 'sold' to Chinese men, nor do they readily identify with or uphold the label of 'trafficking victim'. Marrying a Chinese man is a survival strategy and a mechanism through which one can provide for family members.

\section{Case Study-Coordinated Local Interventions for Trafficked Women: The 'blue card system}

Though the Chinese Ministry of Public Security officials claim that Burmese women are not repatriated unless they choose to be, these women are in fact considered to be illegal immigrants in the country and have no legal rights. ${ }^{51}$ On the Chinese side of the border, there are no shelters specifically for women who were forced

49 Personal interview with World Vision-Myanmar, in Rangoon, Burma, 20 September 2013.

50 According to Article 4 of the Nationality Law of the People's Republic of China, 'Any person born in China whose parents are both Chinese nationals or one of whose parents is a Chinese national shall have Chinese nationality.

51 Personal interview with China's Ministry of Public Security's Anti-Trafficking Unit officials, in Beijing, China, 19 August 2013. 
into marriage in China, and most are sent straight to police stations.

In 2010, Dehong Prefecture, a Dai and Jingpo ethnic minority autonomous region in the western part of Yunnan, created the first and only system of documenting and provided services to foreign women who entered the country to become wives of Chinese men. The local government created the Documented Registration Certificate for Border Residents in the Cross-Border Marriages, commonly referred to as 'lanka' or 'blue card' due to its colour, in response to the increase of Burmese women entering Yunnan in the past decade. Dehong Prefecture is home to the major border city of Ruili, and, in 2011, approximately 7,000 blue cards were issued to Burmese women. ${ }^{52}$ This card ensures that its bearer is no longer considered a illegal immigrant even if documentation from her home country cannot be produced. It also provides immunity from being categorised as a 'person of three illegalities', referring to a person who has entered the country illegally, resides in the country under illegal conditions and is banned from working in the country. ${ }^{53}$ Additionally, women who obtain this card are able to apply with the rural cooperative medical care and health services stations found in Dehong Prefecture to receive free and/or subsidised healthcare. Other illegal wives in Yunnan have to rely on social networks, brokers, or bribery to receive provincial rates of Chinese citizens for healthcare. ${ }^{54}$

In my interviews, I found that the blue card does have several limitations. It must be renewed every year at the prefecture (not county) level

52 Personal interview with anthropology professor at Yunnan Ethnic Minorities University, in Kunming, China, 1 September 2012.

53 Ibid.

${ }^{54}$ Personal interview with 'Molly', anthropologist at Yunnan University, in Kunming, China, 16 November 2013. *Note these names have been changed (and others omitted) to preserve the anonymity of key informants. 
adminitrative office. ${ }^{55}$ This process incurs heavy travel and time costs for many women, and is often dependent on the acquescience of the women's husband. Women with a blue card are also unable to leave Dehong Prefecture, as this system is not recognised in China as a whole. Beijing Ministry officials deny the blue card system's very existence because of the ramifications that this policy could have on immigration on a nation wide scale and because of the accountability this system would bring to bear on trafficking in persons reporting. The system remains hidden and contained at the local level, and quietly maintains semi-official records on the size of the bride population entering China from Burma. ${ }^{56}$

The official anti-trafficking regimes adopted in Burma and China from international models target the marriage transaction and the movement of peoples across the border. For Burmese brides within China, a more appropriate human rights response to their situation is needed to address the dearth of protective laws and positive rights that should protect them in their new marriage and home. Migrating for marriage or a job is frequently an act of economic necessity and ought be seen as a bold act of courage taken by women who have no economically viable alternative. The lack of recognition of their rights as migrants, wives, mothers and workers only harms the anti-trafficking cause.

\section{Conclusion}

The purpose of this study is to expose several of the pitfalls and misconceptions inherent in the anti-trafficking movement's universal criminalisation of human trafficking under the Trafficking Protocol. Traditional marriage in China is expanding

5 Ibid.

56 Personal interview with Li Xiaotang, Chinese anthropologist, in Dimaluo, Yunnan Province, 9 November 2013. 
to accommodate the increased demand for brides by Chinese men. This expansion has caused the market to evolve, but many of its core principles have remained intact. Criminalisation of bride trafficking puts challenges on people heavily influenced by the importance of the institution of marriage in Chinese society. It also disproportionately discriminates against the poorest of Chinese male citizens. For Burmese women, prosecutions, repatriations and anti-trafficking raids are contrary in nature to the wishes of Burmese with ties to China. These methods also do not address factors contributing to their original motivations for migration, and do not provide protections to those who wish to stay in China.

Criminal prosecutions cannot be a substitute for access to structures of power within the government and society or for the ability to demand rights and represent one's own interests. The Chinese and Burmese governments have recognised the trade in Burmese women across the China border, but now they must address its subtleties and linkages to the broader society. Through comprehensive understanding of the region and the desires of its inhabitants, there must be practical application of this knowledge through policy reform and appropriate NGO intervention. As anti-trafficking efforts continue to attract attention around the globe, international institutions, governments and communities of activists must be aware of the situations facing the populations they are trying to serve, and combat the biases that human trafficking language and legislation can create in the field. A new outlook and awareness will create a stronger, more successful anti-trafficking movement, and, more importantly, address the needs, desires and rights of people working to improve their lives. 
Laura K Hackney is currently a Program Associate for the Freeman Spogli Institute for International Studies at Stanford University, United States of America. She worked as the Research Associate for Stanford's Anti-Trafficking Project in the Mekong Sub-Region and holds a Master's degree from Stanford's Department of East Asian Studies and a Bachelor's Degree from the University of California, Berkeley. Hackney's work focuses on examining the connections between regional and cross-border irregular migration practices, gender dynamics and changing immigration policies in Burma, China and Thailand. Domestically, she works with the Human Trafficking Task Force within the San Francisco Police Department's Special Victims Unit, and she is the co-founder of Annie Cannons, an organisation working to train human trafficking survivors in computer literacy and programming. Email: lhackney@stanford.edu 


\title{
Trafficking in Persons for Ransom and the Need to Expand the Interpretation of Article 3 of the UN Trafficking Protocol
}

\author{
Mogos O Brhane
}

\section{Abstract}

As the nature of trafficking in persons continues to manifest itself in myriad ways all over the world, interpretation of the UN Protocol to Prevent, Suppress and Punish Trafficking in Persons, Especially Women and Children (Trafficking Protocol), should be broadened to include newly emerging practices that are similar in nature to those it has already embraced under its definition. The Protocol appears to encompass other forms of trafficking which are unnamed or unforeseen by the definition provided under Article 3 . It is time to expand its spectrum. Northeast Africa is plagued by a unique form of trafficking in persons-trafficking in persons for ransom. This involves a practice where people are smuggled, abducted, kidnapped and tortured to compel their relatives and families to pay ransom money. Victims are nationals of Eritrea, Ethiopia, Sudan and South Sudan. However, as Northeast Africa hosts particularly high numbers of Eritrean migrants and the largest Eritrean diaspora globally, Eritreans are very vulnerable to being targeted for trafficking for ransom. As trafficking for ransom is an emerging trend, legal ramifications have never been studied in full. Few reports try to address legal issues around the phenomenon, and those that do only give it a few paragraphs of attention. There is need for a closer look at this form of trafficking.

Keywords: ransom, trafficking, Trafficking Protocol, torture, exploitation, forced begging, debt bondage, Eritreans, migration, kidnapping 
Please cite this article as: M O Brhane, 'Trafficking in Persons for Ransom and the Need to Expand the Interpretation of Article 3 of the UN Trafficking Protocol', Anti-Trafficking Review, issue 4, 2015, pp. 120-141, www.antitraffickingreview.org

Reality in Northeast Africa reflects the intricate nature of migration, smuggling and trafficking in persons. Inside the region, migrants are trafficked for ransom, which involves being smuggled, abducted, kidnapped and kept as hostages. ${ }^{1}$ In hostage camps, captives are tortured often while on the phone with relatives or friends, as a means to expedite the payment of ransom.

The harsh political and economic reality in Eritrea is attributed as the main reason Eritrean nationals flee at an alarming rate. Desperate journeys in search of safety and security make Eritrean migrants vulnerable to traffickers. The traffickers are organised criminal groups who build livelihoods on the continuous flow of migrants and take advantage of the social, political and economic repression in Eritrea. The legal response to this problem in the countries of origin, transit and destination is very weak. Almost all countries affected lack a comprehensive legal framework and show limited interest in investigating and prosecuting the act inside or outside their territories. Trafficking in persons for ransom is one of the newest patterns of trafficking in persons. Records show that apart from Northeast Africa, the practice has plagued the Middle East (Yemen), Southeast Asia

1 The research is based on secondary data of recorded and compiled interviews with victims and other actors in trafficking in persons: Human Rights Watch, (HRW), 'Eritrea, Service for Life State Repression and Indefinite Conscription in Eritrea', HRW, 2009; HRW, “" Wanted to Lie Down and Die” Trafficking and Torture of Eritreans in Sudan and Egypt', HRW, 2014; HRW, 'Yemen's Torture Camps, Abuse of Migrants by Human Traffickers in a Climate of Impunity', HRW, 2014; M van Reisen, M Estefanos \& C Rijken, Human Trafficking in the Sinai: Refugees between Life and Death, Nijmegen: Wolf Publishers, 2012; M van Reisen, M Estefanos \& C Rijken, The Human Trafficking Cycle: Sinai and Beyond, Nijmegen: Wolf Publishers, 2014; Amnesty International, 'Egypt/Sudan Refugees and Asylum Seekers Face Brutal Treatment, Kidnapping for Ransom and Human Trafficking', Amnesty International, 2013. 
(Burma, Malaysia and Thailand) and North America (Mexico), ${ }^{2}$ and yet it is one of the most poorly studied forms of trafficking. A few existing reports attempt to link trafficking for ransom with trafficking for debt bondage and/or forced begging, and a careful assessment of the facts and circumstances of the case reveals the limitation of Article 3 of the Trafficking Protocol in addressing the problem. This article provides a wider perspective on the issue and tries to demonstrate unique features of trafficking for ransom by focusing on the experiences of Eritreans who constitute a relatively large proportion of those experiencing it. The article looks at ways in which trafficking for ransom can be included in interpretations of the Trafficking Protocol, and it makes the case for states to look at the possibility of amending their national anti-trafficking legislation and policy to specifically include trafficking for ransom.

\section{Trends of Trafficking for Ransom in Northeast Africa and the Middle East}

Eritrea, situated in Northeast Africa, is a country of origin for the highest number of people in migration, smuggling and/or trafficking situations in Ethiopia, Egypt, Libya and Sudan and, to certain extent, Yemen. In 1998, the border war between Eritrea and Ethiopia claimed the lives of hundreds of thousands of people, displaced thousands of citizens and destroyed economic infrastructure. The Eritrean

2 HRW, 'Yemen's Torture Camps', p. 34, retrieved 28 May 2014, http://www. hrw.org/sites/default/files/reports/yemen0514_ForUpload.pdf. People of the ethno-religious minority Rohingya who flee Burma to escape religious persecution are sold by Thai officials to traffickers in Malaysia who in turn hold them in hidden camps 'until relatives pay thousands of dollars to release them.' See also J Szep \& A Marshall, 'Thailand's clandestine Rohingya Policy Uncovered', Thomson Reuters, 2013, p. 2, retrieved 1 December 2014, http://graphics.thomsonreuters. com/13/12/ROHINGYA-THAILAND.pdf. In Mexico, criminal gangs kidnap migrants who follow routes through Mexico and keep them hostage forcing them to reveal telephone numbers of their relatives and demand ransom. Amnesty International, 'Invisible Victims: Migrants on the Move in Mexico', Amnesty International, 2010, pp. 11 and 17, retrieved 14 January 2015, http://www. amnesty.org/en/library/asset/AMR41/014/2010/en/8459f0ac-03ce-4302-8bd23305bdae9cde/amr410142010eng.pdf 
government follows an isolationist policy in handling the war and post-war impacts which has already resulted in increased political hardship and violations of fundamental human rights. ${ }^{3}$ Especially since 2001, the human rights situation in the country has gradually degraded. ${ }^{4}$ Eritreans began to flee the country in larger numbers to Ethiopia, Sudan, Djibouti and Yemen. As the influx increased, particularly since 2006, trends started to portray intertwined characteristics of smuggling and trafficking affecting the neighbouring countries. An intermix of smuggling, deceit, abduction, coercion, abuse and extortion has led some observers to the conclusion that the trends partly constitute human trafficking. ${ }^{5}$ Although the problem also affects nationals of Ethiopia, Sudan and South Sudan, because Northeast Africa hosts particularly high numbers of Eritrean migrants and the largest Eritrean diaspora globally, Eritreans are very vulnerable to being targeted for trafficking for ransom.

Moreover, the countries become increasingly recognised as having multiple roles as countries of origin, transit and destination for trafficking. The trend of trafficking follows three main migration routes. The first route is an Eritrea-(Ethiopia)-Sudan-Egypt route where by the majority of Eritreans flee to Sudan directly or via Ethiopia with smugglers. In some cases, smugglers turn out to be traffickers at certain destinations and surprise migrants who are not aware of the fact that they have been smuggled by traffickers. ${ }^{6}$ After crossing the Sudanese border, many

3 HRW, 'Eritrea, Service for Life', p.3, retrieved 2 March 2014, http:// www.hrw.org/sites/default/files/reports/eritrea0409web_0.pdf; M van Reisen et al., 'Human Trafficking in the Sinai', p.16.

4 Ibid., the pinpointed reason for people's discontent that causes migration is conscription of adults into the Eritrean National Service for indefinite periods of time. Eritrean National Service Proclamation No.82/1995 obliges citizens between 18-50 years old to take part, for eighteen months, in military training and national development programmes with inadequate remuneration. After the outbreak of the war with Ethiopia, a de facto state of emergency was declared and extended the time to an unlimited period.

5 D Connell, 'Refugees at Risk', Foreign Policy in Focus, 11 April 2014, retrieved 9 May 2014, http://www. danconnell.net/sites/default/files/Eritrean\%20 Refugees\%20at\%20Risk.pdf

6 R Humphris, 'Refugees and the Rashaida: Human smuggling and trafficking from Eritrea to Sudan and Egypt', UN High Commissioner for Refugees (UNHCR), 2013, p.22, retrieved 4 March 2014, http://www.unhcr.org/51407fc69.pdf 
are forcefully picked up and transported to Sinai, Egypt. Trafficking starts from Ethiopian territory where incidences of kidnapping incidents have been reported in Mai Aini and Shimelba refugee camps. ${ }^{7}$ Similarly in Sudan, trafficking also begins with abduction and kidnapping taking place in and around Shegarab refugee camp, mainly by members of the Rashaida ethnic group. ${ }^{8}$ Victims are transferred to final hostage takers passing through a chain of financial arrangements or deals between different traffickers. ${ }^{9}$ Numbers of cases also involve collaboration of Eritrean, Sudanese and Egyptian police and security forces who take part in and facilitate the kidnapping and transportation of victims for hostage taking. ${ }^{10}$ For a number of cases, traffickers demand ransom money, which may be as high as USD 16,000.11 Upon payment, migrants are either freed or sold to other traffickers in Egypt's Sinai. ${ }^{12}$ At the main

7 M van Reisen et al., 'Human Trafficking in the Sinai', pp. 25 \& 40; Physicians for Human Rights-Israel, 'Hundreds of Refugees Held Hostage in Sinai Torture Camps Need Rescuing', 2012, retrieved 4 March 2014, http://www.phr.org.il/ default.asp?PagelD=183\&ltemID=1176; HRW, 'I Wanted to Lie Down and Die', p. 22.

8 M van Reisen et al., pp. 28 \& 30; The Rashaida ethnic groups are recent migrants from the Arabian Peninsula into Africa who practice pastoralism around the borders of Eritrea, Sudan and Southern Egypt. See also R Humphris, Refugees and the Rashaida, p.2. At first, members of this group helped Eritrean migrants with an illicit border crossing. Later, they began to exploit worsening situations in Eritrea that lead to a greater influx of migrants. With collaborators in Eritrea, Ethiopia, Sudan and abroad, they facilitate the abduction and kidnapping of Eritrean migrants and ask ransom of their families. They have formed new criminal networks or built on existing ones; see also L Lijnders \& $S$ Robinson, 'From the Horn of Africa to the Middle East: Human trafficking of Eritrean asylum seekers across borders', Anti-Trafficking Review, issue 2, 2013, pp.147 \& 149.

9 M van Reisen et al., 'Human Trafficking in the Sinai', p. 25.

10 HRW, 'I Wanted to Lie Down and Die', pp. 42-47; Tom Dale, 'Are Eritrean and Egyptian Officials Profiting From Torture?’, Vice, 12 February 2014, retrieved 4 March 2015, http://www.vice.com/en_uk/read/egypt-eritrea-trafficking-sinai

11 HRW, 'I Wanted to Lie Down and Die', p.12; D Connell, 'The Rerouted Trafficking in Eritrean Refugees', Middle East Research and Information Project, vol. 43, 2013, retrieved 10 Oct 2013, http://www.merip.org/mer/mer268/reroutedtrafficking-eritrean-refugees; $M$ van Reisen et al., 'Human Trafficking in the Sinai', p.28.

12 R Humphris, 'Refugees and the Rashaida', p. 12. The Bedouins are typically socially and economically marginalised people who avoid government control around borders of Eritrea, Sudan and southern Egypt. Some among the members of this group build lives along borders and routes to Israel, making money through illicit smuggling of trafficked persons, drugs and weapons. 
locations of El Arish, El Masouraand Al Mahdiain the Sinai, some members of the minority Bedouin tribes force payment of up to USD 50,000 per person. ${ }^{13}$ Different techniques of torture are applied to facilitate payment including whipping, burning bodies with molten plastics, electrocution, hanging and drowning the victims in water while they are in telephone conversation with their families. ${ }^{14}$ Hundreds die due to the dire hostage situations. ${ }^{15}$ Those who are not able to pay are often killed by the traffickers. ${ }^{16}$ Between 2006 and 2012,

13 Ibid., p. 4; see The CNN Freedom Project, 'Stand in Sinai now Online', 26 September 2012, retrieved 5 March 2014, http://thecnnfreedomproject.blogs.cnn.com/ 2012/09/26/stand-in-the-sinai-now-online/; D Connell, 'The Rerouted Trafficking in Eritrean Refugees'; L Lijnders and S Robinson, 'From the Horn of Africa to the Middle East', p.139.

14 The CNN Freedom Project, 'Stand in Sinai now Online'; The 1984 Convention against Torture defines torture as 'any act by which severe pain or suffering, whether physical or mental, is intentionally inflicted on a person ... by or at the instigation of or with the consent or acquiescence of a public official or other person acting in an official capacity...' However, since traffickers are mainly a group of individuals, trafficking for ransom seems to fall outside the spectrum of this definition. A flexible interpretation of the definition could lead to States' liability for failure to exercise due diligence to investigate and punish acts of torture committed by private actors or organised criminals that may amount to a State's facilitation or complicity with the private operations. Further, in the UN Human Rights Committee, General Comment 31, Nature of the General Legal Obligation on States Parties to the Covenant, UN Doc. CCPR/C/21/Rev.1/ Add.13, 2004, paragraph 8, States are required to 'prevent, punish, investigate or redress the harm caused by such acts [violations] by private persons or entities'. In addition, the fact that some security officers collude with traffickers amounts to a State's complicity in the unlawful practice. See also Article 1, Convention against Torture and Other Cruel, Inhuman or Degrading Treatment or Punishment, December 1984, retrieved 5 April 2014, http:// www.ohchr.org/EN/Professionallnterest/Pages/CAT.aspx; see also A v United Kingdom [1998] ECHR 22 \& H.L.R. v France [1997] ECHR 30; UN Office of the High Commissioner for Human Rights, 'Report of United Nations Committee against Torture', $4^{\text {th }}$ and $50^{\text {th }}$ Session, 2013, p. 255, retrieved 5 April 2014, http://tbinternet.ohchr.org/_layouts/treatybodyexternal/Download.aspx? symbolno=HRI\%2fGEN\%2f1\%2fRev. 9\%20(Vol.\%20l)\&Lang=en

15 M van Reisen et al., 'Human Trafficking in the Sinai', p. 48; H Sherwood, 'Hundreds of Eritreans enslaved in torture camps in Sudan and Egypt', The Guardian, 11 February 2014, retrieved 9 March 2014, http://www.theguardian.com/ world/2014/feb/11/eritreans-enslaved-traffickers-sudan-egypt-torturecamps

16 S M Weldehaimanot, 'Kidnapping, Hostage-Taking And Ransoming Of Eritrean Asylum Seekers In The Sinai Desert', Release Eritrea, 2011, p. 16, retrieved 18 February 2015, http://papers.ssrn.com/sol3/papers.cfm?abstract_id=19324 57; $M$ van Reisen et al., 'Human Trafficking in the Sinai', pp. 40 \& 52. 
Israel was a destination for most of the fleeing migrants. ${ }^{17}$ In 2012, the Israeli government renewed its anti-infiltration regulation and fenced its border to deter the growing number of African migrants. ${ }^{18}$ Another deterrent was the shoot-to-kill measures carried out by Egyptian border patrol guards at the Israeli border. ${ }^{19}$ Due to these measures, while the overall flow of migrants through Egypt significantly reduced, numbers of people released on payment and those who escape the torture camps and return to Cairo have increased. ${ }^{20}$

Since 2013, most migrants have taken the second route Eritrea-(Ethiopia)-Sudan-Libya. The trafficking pattern has also shifted to this route. To date, large influxes of Eritrean migrants follow this route hoping to cross to Europe from Libya. ${ }^{21}$ Many organised criminals smuggle and traffic migrants from all over the continent. In most cases, Eritreans coming directly or via Ethiopia gather in Sudan and are led by smugglers across the Libyan border. Other traffickers pick up the migrants at the border and keep them in places like Ajdabiya, for extortion. ${ }^{22}$ In some cases, migrants who made

17 UNHCR, 'Population Statistics', http://popstats.unhcr.org/PSQ_RSD.aspx; HRW, “"Make Their Lives Miserable" Israel's Coercion of Eritrean and Sudanese Asylum Seekers to Leave Israel', HRW, 2014, p.17, retrieved 2 October 2014, http:// www.hrw.org/sites/default/files/reports/israel0914_ForUpload_1.pdf

18 M Omer-Man, 'The Origin and Politics of Israeli's Refugee Debate', +972, 28 January 2014, retrieved 18 February 2015, http://972mag.com/the-originsand-politics-of-israels-refugee-debate/86180/ The new regulation authorises detention of infiltrators for three years with the possibility of renewing until deportation. In addition, fences recently built along the border made crossing impossible.

19 HRW, 'I Wanted to Lie Down and Die', p. 26.

20 T Dale, 'Sinai Trafficking Victims Face Hardship in Cairo as they Await Resettlement', The Guardian, 9 May 2014, retrieved 25 Jan 2015,http:// www.theguardian.com/global-development/2014/may/09/sinai-traffickingvictims-cairo-resettlement

21 US Department of State, Trafficking in Persons Report 2013, pp. 397-399; M Manrique, J Barna, P Hakala, B Rey \& E Claros, 'In-Depth Analysis Mediterranean flows into Europe: Migration and the EU's foreign policy', European Union, 2014, p. 5, retrieved 18 February 2015, http://www.europarl.europa.eu/euroscola/ resource/static/files/mediterranean-flows.pdf

22 Xinhua, 'Somali man arrested over Lampedusa migrants' ship tragedy', 9 November 2013, retrieved 18 February 2015, http://news.xinhuanet.com/ english/africa/2013-11/09/c_132874172.htm; Human Rights Concern, 'Eritrean Refugees in Libya: Forced to Clear Land Mines', Asmarino Independent,19 March 2013, retrieved 20 May 2014, http://asmarino.com/press-releases/ 1690-eritrean-refugees-in-libya-forced-to-clear-land-mines 
it to the Libyan territory are kidnapped and transferred for ransom and afterwards handed over to other groups who take additional money to arrange for their journey by sea to Europe. ${ }^{23}$ Traffickers are nationals of Sudan, Tunisia, Libya, Somalia and Eritrea who physically and mentally assault hostages, with tactics including various methods of torture and rape. ${ }^{24}$ The amount of money usually requested is relatively very small reaching up to USD 3,000. ${ }^{25}$

The third, currently active, migration route includes Eritrea-(Djibouti)-Yemen. Though relatively small in number, Eritreans who follow this route also face risk of kidnapping, torture and ransom inside the territory of Yemen. The majority of the victims are nationals of Ethiopia and Somalia. ${ }^{26}$ Migrants who cross the Red Sea to the shores of Yemen are abducted and kept hostage for ransom. Since 2006, organised criminal groups operate in smuggling networks extending through Ethiopia, Djibouti, Somalia and Saudi Arabia. ${ }^{27}$ Trafficking intensified as desperate migrants were kidnapped and detained for ransom by traffickers in the desert camp around Haradh. ${ }^{28}$ Migrants pass through chains of sales or deals between different gang groups before reaching their final destination. ${ }^{29}$ Inside Yemen, the sales start when migrants reach the shore and are picked up by traffickers who pay boat crews USD 133 per head. ${ }^{30}$ Traffickers sell the migrants to other traffickers who run their own independent camps. ${ }^{31}$ Migrants are kept in the camps where they are forced

23 M Schwartz, 'Letter from Lampedusa: The Anchor', The New Yorker, 21 April 2014, retrieved 29 April 2014, http://www.newyorker.com/reporting/2014/ 04/21/140421fa_fact_schwartz April 212014

24 Ibid.

25 Agence France-Press, 'Lampedusa shipwreck migrants 'raped by traffickers', The Telegraph, 8 November 2013, retrieved 18 February 2015, http:// www.telegraph.co.uk/news/worldnews/europe/italy/10436645/Lampedusashipwreck-migrants-raped-by-traffickers.html

${ }^{26}$ HRW, 'Yemen's Torture Camps', p. 22.

27 Ibid., p. 30.

28 Ibid., p. 27.

29 Ibid., p. 30.

30 Ibid., p. 35.

31 Ibid., p. 37. 
to make phone calls to ask for money of amounts up to USD $1,300 .{ }^{32}$ Treatment of hostages in these camps is similar to Sinai's torture camps where captives are beaten, sexually harassed and raped to facilitate payment.

\section{Trafficking for Ransom under Article 3 of the Trafficking Protocol}

The 2000 Trafficking Protocol adopted to supplement the UN Convention on Transnational Organized Crime (UNTOC) was part of the response to a global 'need for a comprehensive international approach' to address 'all aspects of trafficking in persons.' ${ }^{33}$ The Protocol makes a significant shift by specifying that victims of human trafficking are not criminals. ${ }^{34}$ It centres on three objectives: prevention and combating of trafficking in persons, protection of victims of the crime, and promotion of cooperation among States. ${ }^{35}$ The Protocol widened the scope of the definition of trafficking at the time to accommodate protection against other forms of exploitation in addition to forced prostitution and forced labour. ${ }^{36}$ Other forms of exploitation specifically mentioned in the Protocol are organ removal, slavery and slavery-like practices and servitude. ${ }^{37}$ The scope also extends to trafficking of men and boys, though it gives special attention to women and children. ${ }^{38}$ Under Article 3, trafficking in persons is defined to mean:

\footnotetext{
Ibid., pp. 22 \& 45.

Preamble, Trafficking Protocol.

Ibid., Articles 6-8.

Ibid., Article 2.

Ibid., Art 3a-c; Article 3, UNTOC.

37 A D Jordan, 'The Annotated Guide To The Complete The Complete UN Trafficking Protocol', International Human Rights Law Group, 2009, pp. 9-10, retrieved 18 February 2015, http://www.hrlawgroup.org/resources/content/Traff_Anno Protocol.pdf

38 Article 3a, Trafficking Protocol.
} 
...the recruitment, transportation, transfer, harbouring or receipt of persons, by means of the threat or use of force or other forms of coercion, of abduction, of fraud, of deception, of the abuse of power or of a position of vulnerability or of the giving or receiving of payments or benefits to achieve the consent of a person having control over another person, for the purpose of exploitation. Exploitation shall include, at a minimum, the exploitation of the prostitution of others or other forms of sexual exploitation, forced labour or services, slavery or practices similar to slavery, servitude or the removal of organs.

Any organised criminal activity is considered to be trafficking in persons upon proof of fulfillment of three elements enshrined in the definition: act, means and purpose. The only exception is trafficking of children where the requirement of means is waived. ${ }^{39} \mathrm{~A}$ careful examination of the facts and circumstances related to trafficking of Eritrean migrants for ransom easily demonstrates the first two elements of the definition. The last, a purpose of exploitation, has been more difficult to demonstrate, primarily because exploitation is undefined, and requires attention.

Act, as defined as '...recruitment, transportation, transfer, harbouring or receipt of persons...' includes elements that commonly suggest mobility (national or transnational) of people by any one or a combination of the means enumerated under the definition. Act in the Eritrean context of trafficking signifies transnationality of the crime encompassing the transportation, transfer, harbouring or receipt of the victims. It is not clear whether recruitment is a relevant consideration in this context; because unlike trafficking in persons for forced labour or sexual exploitation, victims are not lured by employment opportunities offered or promised by traffickers before they fall into the traffickers' hands. ${ }^{40}$ A series of acts of receiving and harbouring victims takes

39 Ibid, Article 3b.

40 L Lijnders \& S Robinson, 'From the Horn of Africa to the Middle East', p.143. 
place during the transporting and transferring of victims as most victims have to go thorough chains of sales or deals until they reach the final destination where they are harboured for extortion of money from their relatives. ${ }^{41}$ Looking at the facts, transferring of Eritrean victims through the chains of deals from one trafficker to another uniquely reflects the criminal act element in the trafficking process.

The second element means is defined as: '...threat or use of force or other forms of coercion, of abduction, of fraud, of deception, of the abuse of power or of a position of vulnerability or of the giving or receiving of payments or benefits to achieve the consent of a person having control over another person...' Trafficking for ransom mainly involves abduction, deception and abuse of position of vulnerability of the victims. ${ }^{42}$ In many cases involving Eritrean migrants, abduction also occurs in collaboration with civilian and security officers. Kidnapping takes place in towns or refugee camps or en route to borders. ${ }^{43}$ Threat and coercion also involve beating, torture, harassment and rape of victims in hostage camps to maintain obedience. ${ }^{44}$ Unlike other forms of trafficking, families of victims are systematically threatened until they submit to the payment demands of the traffickers. ${ }^{45}$ Delay in payment may result in serious harm, continued or intensified torture and even death of the captive. ${ }^{46}$ Using torture as a means to achieve the trafficking purpose is not common among other forms of trafficking, though the overall treatment of victims, for instance, in trafficking for sexual exploitation or forced labour may amount to torture. ${ }^{47}$ Nonetheless, trafficking for ransom clearly meets

41 HRW, 'I Wanted to Lie Down and Die', p. 4.

42 D Connell, 'Refugees at Risk'.

${ }^{43}$ Amnesty International, 'Egypt/Sudan Refugees', p.10; HRW 'I Wanted to Lie Down and Die', p. 23.

${ }^{44}$ D Connell, 'The Rerouted Trafficking in Eritrean Refugees'.

${ }^{45}$ M van Reisen et al., 'Human Trafficking in the Sinai', p. 48; H Sherwood, 'Hundreds of Eritreans enslaved in torture camps in Sudan and Egypt'.

46 HRW, 'I Wanted to Lie Down and Die', pp. 33, 34 \& 37; S M Weldehaimanot, 'Kidnapping, Hostage-Taking And Ransoming'; M van Reisen et al., 'Human Trafficking in the Sinai', pp. 62-63.

47 Organization for Security and Co-operation in Europe, 'Trafficking in Human Beings Amounting to Torture and other Forms of Ill-Treatment', 2013, pp.14-39, retrieved 26 April 2014, http://www.refworld.org/pdfid/51d4158d4.pdf 
the means element of the Protocol's trafficking definition, as abduction, deception, abuse of a position of vulnerability, threat and coercion are demonstrably present.

The purpose of trafficking is exploitation, elaborated by the definition as constituting '....at a minimum the exploitation of the prostitution of others or other forms of sexual exploitation, forced labour or services, slavery or practices similar to slavery, servitude or the removal of organs.' Exploitation is an oft-noted problematic part of the Protocol, as no definition of 'exploitation,' especially 'exploitation of the prostitution of others' and 'sexual exploitation,' is given by either the Protocol or any other international law. ${ }^{48}$ The supposedly 'catch all' phrase, 'at a minimum' was intended to ensure the inclusion of additional forms of exploitation that are not included in the definition, such as 'forced marriage', 'forced adoption', 'the purchase or sale of children' and 'the making or distribution of child pornography. ${ }^{49}$ Analysts claim the definition provides a nonexhaustive list of exploitation. ${ }^{50}$

The purpose in this case is collection of ransom. In some trafficking for ransom cases, purposes outlined in the Protocol's definition, such as sexual exploitation, forced labour, slavery or practices similar to slavery, are used as means to arrive at the purpose of collecting ransom. While in the hands of traffickers, captives (mainly women) suffered sexual assault or rape, and others were forced to work. ${ }^{51}$ The fact that captives are abducted, kidnapped, kept under control of the traffickers and sold and transferred through various dealers also portrays elements enshrined under the definition of

48 A D Jordan, 'The Annotated Guide', p. 8.

49 UNTOC, 'Travaux Préparatoires of the Negotiations for the Elaboration of the UNTOC and the Protocols Thereto', UNTOC, 2006, p. 344, retrieved 8 June 2014, http: / / www.unodc.org/pdf/ctoccop_2006/04-60074_ebook-e.pdf

50 S Scarpa, Trafficking In Human Beings: Modern Slavery, Oxford University Press, Oxford, 2008, p. 5.

51 HRW, 'I Wanted to Lie Down and Die', pp. 34-36; see also M van Reisen et al., 'Human Trafficking in the Sinai', p.26. 
slavery in the 1926 Slavery Convention..$^{52}$ However, the question as to whether ransom qualifies as exploitation in the Protocol definition remains open.

\section{Does Exploitation Encompass Ransom?}

Ransom is a commonly recognised crime among various countries mainly linked with kidnapping, abducting and taking hostage of individuals. ${ }^{53}$ Although no international framework directly counters ransom, some international conventions can apply to ransom as committed in relation with other criminal activities. The 1983 International Convention against the Taking of Hostages considers hostage taking as seizing or detaining and threatening to kill, to injure or continue to detain any person in order to compel any third party 'to do or abstain from doing any act as an explicit or implicit condition for the release of the hostage. ${ }^{\prime} 54$ The definition of hostage taking and its inclusion of ransom apply to practice in Sudan and Egypt as it is common that hostages face kidnapping, abduction, and threats of death, injury or continued detention in order to compel relatives to pay ransom as a condition for their release. ${ }^{55}$

The Trafficking Protocol does not define the term 'exploitation'. Neither do other international laws. Despite this, it can be understood, from the context, that exploitation entails taking advantage of another person. The International Organization of Migration (IOM) defines exploitation as 'the

52 Article 1, Slavery Convention, 1926; Supplementary Convention on the Abolition of Slavery, the Slave Trade, and Institutions and Practices Similar to Slavery, 1956; R Humphris, 'Refugees and the Rashaida', p.12; M Van Reisen et al., 'Human Trafficking in the Sinai', pp. 42, 47-57; HRW,'I Wanted to Lie Down and Die', pp. 33-36 \& 59.

53 'Global Incident Map', retrieved 3 Nov 2014, http:// www.globalincidentmap.com/beta/kidnapping-for-ransom; see also US legislation: 18 U.S. Code §1201 - Kidnapping.

54 Article 1, International Convention Against Taking of Hostages, G.A.Rea.146, 1938.

55 R Humphris, 'Refugees and the Rashaida', p. 12; $M$ van Reisen et al., 'Human Trafficking in the Sinai', p. 40; Connell, The Rerouted Trafficking in Eritrean Refugees; L Lijnders \& S Robinson, 'From the Horn of Africa to the Middle East', p.139. 
act of taking advantage of something or someone, in particular the act of taking unjust advantage of another for one's own benefit.' 56 However, the meaning of exploitation can go further to imply benefiting of whatsoever as a result of contravention with the physical integrity of another person. ${ }^{57}$ Trafficking for ransom meets both of these as we see that the traffickers benefit (in this case financially from ransom payments) from taking advantage of people they are holding. Taking advantage in practice here is both by contravention of physical integrity (as in the second understanding above) or further by threats. As a side note, this definition of exploitation includes means (taking advantage) within it for the end result of benefit to the trafficker. This is tautological as the definition of trafficking then includes a means to exploitation, but then common definitions of exploitation include means within them as well.

Limited to the context of trafficking, ransom can be understood as coercive or forceful transporting, transferring and harbouring or taking hostage of persons for the purpose of extortion of money in exchange for their release. Thus, the intention of the trafficker is to threaten the families of captives, forcing them to pay a demanded amount of money. Traffickers apply various methods of facilitating extortion which are successful enough to motivate them to target more victims. Unlike the categories of exploitation included under the Trafficking Protocol definition, ${ }^{58}$ the act of contravention

56 IOM, 'International Migration Law: Glossary On Migration', 2004, p. 22, retrieved 10 June 2014, http://publications.iom.int/bookstore/free/IML_1_EN.pdf

57 A G Korvinus et al., 'Trafficking in Human Beings: The concept of exploitation in the Dutch trafficking provision', 2006, retrieved 18 February 2015, pp. 3-4, http: / / www.legislationline.org/download/action/download/id/4992/file/Article_-exploitation-in-the-dutch-trafficking-provision_2006_en.pdf

58 Under the trafficking definition, the concept of exploitation was broadly interpreted in to two categories: labour exploitation and sexual exploitation. Organ removal is the third. These three categories have a common characteristic: the act of contravention with the victim's physical integrity. It can be with or without consent. The same could apply to other forms of exploitation that were foreseen to be included within the sphere of the definition. Global Alliance against Forced Labour, 'Global Report under the Follow-up to the ILO Declaration on Fundamental Principles and Rights at Work', ILO, 2005, p. 7, retrieved 8 June 2014, http://www.ilo.org/wcmsp5/groups/public/-ed_norm/ declaration/documents/publication/wcms_081882.pdf ; UNODC, 'Travaux Préparatoires', p. 344. 
with the victim's physical integrity in this case not only affects the victim, but also impacts third parties in order to bring about the desired result. Involving exploitation of more than one class of victims (the third-party relatives) portrays a distinct characteristic. Trafficking for sexual exploitation, forced labour and organ removal constitute exploitation of only one class of victims who are actually kept under the control of their traffickers. The Trafficking Protocol is silent about third party victimisation through trafficking, and this should be explored further. ${ }^{59}$ In addition, intention of the trafficker to gain advantage by contravention with victim's physical integrity does not involve work or service of the victims.

As we explore below, recent research by Reisen et al. links ransom situations with concepts of debt bondage and forced begging, which have been defined as forms of exploitation in trafficking. In international anti-slavery law, debt bondage is considered a practice similar to slavery and thus fits the Trafficking Protocol's list of possible forms of exploitation which includes slavery-like practices. ${ }^{60}$ Forced begging on the other hand is not tied to the Protocol as specifically, bar being something that could arguably be included in the nonexhaustive listing of examples of exploitation, or arguably be defined as forced labour which is in the list. ${ }^{61}$ Nonetheless,

59 Further study may be needed to determine whether families and friends of captives can be regarded as victims of trafficking or victims of threat. Reference was made to third parties affected by trafficking involving labour or sexual exploitation as 'derivative victims' that includes families or dependents of victims who suffered in intervening victims in distress or to prevent victimisation. However, it is not clear whether such reference can also be extended to families affected by trafficking for ransom due to the fact that intervention by third parties is non-physical, inevitable and enforced constantly. See M Y Mattar, 'Incorporating the Five Basic Elements of a Model Anti-trafficking in Persons Legislation in Domestic Laws: From the United Nations Protocol to the European Convention', Tulane Journal of International and Comparative Law, vol. 14, no. 1, 2006, p. 27.

60 Article 1(a) Supplementary Convention on the Abolition of Slavery, the Slave Trade, and Institutions and Practices Similar to Slavery, 1957.

61 Though not globally applicable, it has however recently been defined as trafficking-related exploitation in European Union (EU) Trafficking Directive $(2011 / 36)$. 'Within the context of this Directive, forced begging should be understood as a form of forced labour or services as defined in the 1930 ILO Convention No. 29 concerning Forced or Compulsory Labour.' 
linking ransom to debt bondage or forced begging does not particularly hold, unfortunately, and this paper maintains that the stronger argument for defining these ransom cases as trafficking is made by exploring how ransom can be defined as exploitation, as above.

\section{The Concept of Ransom and Debt Bondage}

Reisen et al. consider the purpose of the trafficking to be debt bondage and forced begging. ${ }^{62}$ Their conclusion is based on situations in which trafficked victims are tortured to pay off debts and are forced to beg. ${ }^{63}$ In international antislavery law, debt bondage is considered a practice similar to slavery and is defined as a status or condition arising out of a person's pledge of his personal or third person's service as security for a debt. ${ }^{64}$ The third person has to be under his control and the value of the services, if assessed, "is not applied, towards the liquidation of the debt or the length and nature of those services are not respectively limited and defined. ${ }^{65}$ In addition, the practice qualifies as a status similar to slavery when the value of such services is not defined or limited. In ransom situations, the victims' pledge of their personal or a third person's service is absent.

In the situation we find in Egypt, Libya, Sudan and Yemen, linking the purpose of trafficking with exploitation for debt bondage is tenuous due to the following points. Firstly, there are no clear indications that service of captive victims is anticipated by the traffickers. Secondly, even if the traffickers may attach the amount of money they spend to buy them as a debt to the captives, the threat and force they apply is not to derive profits out of the extorted, but is to collect money from the families of the captives.

${ }^{62} \mathrm{M}$ van Reisen et al., p. 80.

63 Ibid.

${ }^{64}$ Article 1(a) Supplementary Convention on the Abolition of Slavery, the Slave Trade, and Institutions and Practices Similar to Slavery, 1957.

65 Ibid. 


\section{The Concept of Ransom and Forced Begging}

Reisen et al. and others have attempted to link ransom with forced begging. ${ }^{66}$ To show the definition of trafficking has been extended, Reisen et al., refer to the recently adopted European Union (EU) Trafficking Directive (2011/36) that includes forced begging as a 'possible form of exploitation. ${ }^{67}$ The Trafficking Protocol does not explicitly refer to forced begging as form of exploitation, but rather leaves this open by providing the non-exhaustive list of examples of exploitation. ${ }^{68}$

A recent ILO meeting considered begging as forced labour 'when people are employed by someone to perform such activities and must give away whatever they obtained by doing so.' ${ }^{69}$ The ILO defines forced labour as 'all work or service which is exacted from any person under the menace of any penalty and for which the said person has not offered himself voluntarily'. ${ }^{70}$ Facts and circumstances in the kidnapping and abduction of migrants clearly show that the relationship between the traffickers is not based on employment/work, and it is unclear how the meaning of service in the definition of forced labour applies. Therefore, the fact

66 L Lijnders \& S Robinson, 'From the Horn of Africa to the Middle East', p. 143, 'captives who do not have connections abroad often see their families forced to beg for money or sell their belongings such as jewellery, property and livestock for their release.' See also $M$ van Reisen et al., p. 80, 'the refugees who find themselves in the houses of the Bedouins are regularly tortured while being forced to beg their relatives to send money.'

${ }^{67}$ The EU Trafficking Directive also states: 'Within the context of this Directive, forced begging should be understood as a form of forced labour or services as defined in the 1930 ILO Convention No. 29 concerning Forced or Compulsory Labour.'

68 UNODC, Travaux Préparatoires, p. 344.

69 ILO, 'Forced labour and human trafficking', 19th International Conference of Labour Statisticians, ILO, Geneva, 2013 p. 9, retrieved 11 June 2014, http:/ /www.ilo.org/wcmsp5/groups/public/-dgreports/-stat/documents/meeting document/wcms_222037.pdf . Note: This was a meeting of statisticians, and thus this definition does not carry the weight of a convention for instance.

70 Forced Labour Convention, 1930, No. 29, retrieved 04 February 2015, http:/ / www.ilo.org/dyn/normlex/en/f?p=NORMLEXPUB:12100:: :NO:12100: P12100_ILO_CODE:C029:NO 
that hostages are forced to communicate with their relatives to beg for money, or the fact that families are forced to beg on the streets and in public places to collect ransom money, could have no importance to determine the existence of forced begging. Rather, coercing captives by torture is the most common method the traffickers use in order to facilitate payment by relatives.

The situation can also be examined to see if it fits with organised begging where proof of employment relationship is not required. Organised begging is recognised as a separate form of trafficking-related exploitation by the UN Office on Drugs and Crime. ${ }^{71}$ However the context of begging may be limited to situations where 'children, elderly persons or disabled migrants...tend to beg in public places and on public transport.' 72 The current trend of organised begging is derived by 'consumer oriented demand' and usually focuses more on engaging children for begging. ${ }^{73} \mathrm{An}$ attempt to link ransom with this form of exploitation has to deal with the following major differences. Firstly, in organised begging, people who give money to the beggars are not controlled by the traffickers, whereas in trafficking for ransom, relatives of the captives are attached to the situation because their families and relatives are being abused inside the hostage camp. Secondly, with regards to organised begging, when beggars receive no or insufficient money through begging, traffickers can and often do simply interrupt the relation with the beggars. ${ }^{74}$ In the hostage camps, however, captives receiving a smaller amount than the traffickers receive extended threats and physical harm, while refusal to pay results in killing of the captive in retribution. ${ }^{75}$ Thirdly, people voluntarily give money to beggars, while relatives of the captives pay money due to the coercion and pressure from

\footnotetext{
71 UNODC, 'Human Trafficking Indicators', retrieved 5 Jan 2014 http:// www.unodc.org/documents/human-trafficking/HT_indicators_E_LOWRES.pdf $\pi$ Ibid.

73 I Cherneva, 'Human Trafficking For Begging', Buffalo Human Rights Law Review, 2011 , p. 65.

74 Ibid, p. 66.

75 HRW, 'I Wanted to Lie Down and Die', pp. 33, 34 \& 37.
} 
traffickers. ${ }^{76}$ Fourthly, in hostage camps, the amount of money to be received by the captives is fixed and sometimes negotiable, while in organised begging the amount is not fixed and no negotiation is made between the traffickers and the people on the street. ${ }^{77}$

\section{From the Trafficking Protocol to National Legislation and Policy}

The article has looked at ways in which trafficking for ransom can be included in interpretations of the UN Trafficking Protocol and has debated with others who have tried to make it fit by considering ransom a form of debt bondage or forced begging and thus trafficking. Considering it as exploitation in its own right however remains the most robust argument for definitional inclusion. Regarding impact of these semantics, the Trafficking Protocol and anything it might include or not include is irrelevant unless states amend or draft their national anti-trafficking legislation and policy to specifically include trafficking for ransom or to be broad enough to allow trafficking for ransom to easily fit definitional criteria of trafficking. Though the scope of this paper is limited to legal analysis, of course states' implementation of appropriately worded and relevant legislation and policy must follow.

In looking at the national legal arrangements in the Northeast African countries affected by the problem, it is evident that almost none of them have adequate legal frameworks and enforcement mechanisms. Eritrea, Ethiopia, Libya and Yemen do not have comprehensive legal frameworks to suppress and punish trafficking committed inside or outside their territories. Only a few provisions are available in their respective criminal codes addressing limited aspects of trafficking and offering very limited protection. ${ }^{78}$ Egypt's new

76 Ibid., pp.1, 25 and 54; $M$ van Reisen et al., p. 68.

$M$ van Reisen et al., p.43.

78 Arts 605 and 565 of Proclamation No.1/91-Transitional Penal Code of Eritrea; Article 418 of the Penal Code of Libya; Articles 596, 597 and 635 of Proclamation No.414/200-Criminal Code of the Federal Democratic Republic of Ethiopia; Article 248 Criminal Code of Yemen. 
law issued in 2010 appears to be clearer than Article 3 of the Trafficking Protocol in defining the scope of exploitation but does not encompass ransom. ${ }^{79}$ The new Sudanese AntiTrafficking Act, however, addresses the issue of trafficking for ransom, although it treats ransom as a distinct 'illegal objective'.

Article 7 of the Sudanese Anti-Trafficking Act defines trafficking in persons as abducting persons or transferring or deporting or harbouring or receiving or detaining them to exploit or use them in illegal acts or to achieve illegal objectives for... material return or gain... through the "use of force or any form of coercion or kidnapping or fraud and deception or abuse of power and influence or the exploitation or abuse of a position of vulnerability or need.' 80 The definition is wide enough in scope to very clearly include all forms of trafficking in persons through a broad interpretation of 'exploitation' that makes it possible to address exploitation beyond sexual exploitation, labour exploitation and removal of organs.

Purpose defined as using a victim to 'achieve an illegal objective for material gain' matches the basic feature of ransom as it aims directly at gaining monetary benefits. Importantly, using victims for gaining benefit does not involve victims' labour or service since an employment relationship between traffickers and victims is never considered. Contravention with captives' physical integrity by itself is not part of the definition of the purpose and instead is used as a means. Thus, circumstances of third party victimisation can possibly be included under the purpose of achieving the illegal objective more adequately.

79 Article 2 of the Law Regarding Combating Human Trafficking, No.64/2010. The Act appears to have been modelled after the Trafficking Protocol. The catch-all phrase: 'in any of its forms' opens space for other forms of exploitation that are not only unnamed but also unforeseen. It also makes clear that exploitation could extend to forcing children to beg and engage in acts of pornography.

80 Article 7 of the Sudan Anti-Trafficking Act, 2013; the Article defines Illegal objectives as material returns, gains, or promises of return or gainor grants of any kind of benefits. 
National legislation and policy both in the Northeast African region and elsewhere would usefully be amended to specifically include trafficking for ransom or to ensure definitional breadth wide enough to ensure trafficking for ransom easily fits definitional criteria of trafficking. Reports from the Middle East (Yemen), Southeast Asia (Malaysia, Myanmar and Thailand) and North America (Mexico) suggest that trafficking for ransom as a phenomenon does not necessarily have regional specificity and policymakers could benefit from legal analysis of the problem vis $a$ vis the Trafficking Protocol as well as national legislation in Northeast African states where the problem is possibly most pervasive.

\section{Conclusion}

We have seen that trafficking for ransom meets commonly used definitions of exploitation, as traffickers benefit financially from ransom payments, through taking advantage of people they are holding. While ransom can be interpreted as exploitation, it does not share the same features of exploitation as the types that are specifically mentioned in the Protocol. Trafficking for ransom affects third parties for instance, and their victimisation needs additional legal exploration. Further, in trafficking for ransom, sexual exploitation, forced labour, slavery or practices similar to slavery are used as means to arrive at the end purpose of collecting ransom, while in other cases sexual exploitation etc., are in and of themselves the end purpose. The Sudanese Anti-Trafficking Act simplifies this by defining the end purpose of trafficking as using a victim 'to achieve an illegal objective for material gain.'

It is necessary for the worldwide effort against trafficking in persons to turn its face to forms of trafficking unforeseen at the time of the drafting of the Trafficking Protocol. It is also important to highlight the need to widen interpretations of the Protocol's trafficking definition in order to properly address new forms of trafficking, with types of exploitation not explicitly mentioned as examples in the Protocol and those that go beyond the three common categories of labour 
exploitation, sexual exploitation and organ removal. It is equally important for the countries already affected by the problem to adopt new and comprehensive national legislation or to amend existing laws and policy in order to address new practices like trafficking for ransom. Limited to the context of trafficking, ransom can be understood as coercive or forceful transporting, transferring and harbouring or taking hostage of persons for the purpose of extortion of money in exchange for their release. It must be possible for interpretations of national law to encompass this.

Mogos 0 Brhane worked as National Coordinator of Community Courts of Eritrea, in Eritrea between 2009-2013. Since 2004, he has worked on various projects in the Ministry of Justice of the State of Eritrea, including as researcher in a project designed to consolidate Eritrean laws issued since 1991. He was also a member of the Review Committee of the Eritrean draft Criminal Code. He studied law at Asmara University, Asmara, Eritrea, and Criminal Law and Criminology LLM course at Groningen University, Groningen, Netherlands.

Email: mogosmoj@gmail.com 



\section{Debate Proposition:}

'The Trafficking Protocol has advanced the global movement against human exploitation.' 


\section{Achievements of the Trafficking Protocol: Perspectives from the former UN Special Rapporteur on Trafficking in Persons}

Joy N Ezeilo

Keywords: Trafficking Protocol, Palermo Protocol, human trafficking, human rights, United Nations, Special Rapporteur, Trafficking Rapporteur

Please cite this article as: J N Ezeilo, 'Achievements of the Trafficking Protocol: Perspectives from the former UN Special Rapporteur on Trafficking in Persons', Anti-Trafficking Review, issue 4, 2015, pp. 144-149, www.antitraffickingreview.org

The United Nations (UN) Protocol to Prevent, Suppress and Punish Trafficking in Persons, Especially Women and Children, Supplementing the UN Convention against Transnational Organized Crime, 2000 (Trafficking Protocol), is a watershed in galvanising the global movement against human trafficking. Thanks to the Protocol, international and regional bodies, along with civil society groups, have become involved in researching the issue and supporting anti-trafficking efforts; and states have begun to introduce new laws and policies aimed at criminalising trafficking, protecting victims and preventing future trafficking. ${ }^{1}$

My unwavering position on this debate supports the proposition that the Trafficking Protocol has advanced the global movement against human trafficking. My experience in the six years while I carried out my global mandate as the UN Special Rapporteur on trafficking in persons, especially

J N Ezeilo, 'First decade of the mandate of the Special Rapporteur on trafficking in persons, especially women and children', A/HRC/26/37, UN, 2014.

This is an open-access article distributed under the terms of the Creative Commons Attribution License (CC-BY). Under CC-BY license, the public is free to share, adapt, and make commercial use of the work. Users must always give proper attribution to the author(s) and the Anti-Trafficking Review. 
women and children (2008-2014), reinforced this position. Of course, that is not to say that the international community has got it all right in taking appropriate action and measures to eradicate trafficking and ensure accountability in the implementation of the Protocol. There are still noticeable gaps between the obligations of States with regard to trafficking and the extent to which those obligations are met in practice. There are gaps in knowledge about trafficking, and there are gaps in quick and accurate identification, protection and provision of assistance to trafficked persons; in prevention and prosecution of traffickers; and also in policy and legal frameworks. For example, national penal laws sometimes fail to comprehensively define or criminalise all forms of trafficking and fail to extend protection to all victims. States are still grappling with integrating a humanrights-based approach; a child-centred approach; and an approach that pays attention to causes and vulnerability factors, including the creation of opportunities for legal, gainful and non-exploitative migration, which is crucial for preventing future trafficking. There is also a gap in cooperation not only between countries but also in public-private partnerships, which can address traffickingrelated exploitation in supply chains.

Notwithstanding, I have been impressed by the development engendered by the Trafficking Protocol around the world.

I want to raise a few specific points addressing the Trafficking Protocol's contribution to the global movement against human trafficking and its inherent exploitation.

1. The Protocol provides an international framework that has impelled a global anti-trafficking movement. The enactment of an international legislative framework, universal in nature and comprehensive in scope is a significant achievement. The Protocol's preamble underscores the fact that effective action requires a comprehensive international approach that will target measures to prevent trafficking, to punish traffickers and to protect trafficked persons, including by protecting their internationally recognised human 
rights. ${ }^{2}$ The Trafficking Protocol is a major shift in the international approach to the exploitation of individuals for private profit and has a higher threshold for rights obligations than the narrowly focused 1949 UN Convention for the Suppression of the Traffic in Persons and the Exploitation of the Prostitution of Others.

2. The Protocol has prompted strong political commitment, evidenced by the fact that it has been ratified by 166 States Parties. Since the enactment of the Protocol more than two-thirds of UN Member States, including those that are yet to ratify the Protocol ${ }^{3}$ have criminalised one or more of the different types of trafficking enumerated in the Article 3 definition of trafficking in persons. ${ }^{4}$

3. The Protocol's definition of trafficking and what amounts to exploitation is now universally accepted as the most comprehensive definition of human trafficking that has informed regional, sub-regional and national counter-trafficking legal frameworks. This has aided prosecutors worldwide, as well as other actors providing assistance and advocating for the rights of trafficked persons. Moreover, trafficking in persons for the purpose of removal of organs would have remained hidden and unknown without specific mention under this Protocol.

4. The Protocol has advanced global action to protect and respect human rights of trafficked persons. While critiqued as a criminal justice response to trafficking, the Protocol is hardly devoid of human rights, and

Trafficking Protocol, Article 5 on Criminalisation: 'Each State Party shall adopt such legislative and other measures as may be necessary to establish as riminal offences the conduct set forth in Article 3 of this Protocol, when committed intentionally.'

3 As at 9 January 2015, 166 countries are Parties to this Protocol. In fact, nineteen countries ratified between 2012 and 2014. In 2014 seven countries became States Parties to the Protocol. Retrieved 10 January 2015, https:// treaties.un.org / Pages /ViewDetails. aspx?src=IND\&mtdsg_no=XVIII-12a\&chapter $=18 \&$ lang $=$ en

4 It was reported in 2012 to be 134 countries, see UNODC, 'Global Report on Trafficking in Persons 2012', UN publication, 2012. 
the rights of trafficked persons are a fundamental objective of the agreement. According to its Article 2(b), the Protocol is intended to protect and assist the victims of trafficking, with full respect for their human rights. ${ }^{5}$ Article 6 elaborated on assistance to and protection of victims of trafficking, including to protect their privacy and identity as well as the provision of assistance to aid victims' physical, psychological and social recovery with due regard to the age, gender and special needs of victims. ${ }^{6,7}$ The saving clause provisions on Article 14 firmly incorporate all existing international human rights standards, ${ }^{8}$ reiterating States' obligations and the rights of individuals thereto, including non-discrimination on the ground that they are victims of trafficking in persons.

5. Cooperation is imperative in advancing the global fight against human exploitation, and the Trafficking Protocol placed a high priority on cooperation amongst governments and between government and intergovernmental organisations including civil society organisations. This has proved successful in mobilising the much-needed global support. ${ }^{9}$ Cooperation in the form of technical assistance towards capacity development for law enforcement, immigration and other relevant officials has enhanced knowledge and skills for victim identification, protection and

5 Article 4 on scope of application also reinforced the protection of victims of trafficking in persons offences. Also Article 9 (1) (b) on the need to protect victims of trafficking in persons from revictimisation.

6 These rehabilitative and reintegrative assistance include: appropriate housing; counselling and information, in particular as regards their legal rights, in a language that the victims of trafficking in persons can understand; medical; psychological and material assistance; employment; educational and training opportunities. See Article 6 (3), States Parties are expected to provide these assistance to victims in cooperation with non-governmental organisations, other relevant organisations and other elements of civil society.

7 J N Ezeilo, 'Report of the Special Rapporteur on trafficking in persons, especially women and children', A/HRC/17/35, UN, 2011 and A/66/283, UN, 2011.

8 This extends to the application of the 1951 Convention and the 1967 Protocol relating to the Status of Refugees and the principle of non-refoulement as contained therein.

9 See Articles 6 (3), 9 (3) and 10 (2) of the Trafficking Protocol. 
assistance as well as prosecution of traffickers. States Parties have the responsibility to address the root causes of trafficking and are to do so through bilateral and multilateral cooperation as well as legislative and other measures, which can be educational, social or cultural. ${ }^{10}$ International cooperation is also imperative in border controls to detect and prevent trafficking. ${ }^{11}$

Although the 2000 Protocol was preceded by several other anti-trafficking instruments, none covers the topic in as much depth. ${ }^{12}$ It is the first universal instrument that addresses all forms of trafficking in persons and all victims. It is now widely accepted that women, men and children are trafficked and that forms of trafficking are as varied as the potential for profit or other personal gain. ${ }^{13}$

By stating its purpose, the Protocol stands out as an international law intended to advance the global movement through collective action to end human exploitation. Consequently, it is a reflection of the political will of governments to fight human trafficking, evidenced by widespread ratification as a first step in the expression of that commitment. My work as Special Rapporteur would have made little impact in the absence of the Protocol. It was the springboard that enabled me to legally and otherwise anchor, explain and guide States towards good practices. A comprehensive approach to trafficking requires action geared towards addressing all forms of trafficking and all victims. It includes the adoption of a human-rights-based and child-centred approach, and an emphasis on causes, vulnerability factors and measures to prevent trafficking in

\footnotetext{
Ibid. Article 9 (5).

Ibid. Article 11.

12 The first international agreement on trafficking in persons since the adoption by the General Assembly in 1949 of the narrowly focused Convention for the Suppression of the Traffic in Persons and the Exploitation of the Prostitution of Others.

13 See A/HRC/26/37 op.cit., paragraph 35.
} 
persons. ${ }^{14}$ My final take is that the global movement is intrinsically empowered by the Protocol. The movement and the Protocol do not simply run in parallel; rather they are fused, mutually reinforcing each other for effective and sustainable action to end human exploitation inherent in human trafficking.

Joy Ngozi Ezeilo teaches Law at the Department of Public and Private Law, Faculty of Law, University of Nigeria. She was appointed in 2008 as the United Nations (UN) Special Rapporteur on Trafficking in Persons, especially women and children, and served in that capacity globally until 31 July 2014. The UN Secretary-General appointed her as a member of the Board of Trustees of the UN Trust Fund for Victims of Trafficking in December 2013. She is the founding director of WomenAid Collective (WACOL), a Nigerian organisation that promotes human rights of women and young people, and currently serves as a member of the Governing Council, Nigerian Institute of International Affairs (NIIA). As a legal practitioner, barrister and solicitor of the Supreme Court of Nigeria, she takes on human rights cases on a pro bono basis. Ezeilo is High Chief in Igboland. She has also received several national and international awards, including being conferred with the national honour of Officer of the Order of Niger (OON) in 2006.

14 J N Ezeilo, 'Report of the Special Rapporteur on trafficking in persons, especially women and children', A/HRC/10/16, submitted to the fourth session of the Human Rights Council in 2009. Also 'Mandate of the Special Rapporteur on trafficking in persons, especially women and children', submitted to the 10th Session (HRC) in 2009, pp. 25-26. 


\section{The Trafficking Protocol has Advanced the Global Movement against Human Exploitation: The case of the United Kingdom}

\section{Caroline Parkes}

Please cite this article as: C Parkes, 'The Trafficking Protocol has Advanced the Global Movement against Human Exploitation: The case of the United Kingdom', Anti-Trafficking Review, issue 4, 2015, pp. 150-155, www.antitraffickingreview.org

When politicians, responding to public campaigns focused on human trafficking, make bold and over-emotive statements, invoking William Wilberforce and the pressing need to lead the global fight against slavery, the Trafficking Protocol, ${ }^{1}$ proves its worth. Insulated from national political rhetoric, international treaties, be it the Trafficking Protocol or regional instruments, provide an invaluable structure for governments' national legislative responses to human trafficking. As the United Kingdom's (UK) Solicitor General noted, ${ }^{2}$

The UK's legal framework has been directly influenced by UN [United Nations] and EU [European Union] Conventions and Directives (emphasis added) ... [and] The 'Palermo Protocol' continues to shape the UK's

1 In full: Protocol to Prevent, Suppress and Punish Trafficking in Persons, Especially Women and Children.

2 Speech, Solicitor General, Oliver Heald QC MP, 'Prosecuting human trafficking and slavery: The law and the UK response', UK Government, 12 October 2012, retrieved 6 January 2015 https://www.gov.uk/government/speeches/ prosecuting-human-trafficking-and-slavery-the-law-and-the-uk-response

This is an open-access article distributed under the terms of the Creative Commons Attribution License (CC-BY). Under CC-BY license, the public is free to share, adapt, and make commercial use of the work. Users must always give proper attribution to the author(s) and the Anti-Trafficking Review. 
response to human trafficking and in particular the care and support afforded to identified human trafficking victims.

The evolution of the Trafficking Protocol represented a new approach to human trafficking and provided an opportunity for States to develop and implement new legislation which reflected the reality of trafficking, an update on antiquated laws against slavery more commonly found on the statute books. The Trafficking Protocol promoted a more accurate, contemporary understanding of this crime, and was to be a 'universal instrument that addresses all aspects of trafficking in persons'. ${ }^{3}$ With a focus on promoting rights, and human dignity, the Trafficking Protocol mandated a holistic approach to anti-trafficking, acknowledging, for example, the socio-economic pressures which increase vulnerability. This was not a document committed either to the regulation of the movement of people or to framing trafficking as a solely criminal justice problem.

The Trafficking Protocol is far from perfect, but it is realistic. To take the Trafficking Protocol as a static document is to misunderstand its intention. Just as the crime of human trafficking continues to evolve, so too the Trafficking Protocol, as a living convention, rises to meet this challenge. An example of this evolution is provided by Anne T Gallagher. She referred to the flexibility within the "international legal definition, set out in the Trafficking Protocol, which has been able to accommodate the change in focus from the criminalisation of the process of trafficking to the criminalisation of exploitation, the end purpose of the trafficking.' 4

3 Emphasis added, UN, 'Preamble, Protocol To Prevent, Suppress And Punish Trafficking in Persons, Especially Women and Children, Supplementing the United Nations Convention Against Transnational Organized Crime', retrieved 6 January 2015, http://www.uncjin.org/Documents/Conventions/dcatoc/final_documents_2/ convention_\%20traff_eng.pdf

4 A T Gallagher, 'Submission to the Joint Committee on the Draft Modern Slavery Bill', retrieved 6 January 2015, http://data.parliament.uk/writtenevidence/ committeeevidence.svc/evidencedocument/draft-modern-slavery-billcommittee/draft-modern-slavery-bill/written/7406.pdf 
The UK ratified the Trafficking Protocol almost a decade ago in 2006. Though much is made of this ratification in Parliamentary Questions, ${ }^{5}$ for example, the Trafficking Protocol only makes up one strand of the government's anti-trafficking strategy which includes compliance with the European Convention on Human Rights, relevant EU Directives, ${ }^{6}$ and UN human rights obligations, among others. In this respect, the Trafficking Protocol should not be viewed in isolation but as a key component of a unified approach to trafficking, just as the various treaties and conventions on trafficking, women's rights, workers' rights, for example, overlap and 'cooperate' with each other.

The Trafficking Protocol functions as a mechanism of national and international accountability, as has been seen in the UK's consultation process for the Modern Slavery Bill. ${ }^{7}$ The Bill Committee found that the proposed definitions used in the Bill 'are not as broad as the Government believes them to be, nor as broad as international definitions such as those in the Trafficking Protocol, and as a result fail to capture current or potential future forms of modern slavery' ${ }^{8}$ This yardstick should insulate national legislation from the vagaries of political expediency. The acknowledgement of international obligations, as set out in the Trafficking Protocol, and the need to comply with these obligations in the design of national legislation should inhibit inaccurate, ineffective or plain incorrect legislation from making it to the statute books. Here the Protocol empowers activists, NGOs, politicians and scrutiny bodies by providing a neutral baseline of standards to which the government has committed and thus by which they can be held to account.

5 See, for example, Hugo Swire MP, Minister of State, Foreign and Commonwealth Office to Andrew Stephenson MP, Hansard, HC Deb, 17 June 2013, c485W.

6 See, Directive 2011/36/EU of the European Parliament and of the Council of 5 April 2011 on preventing and combating trafficking in human beings and protecting its victims, and replacing Council Framework Decision 2002/629/ JHA [OJ L 101 of 15.4.2011].

7 Joint Select Committee, Draft Modern Slavery Bill, retrieved 6 January 2015, http://www. parliament.uk/business/committees/committees-a-z/jointselect/draft-modern-slavery-bill/

8 Joint Select Committee, 'Report: Draft Modern Slavery Bill', 2014, retrieved 6 January 2016,http://www.publications.parliament.uk/pa/jt201314/jtselect/ jtslavery/166/166.pdf 
The Modern Slavery Bill has the potential to significantly improve the protections afforded to victims, though activists argue that the government could go further. The Bill provides for a statutory defence for victims and special measures for witnesses in criminal proceedings, for example. In this respect, the Bill engages with the Trafficking Protocol where, as Kelly Hyland Heinrich notes: 'Without the implementation of the fundamental concept of the interdependence between prosecution and protection that is set forth in the Palermo Protocol, State Parties will continue to misplace their resources and efforts."

The Modern Slavery Bill Committee further commented: 'We believe that maintaining a link to international definitions is important to prevent the "double criminality" requirement [where extradition is requested, an offence being investigated by the requesting country must also be an offence in the receiving country] being used as an escape route from prosecution by slave masters and traffickers'. ${ }^{10}$ This is a key point. The provision of an international standard, for an international crime, will further strengthen cooperation and the likelihood of a unified response. If the UK and Ireland, which share a land border, are both utilising the same definition of trafficking, then the ability of these governments to successfully address (via prosecution or otherwise) this crime is undoubtedly enhanced.

In Northern Ireland, Lord Morrow's Private Members Bill on human trafficking has wrongly conflated sex work with sex trafficking ${ }^{11}$ and a recent vote in the Assembly on this Bill has led to the criminalisation of the purchase of sex. ${ }^{12}$ However,

9 K H Heinrich, 'Ten Years After the Palermo Protocol: Where are protections for Human Trafficking?', Human Rights Brief 18, no. 1, 2010, p. 4.

10 Ibid., no. 7.

11 G Ellison, 'The Sex Trade in Northern Ireland: The Creation of a Moral Panic', Institute of Criminology and Criminal Justice Working Paper, School of Law, Queen's University, Belfast, 2012, retrieved 6 January 2015, SSRN: http:// ssrn.com/abstract $=2184040$ or http: //dx.doi.org/10.2139/ssrn. 2184040

12 Northern Ireland Assembly, Human Trafficking and Exploitation (Further Provisions and Support for Victims) Bill, October 2014. 
while there may be opponents to the approach taken in this Bill, the flexibility of the Protocol enables States to ensure that its implementation is adapted to local contexts. ${ }^{13}$ This flexibility strikes the balance between ensuring key principles are non-negotiable, such as the definition of trafficking, and that national political cooperation can be assured by the power to tailor the implementing legislation appropriately.

In line with human rights treaties, the approach taken by the Trafficking Protocol is cautious, sensitive to claims of the infringement of State sovereignty and the economic challenges of developing countries. As such, the Trafficking Protocol is rich with 'endeavours to' and 'considers'; it both provides minimum standards and elements of aspiration enabling a State's response to evolve and improve from a communal baseline. It challenges the argument that States cannot ratify the Trafficking Protocol on the basis of their limited resources. Indeed, it actively encourages States to assist and support the anti-trafficking efforts of its fellow Protocol signatories, communally overcoming economic constraints. The UK, for example, has recently committed to supporting Vietnam's anti-trafficking efforts, recognising that strengthening Vietnam's response to trafficking in turn strengthens the UK response. ${ }^{14}$ This cooperation, in the form of advice and the provision of resources, directly challenges the ability of traffickers to work transnationally.

The ratification of the Trafficking Protocol does not guarantee that a State will easily eradicate trafficking; for example, the recent examination of the UK by the UN Committee on

13 The Interpretative Notes for the official records (travaux préparatoires) of the negotiation of the United Nations Convention against Transnational Organized Crime and the Protocols thereto, at para 64 state, 'The travaux préparatoires should indicate that the Protocol addresses the exploitation of the prostitution of others and other forms of sexual exploitation only in the context of trafficking in persons. The terms 'exploitation of the prostitution of others' or 'other forms of sexual exploitation' are not defined in the Protocol, which is therefore without prejudice to how States Parties address prostitution in their respective domestic laws.'

14 Hugo Swire MP, Minister of State, Foreign and Commonwealth Office to Kerry McCarthy MP, Hansard, HC Deb, 12 May 2014, c357W. 
the Elimination of Discrimination against Women highlighted 'the lack of a comprehensive national framework on trafficking, in view of the nature and complexity of this phenomenon and its prevalence'. ${ }^{15}$ However, it provides a clear set of objectives to work toward and enables the global response to trafficking to be efficient, concise and unified.

Caroline Parkes is Co-Founder and Researcher at The Trafficking Research Project. She currently works for the Prisons and Probation Ombudsman as an investigator. Caroline has ten years work experience in human rights including five years as a Researcher at British Irish Rights Watch, focusing on transitional justice, equality and counter-terrorism and as a human rights consultant to the All Party Parliamentary Group on Drones. She has also worked for the Committee on the Administration of Justice in Belfast and undertaken field research and policy analysis in Bosnia and Israel. Caroline holds an LLM Human Rights Law (dist), an MSc in Development Practice (dist) and an MA in American Studies. She is based in London, United Kingdom.

15 UN, 'Report of the Committee on the Elimination of Discrimination against Women, Examination of the United Kingdom', 55th session (2013), CEDAW/C/ $\mathrm{GBR} / \mathrm{CO} / 7$. 


\title{
From Palermo to the Streets of Oslo: Pros and cons of the trafficking framework
}

\author{
Synnøve Økland Jahnsen and May-Len Skilbrei
}

Please cite this article as: $S \varnothing$ Jahnsen \& M-L Skilbrei, 'From Palermo to the Streets of Oslo: Pros and cons of the trafficking framework', Anti-Trafficking Review, issue 4, 2015, pp. 156160, www.antitraffickingreview.org

The development of Norwegian anti-trafficking efforts and how they relate to obligations set forth by the United Nations Trafficking Protocol (also known as the 'Palermo Protocol') illustrates some of the constraints connected to international policymaking. While national trafficking policies on paper are in alignment with the definitions and priorities in the Protocol, the local and institutional context simultaneously influence how these international ambitions are interpreted and implemented. Thus, we argue that to understand the impact of the Protocol one must necessarily explore how it interacts with national agendas and instruments.

Local realities have been, and always will be, imbedded in distinct spatial, cultural and historical discourses. When Norway signed the Trafficking Protocol in the year 2000, Norwegian prostitution and labour market relations were not as marked by transnational mobility as they would be only a few years later. In the first period after its implementation, Norwegian authorities invested a lot of political prestige in developing policies in alignment with the priorities of the Protocol. Later, as knowledge and experience was gained, these policies had to be adjusted significantly as the 'map turned out not to fit the terrain'.'

M-L Skilbrei, 'Moving Beyond Assumptions? The Framing of Anti-trafficking Efforts in Norway' in Ragnhild Sollund (ed.), Transnational Migration, Gender and Rights, Emerald Insight Publishing, 2012.

This is an open-access article distributed under the terms of the Creative Commons Attribution License (CC-BY). Under CC-BY license, the public is free to share, adapt, and make commercial use of the work. Users must always give proper attribution to the author(s) and the Anti-Trafficking Review. 
We want to highlight two distinct features of the implementation of the Protocol in the Norwegian context. The first is how its definitions and instruments interact with the already established abolitionist agenda on prostitution. The second is how efforts against forced labour have been under-prioritised.

Since ratifying the Protocol in 2003, the Norwegian government has altered the Penal Code and produced four plans of action. This can be seen as an expression of Norwegian authorities' eagerness to adhere to the standards of the Protocol. At the same time it can be understood as a correspondence between the trafficking agenda and changing local definitions of prostitution. Public debates concerning prostitution policy have taken place since the early 1980 s. A reoccurring theme has been whether or not to criminalise the purchase of sex.

At the beginning, taking a political stand in support of the Sex Purchase Act, which criminalises the purchase of sex, was a fairly marginalised position mainly promoted by the anti-pornography movement. The arguments that supported the ban were primarily based on feminist arguments that equated prostitution with violence against women and viewed it as a societal problem that is both damaging to the individuals involved and to the society at large. ${ }^{2}$ With emerging concerns over migration to Norway during the 1990s and the implementation of the Trafficking Protocol, debates over prostitution and trafficking increasingly became conflated. Thus, when the debate on the Sex Purchase Act resurfaced in the public debate in 2006, the terms 'trafficking' and 'prostitution' were used interchangeably. There is undoubtedly much that can be said regarding this particular feature of the Norwegian prostitution policy. ${ }^{3}$ What

2 M-L Skilbrei \& C Holmström, Prostitution Policies in the Nordic Region: Ambiguous Sympathies, Farnham, Ashgate, 2013.

3 M-L Skilbrei, 'A Marriage of Convenience between Pragmatism and Principles: The development of Norwegian prostitution policies', Sexuality Research and Social Policy (9)2, 2012, pp. 244-257; S $\varnothing$ Jahnsen, 'Norge er ikke en $\varnothing \mathrm{y}$ (Norway is not an Island): Mediedekningen av kriminaliseringsdebatten i Norge' in M-L Skilbrei \& C Holmström (eds.), Prostitusjon i Norden, Nordiska ministerrådet, Copenhagen, 2008, pp. 255-277. 
we want to underline here is that the Sex Purchase Act only gained political momentum when the anti-prostitution agenda corresponded with increasing fears over unwanted migration and organised crime, and that such a law was implemented in 2009.

The introduction of the Sex Purchase Act is not the only change in legislation that can be linked to the Protocol. The introduction of a Trafficking Act in the Penal Code also resulted in revisions of the Procurement Act, which criminalises aiding and abetting prostitution. Most importantly, any form of prostitution or organisation of someone else's prostitution is now criminalised in Norway, something that was not the case pre-Palermo. The application, and, not least the combination, of the Trafficking Act, the Sex Purchase Act and the Procurement Act has led to an increased policing of prostitution. ${ }^{4}$

The shift towards a penal approach to prostitution needs to be seen together with how efforts to assist victims of trafficking have led to the establishment of a broad range of services that aim to motivate them to exit prostitution. The main bulk of these services are provided by nongovernmental organisations (NGOs) and municipal institutions that were originally set up to assist women in prostitution or women who had experienced violence. Organising services in this way has led to a bias in how they are designed, who they are targeted at, and who receives them. Services and identification of victims of trafficking are predominantly directed at migrant women in prostitution, not men or victims of other forms of exploitation.

To understand the way international ambitions are translated into national and local policy it is important to look at how trafficking as a label for societal problems has offered funding opportunities and increased visibility and importance for some political issues, while others are neglected. While

S $\varnothing$ Jahnsen, 'Innestengt eller Utestengt? Norsk prostitusjonspolitikk og kampen mot menneskehandel', PhD thesis, Sosiologisk Institutt, Universitet i Bergen, 2014. 
the NGOs and governmental bodies working on prostitution and gender issues before 2003 readily appropriated the trafficking concept, although often for pragmatic reasons, NGOs and governmental bodies working on labour and industrial relations have not.

The bias towards prostitution-related trafficking and female victims mirrors the signals of the Trafficking Protocol, as it too prioritises exploitation of women and children. However it also relates to the widespread view in Norway that exploitation in the labour market needs to be approached differently to exploitation in the prostitution market. Neither Norwegian labour unions nor the government seem to have seen the trafficking framework as ideal for addressing discrimination of migrant workers and exploitation in the labour market. This is because the Norwegian labour market is already seen as subject to sophisticated forms of preventive mechanisms seeking to control and regulate, rather than prosecute and penalise. ${ }^{5}$ To approach forced labour as trafficking also mandates changes in the design of Norwegian anti-trafficking work, as this is explicitly designed to address victimisation through sexual exploitation rather than through different forms of labour.

To conclude, it can be considered a positive development that the Trafficking Protocol forced the Norwegian government to take exploitation in cross-border prostitution more seriously than before. Especially important is the establishment of residence permits for victims of trafficking, which are particularly important to victims. ${ }^{6}$ At the same time, the increased policing of prostitution has resulted in a new type of regime where migrants in prostitution are subjected to extensive forms of surveillance and control in the name of

S $\varnothing$ Jahnsen, Menneskehandel og Tvangsarbeid. En forstudie om gråsoneproblematikk innenfor innsatsområd et arbeidsmarkedskriminalitet, PHS Forskning, Oslo, 2014.

$6 \quad$ M-L Skilbrei \& M Tveit, 'Mission Impossible? Voluntarily and dignified repatriation of victims of trafficking to Nigeria' in T-D Truong \& D Gasper (eds.), Transnational Migration and Human Security, Springer Publications, 2008. 
rescue and security. ${ }^{7}$ That new policies in practice may increase vulnerabilities to trafficking and other exploitative situations, rather than reduce them, is an issue that is increasingly taken up in discussions in Norway, and in particular as these debates relate to the Sex Purchase Act. ${ }^{8}$ These debates illustrate the unanswered question of how the Trafficking Protocol should ideally be interpreted and implemented bearing in mind national agendas and instruments.

Synn $\varnothing$ ve $\varnothing$ kland Jahnsen works in Norway at the Department of Criminology and Sociology of Law at the University of Oslo, and is affiliated with the Norwegian Police University College and Centre for Women and Gender Research at the University of Bergen. Her areas of expertise are gender, mobility and labour. Her work addresses how 'migration' and 'trafficking' become the locus for contemporary forms of policing and control. Jahnsen is a co-editor of the forthcoming book Assessing European Prostitution Policy. She is also a member of the COST Action Comparing European Prostitution Policies: Understanding Scales and Cultures of Governance (ProsPol).

May-Len Skilbrei is a Professor of Criminology at the University of Oslo. Her research focuses on human trafficking, prostitution, migration, gender and globalisation, and she recently published a book with Ashgate together with Charlotta Holmström on Nordic prostitution policies. She is currently the editor of the Routledge book series Interdisciplinary Studies in Sex for Sale, heads a Working Group of the European Society of Criminology on Immigration, Crime and Citizenship, and is deputy chair of the COST Action Comparing European Prostitution Policies: Understanding Scales and Cultures of Governance (ProsPol).

$S \varnothing$ Jahnsen, 'Innestengt eller Utestengt?'

I Rasmussen, S Strøm, S Sverdrup \& V W Hansen, 'Evaluering av Forbudet mot Kjøp av Seksuelle Tjenester’, Vista Analyse, Oslo, 2014; A Brunovskis \& M-L Skilbrei, 'The Evaluation of the Sex Purchase Act Brings Us No Closer to a Conclusion', Fafo, 2014, retrieved 11 February 2015, http://www. fafoarkiv.no/prostitution/140816-ABR-oped.html 


\title{
Trafficking as a Floating Signifier: The view from Brazil
}

\author{
Grupo Davida ${ }^{1}$
}

Please cite this article as: Grupo Davida, 'Trafficking as a Floating Signifier: The view from Brazil', Anti-Trafficking Review, issue 4, 2015, pp. 161-166, www. antitraffickingreview.org

The fact that the United Nations (UN) Trafficking Protocol is not an autochthonous product of the Brazilian political system has resulted in its being brought into that system as a 'floating signifier': something that does not point to any actual object or agreed upon meaning. ${ }^{2}$ People who wish to criminalise prostitution have attempted to bend the Protocol in that direction while prostitutes' rights groups have used it to critique current Brazilian laws, emphasising the need to distinguish migration for voluntary, consensual sex work from trafficking. Groups concerned with organ trafficking (a crime for which there are practically no proven cases in Brazil) have managed to push their banner to the fore in the trafficking debate. Meanwhile, Brazil's long-established and relatively successful anti-slave labour movement has been loath to 'change their brand', having already gained a considerable degree of institutionalisation prior to Brazil's ratification of the Protocol in 2004.

1 Grupo Davida is a conglomerate of academic researchers associated with the Davida prostitutes' rights association in Rio de Janeiro, Brazil. The group is made up of Dr A P Silva (Fluminense Federal University-UFF), L Murray (Doctoral candidate, Columbia), Dr S Simões (Federal University of Rio de Janeiro-UFRJ), Dr T Blanchette (UFRJ) and Flávio Lenz (Masters program, UFRJ).

2 C Lévi-Strauss, 'Introduction à l'oeuvre de Marcel Mauss' in Mauss, Sociologie et Anthropologie, Paris, 1950.

This is an open-access article distributed under the terms of the Creative Commons Attribution License (CC-BY). Under CC-BY license, the public is free to share, adapt, and make commercial use of the work. Users must always give proper attribution to the author(s) and the Anti-Trafficking Review. 
The rush to implement an official anti-trafficking policy in Brazil in response to the Protocol created a dynamic in which the perceived need to 'do something' about trafficking outstripped both the ability of the country's researchers to produce useful data regarding the phenomenon and its capacity to conduct legal reforms. The policies and programmes which the various municipal, State and federal governments have implemented in Brazil have thus tended to be based around prejudices, stereotypes and misinformation, privileging an overly formalised and legal reading of 'trafficking', which understands the phenomenon almost exclusively as the migration of sex workers (coerced or not), while largely leaving other forms of coerced migration and labour out of the picture. ${ }^{3}$

Because of this, Brazil's only law regarding trafficking continues to be Article 231 of the Penal Code, which was originally formulated in 1940. This defines the crime as the assisted migration of women across international borders for the purpose of prostitution. In 2005 (in part as a response to Brazil's ratification of the Trafficking Protocol), the law was changed to consider victims of all genders. It was also expanded by Article 231a, which criminalises the assisted migration of prostitutes within Brazilian territory.

In 2009, the Article 231 was modified once again, this time to specifically equate 'prostitution' with 'sexual exploitation'an equivalence which had hitherto not appeared anywhere in the Brazilian legal code.

Although these changes were conducted against a background of widespread debate regarding the Trafficking Protocol and Brazil's need to conform to it, neither brought the country's trafficking laws in line with the UN treaty. Instead, the law

3 A Piscitelli, "Entre as "mafias" e a "ajuda": a construção de conhecimento sobre trafico de pessoas', Cadernos Pagu, no. 31, 2008, pp. 29-62; T G Blanchette, A P Silva, A Bento, 'The Myth of Maria and the Imagining of Sexual Trafficking in Brazil', Dialectical Anthropology, vol. 37, issue 2, 2013, pp. 195-227. 
was adjusted to make it more similar to the United States Mann Act $^{4}$ in scope and intent. To date (February 2015), no changes have been promulgated in the Brazilian criminal or civil code to bring the country's laws into accordance with the Trafficking Protocol, even though national anti-trafficking policies and plans endlessly reference the Protocol as their inspiration and touchstone. A new bill (PL 7370/2014) currently being considered by the Brazilian Congress would redefine trafficking to bring Brazilian law more in line with the Protocol. The discussions surrounding PL 7370/2014, however, and particularly the report by House reviewer Deputy Arnaldo Jordy, have attempted to widen the bill's scope so that it would criminalise several non-coercive, nontrafficking-related practices common to both sex work and Brazil's transgender community.

In particular, Jordy's committee seeks to include in the definition of trafficking the 'clandestine modification of the body of another person', a practice which is not included in the Trafficking Protocol. It also would criminalise bodily modifications undertaken by non-licensed people or in unhealthy conditions. Given that body modifications of this sort are common among Brazil's trans population, this rider would open space for a back-door attack on stigmatised gender identities. Many similar riders and suggestions have come out of Jordy's committee, oftentimes at the behest of evangelical Christian congress people, and it is still an open question as to how these discussions will modify the final bill. Given that PL 7370/2014-like many anti-trafficking bills worldwide-raises allowed surveillance levels of people suspected of trafficking, and given the climate of increased political opposition to the rights of lesbian, gay, bisexual and transgender (LGBT) people and sex workers, which has

The Mann Act, originally passed in 1910 and most recently amended in 1986, makes it illegal to transport people across State lines for the purpose of prostitution or illegal sexual activity. In its original formulation, it prohibited such transport for 'debauchery, or for any other immoral purpose', whichnotoriously-included transracial sexual-affective relationships. 
recently taken hold of significant parts of the Brazilian State, these riders are particularly worrisome. ${ }^{5}$

As a result, while Brazil's National Anti-Trafficking Plan recognises migration for slave labour and the removal of organs as forms of trafficking, there is still no legal definition of these two crimes as such. ${ }^{6}$ Thus, while Brazil has almost five times as many slave labour cases on the books as trafficking for sexual exploitation cases, and fifteen times the number of slave labourers rescued as opposed to victims of sexual exploitation rescued, ${ }^{7}$ most awareness campaigns and the great majority of public and academic attention remain focused on sex work as a necessary and sufficient component of trafficking in persons. This state of affairs was heavily reinforced by Brazil s first anti-trafficking study, PESTRAF (Pesquisa sobre Tráfico de Mulheres, Crianças e Adolescentes para Fins de Exploração Sexual Comercial no Brasil). Published in 2004, it continues to be the most cited source of information regarding trafficking by media, government and civil society anti-trafficking actors, even though the study promiscuously mixes non-coerced prostitute

5 See the Special Committee Report at http://www.camara.gov.br/ proposicoesWebprop_mostrarintegra?codteor $=1270327 \&$ filename $=$ Tramitacao$\mathrm{PL}+7370 / 2014$, especially pages 5-10. For information on anti-sex worker sentiment in the federal government, see http://www1.folha.uol.com.br/ cotidiano/2013/06/1289525-ministro-da-saude-recua-em-campanha-paraprostitutas.shtml. For an example of recent anti-LGBT activity in Congress, see http://noticias.uol.com.br/politica/ultimas-noticias/2013/03/07/ comissao-de-direitos-humanos-elege-pastor-polemico-como-presidente.htm. For an example of the sort of report which situates young men as victims of recruitment into 'travesti prostitution', see 'Jovens são aliciados para se transformarem em travestis’, http://paroutudo.com/2012/02/13/jovens-saoaliciados-para-se-transformarem-em-travestis/ (all weblinks retrieved 6 March 2015).

6 Secretaria Nacional de Justiça/Ministério da Justíça (SNJ/MJ), 'Enfrentamento ao Tráfico de Pessoas: Relatório do Plano Nacional’, SNJ/MJ, Brasília, 2010.

7 Betweem 2005 and 2011, 940 cases of slave labour with over 27,000 victims, and 200 cases of trafficking for sexual exploitation with around 1,800 victims were registered by the authorities. SNJ/MJ, 'Relatório Nacional sobre Tráfico de Pessoas: consolidação dos dados de 2005 a 2011', SNJ/MJ, Brasília, 2013, pp. $33-34,42$. 
migration with forced migration for sexual exploitation in its mapping of Brazilian trafficking routes and its characterisation of trafficking victims. ${ }^{8}$

In this sense, then, the Trafficking Protocol has not done much to serve the struggle against human exploitation in Brazil. This struggle was already well underway in the 1990s and early 2000s in the Labour Ministry's increased repression of slave labour, resulting in more than 27,000 freed slaves between 1995 and 2009. ${ }^{9}$ Brazil's ratification of the Trafficking Protocol pushed the government to 'do something' about the specific problem of 'trafficking', defined by Brazilian law as the assisted migration of prostitutes and conceived of as a separate (although related) problem to slave labour. As funds and political pressure flowed into Brazil around the trafficking issue, these became ever-more directed towards the repression of prostitute migration-the only thing legally understood as trafficking by the Brazilian criminal code.

Today, the non-coerced, voluntary migration of self-employed sex workers continues to be counted as trafficking and widely reported as such by the media, by government agencies and by NGOs engaged in 'awareness raising' in Brazil. The anti-trafficking efforts of the Federal Police (and many local and State police forces) continue to be directed by Article 231 and have focused almost entirely on the repression of

8 M L Leal \& M F Leal, Pesquisa Sobre Tráfico de Mulheres, Crianças e dolescentes para Fins de Exploração Sexual Comercial-PESTRAF, Brasília: CECRIA, 2002. For PESTRAF's continued use as a touchstone for trafficking information, see the recently published Final Report of the Chamber of Deputy's Parlimentary Inquiry Comittee (CPI da Camera dos Deputados) regarding trafficking in persons (Camera dos Deputados, CPI-Tráfico de Pessoas no Brasil, Brasília, 2014, p.8). For criticisms of PESTRAF, see A Piscitelli, "Entre as "mafias" e a “ajuda": a construção de onhecimento sobre tráfico de pessoas', Cadernos Pagu, no.31, 2008, p. 29-63; and T G Blanchette \& A P Silva, 'On Bullshit and the Trafficking of Women: Moral entrepreneurs and the invention of trafficking of persons in Brazil', Dialectical Anthropology, vol. 36, 2012, pp. 107-125.

9 SNJ/MJ, p.52. 
prostitute migration, irrespective of whether this involves coercion or conditions similar to slavery. As has been documented elsewhere, ${ }^{10}$ this repression has led to much 'collateral damage', with the rights to migration of women, men and trans- people classified as 'prostitutes' being curtailed in arbitrary fashion and their supporting kinship and friendship networks often being criminalised as 'traffickers'.

Grupo Davida is a conglomerate of academic researchers associated with the Davida prostitutes' rights association in Rio de Janeiro, Brazil. The group is made up of Dr A P Silva (Fluminense Federal University-UFF), L Murray (Doctoral candidate, Columbia), Dr S Simões (Federal University of Rio de Janeiro-UFRJ), Dr T Blanchette (UFRJ) and Flávio Lenz (Masters program, UFRJ). They can be contacted on Facebook at https: //www.facebook.com/observatoriodaprostituicao? fref=ts or by email: flaviolenzcesar@hotmail.com, sosimoes 01@gmail.com, macunaima30@yahoo.com.br, trm2137@ columbia.edu, and ana51@uol.com.br

10 F Nederstigt \& L C R Almeida, 'Brazil', in GAATW, Collateral Damage: The Impact of Anti-Trafficking Measures on Human Rights Around the World, GAATW, Bangkok, 2007, p. 87-213; T G Blanchette and A P Silva, 'O Mito de Maria, uma traficada exemplar: Confrontando leituras mitológicas do tráfico com as experiências de migrantes brasileiros, trabalhadores do sexo', Rev. Inter. Mob. Hum., vol. 37, pp. 79-105. 


\section{The Trafficking Protocol and the Anti-Trafficking Framework: Insufficient to address exploitation}

Kathryn Baer

Please cite this article as: $\mathrm{K}$ Baer, 'The Trafficking Protocol and the Anti-Trafficking Framework: Insufficient to address exploitation', Anti-Trafficking Review, issue 4, 2015, pp. 167172, www.antitraffickingreview.org

The Trafficking Protocol ${ }^{1}$ has shaped and advanced a global movement against human trafficking; notably through establishing a global definition and creating criminal justice remedies befitting an international crime. ${ }^{2}$ Borne out of and including the Protocol, a global anti-trafficking framework has emerged. This framework reflects these two central tenets at international, regional and national levels and includes initiatives by States not party to the Protocol, such as Singapore. However, the emphasis on these tenets, which comprise only part of a robust anti-trafficking strategy, has rendered the existing framework insufficient to address exploitation.

1 In full: Protocol to Prevent, Suppress and Punish Trafficking in Persons, Especially Women and Children

2 K H Heinrich, 'Ten Years After the Palermo Protocol: Where are Protections for Human Trafficking?', Human Rights Brief 18, no.1, 2010, retrieved 5 January 2015, http://digitalcommons.wcl.american.edu/cgi/viewcontent.cgi?article= 1145\&context=hrbrief ; K E Hyland, The Impact of the Protocol to Prevent, Suppress and Punish Trafficking in Persons, Especially Women and Children, Human Rights Brief 8, no. 2, 2001, retrieved 5 January 2015, http://digitalcommons. wcl.american.edu/cgi/viewcontent.cgi?article=1492\& context=hrbrief

This is an open-access article distributed under the terms of the Creative Commons Attribution License (CC-BY). Under CC-BY license, the public is free to share, adapt, and make commercial use of the work. Users must always give proper attribution to the author(s) and the Anti-Trafficking Review. 
A clearly articulated and operationalised definition of human trafficking is absolutely necessary to identify victims and provide recourse to justice. A universal definition arguably promotes international standardisation and accountability, presuming States are party to the Protocol, and adopt and incorporate a definition proffered by national legislation. In practice, States may selectively implement anti-trafficking provisions (particularly those concerning sex trafficking over labour trafficking), detracting attention and resources from less clear-cut or politically divisive cases of exploitation and abuse.

One by-product of this focus is an underdevelopment of political will and funding dedicated to victim protection and primary prevention efforts. As a result, protections for victims are negligible; criminal justice responses may infringe on the rights of groups affected by trafficking, such as labour migrants and sex workers (through the use of raids, for instance); and very little investment in primary prevention research or interventions exists beyond those which claim to promote 'awareness raising'. To effectively prevent human trafficking, the anti-trafficking movement should reallocate its discourse and resources to the conditions that underpin exploitation.

Singapore provides an example of this deficient approach. At the time of writing, the city-state is not party to the Protocol, but recently passed the Prevention of Human Trafficking Act 2014, which creates a legislated definition of trafficking. Mirroring the Protocol, the law prioritises criminal justice anti-trafficking strategies. ${ }^{3}$

The international prioritisation of criminal justice has unintentionally done a disservice to prevention and protection measures, which are inextricably linked, though little emphasised. Trust in law enforcement by potential victims

Republic of Singapore, 'Prevention of Human Trafficking Act 2014', retrieved 2 March 2015, http://statutes.agc.gov.sg/aol/search/display/view.w3p;page $=0$; query $=$ Compld\%3Ae87a7435-17f4-4bb7-8d47-5a3d5cb8d62a;rec $=0$ 
is key in identifying and referring trafficking cases. Betterprotected victims are more likely to participate with authorities. ${ }^{4}$ Building trust may be compromised and compounded by law enforcement interventions that increase risk or vulnerability to potentially trafficked persons.

For instance, in Singapore law enforcement raids are used, allegedly, to identify victims of sex trafficking, despite international research highlighting the ineffectiveness of identification in raids ${ }^{5}$ and local reports of abuse. ${ }^{6}$ The government also relies on law enforcement raids to identify illegal migrant workers and sex workers. Those who are identified as offenders are deported. As a component of its ongoing anti-sex trafficking approach, the government notes that it will 'continue [its] efforts to keep the vice situation in Singapore under control'?

The consequence of this selective use of the Protocol in Singapore is two-fold. First, it reflects a narrowly constructed anti-trafficking strategy, which favours criminal justice responses over victim protection and prevention. For instance, within the new law, victim protection measures are largely contingent upon participation in the criminal justice process, ignoring victims' concerns about forced repatriation or the

4 A Ahmed \& M Seshu, 'Accountability and the Use of Raids to Fight Trafficking', Anti-Trafficking Review, issue 1, 2012, pp. 134-148.

5 J Godwin, 'Sex Work and the Law in Asia and the Pacific', United Nations (UN) Development Programme Asia-Pacific Regional Centre and UN Population Fund Asia Pacific Regional Office, in partnership with the Joint United Nations Programme on HIV/AIDS, Asia Pacific Network of Sex Workers, 2012; M Ditmore \& J Thukral, 'Accountability and the Use of Raids to Fight Trafficking', AntiTrafficking Review, issue 1, 2012, pp.134-148.

6 'Project X 2013. Report on human rights violations against sex workers in Singapore: January to November 2013' [confidential submission to the UN Special Rapporteur on violence against women, its causes and consequences].

7 T Y Chuan, 'More than 300 views received on proposed human trafficking law: Taskforce', The Straights Times, 25 May 2014, retrieved 5 January 2015, http:/ /www.straitstimes.com/news/singapore/more-singapore-stories/story/more300-views-received-proposed-human-trafficking-law-t 
right to seek alternative employment. Moreover, prior to the law's passing in November, protections afforded to (identified) victims were largely relegated to administrative discretion, provided piecemeal (where available) within existing legislation. As the new law remains in infancy, the extent to which it offers victim protection remains to be tested.

Second, the emphasis on trafficking per se by policymakers often supersedes the need to engage with and develop tailored approaches to conditions underpinning exploitation that may contribute to trafficking. For instance, deceptive practices are prevalent in the recruitment of migrant workers in Singapore. ${ }^{8}$ While the majority of these workers are not trafficked, cases of deceptive recruitment (a recognised indicator of trafficking) are considered by the government to fall under the protection of inadequately enforced local labour laws, distinct (in policy and practice) from potential cases of human trafficking.

This is partially the result of the political will to utilise the Protocol's definition of trafficking, which does not adequately define 'deception', paralleled by a disinterest in the substantial integration of supplementary anti-trafficking tools, including the International Labour Organization trafficking indicators. This view is reflected in the government's reply to concerns voiced by local NGOs about the lack of protections for victims of trafficking included within the aforementioned law during a consultation period for the Bill:

While we understand the desire for the Bill to comprehensively cover various situations where workers are mistreated, many of these wrongs are already addressed by existing employment laws which provide deterrent penalties against errant employers as well as

ECPAT International \& $S$ Yea, Commercial sexual exploitation and trafficking of children and young people in Singapore, Bangkok: ECPAT, 2010; Humanitarian Organization for Migration Economics (HOME), 'FDW Trafficking Research Report', HOME, 2012; Transient Workers Count Too (TWC2), 'Worse Off for Working? Kickbacks, intermediary fees and migrant construction workers in Singapore', TWC2, 2012. 
avenues of redress to the workers. [...] This approach ensures that the Bill remains focused at targeting genuine egregious trafficking cases (emphasis added). ${ }^{9}$

It is not clear what is meant by the terms 'genuine' and 'egregious'. Nonetheless, the statement appears to distinguish between trafficking and worker mistreatment. Treated separately, the presence of human trafficking indicators is ignored or overlooked in cases of worker exploitation.

In addition, to address 'prevention' (a key component of the government's National Plan of Action Against Trafficking in Persons), the task force initiated a grant to assist projects designed to heighten public awareness of human trafficking. ${ }^{10}$ This tactic assumes that an educated public would be more likely to detect and report cases of trafficking to the authorities. However, much of this awareness raising focuses on cases of trafficking that occur outside the local context (for instance, child sex trafficking in Cambodia); subsequently disengaging the public from Singapore-specific forms of exploitation (such as that which is experienced by domestic workers). Instead, primary prevention efforts would acknowledge underlying social structures, such as discrimination faced by foreign domestic workers, ${ }^{11}$ support a greater understanding of the relationship between existing laws that aim to curb exploitation and trafficking indicators, and address gaps in migrant worker protections.

9 Singapore Ministry of Home Affairs, Response to Consultations, retrieved 5 January 2015, http://www.mha.gov.sg/news_details.aspx?nid=MzE30Q\% 3D\%3D-Xh1WT7v\%2Bq10\%3D

10 Ministry of Manpower, ' $\$ 80,000$ Fund Launched to Raise Awareness for TraffickingIn-Persons', Singapore Government, 11 January 2013, retrieved 2 March 2015, http://www.mom.gov.sg/newsroom/Pages/PressReleasesDetail.aspx?listid $=480 \#$ sthash. HnK4zQwe.dpuf

11 L Clarke, 'Behind Closed Doors: Trafficking into domestic servitude in Singapore', The Equal Rights Review, vol. 10, 2013, pp. 33-58. 
Kathryn Baer is a Co-Founder of and Researcher at The Trafficking Research Project. Her prior anti-trafficking experience includes working at Polaris Project in the United States of America as well as Anti-Slavery International in the United Kingdom (UK). She has an MSc in Social Policy from the London School of Economics and Political Science, United Kingdom. 
Interview 


\title{
Human Trafficking in Brazil: Between crime-based and human rights-based governance
}

\author{
Ela Wiecko V. de Castilho
}

Keywords: Brazil, anti-trafficking, sex worker rights, Trafficking Protocol, human trafficking

Please cite this article as: E W V de Castilho, 'Human Trafficking in Brazil: Between crime-based and human rights-based governance', Anti-Trafficking Review, issue 4, 2015, pp. 174185, www.antitraffickingreview.org

\section{Interview Summary}

This interview with Ela Wiecko V. de Castilho, Vice-Prosecutor General of the Republic in Brazil, looks at the development of anti-trafficking law and agendas since Brazil's ratification of the United Nations Protocol to Prevent, Suppress and Punish Trafficking in Persons, Especially Women and Children (Trafficking Protocol). Castilho looks at how the externallyimposed concept of anti-trafficking gained momentum in the country and details debates and tensions in the subsequent development of national policy. Brazilian criminal law has significant conceptual differences with the Trafficking Protocol, particularly around consent and internal trafficking. Castilho discusses unresolved issues on rights of sex workers and migrants and points to a data collection methodology that was recently established and will allow for analysis of whether victims' situations meet the international definition of human trafficking. If they do not, she suggests that this definition may not need to be maintained in Brazil. 
Anti-Trafficking Review: How has the Brazilian government responded to human trafficking after signing the United Nations (UN) Convention against Transnational Organized Crime and its Trafficking Protocol?

Castilho: In 2000 Brazil signed the UN Convention and two of its Protocols-the Protocol to Prevent, Suppress and Punish Trafficking in Persons, Especially Women and Children (Trafficking Protocol), as well as the Protocol Against the Smuggling of Migrants by Land, Sea and Air. The National Congress ratified the Convention in January 2004. Ten years later the Brazilian government has still not adapted its existing criminal legislation to international requirements. This has not prevented the government from publicly promoting an anti-trafficking agenda-a process which began in 2004 and was entirely driven by international rather than local demands.

Anti-Trafficking Review: You said that the adoption of the anti-trafficking agenda was not homegrown. How was the agenda introduced to Brazil?

Castilho: Early stimulus came from the United Nations Office on Drugs and Crime (UNODC), Organization of American States (OAS), International Labour Organization (ILO), and the United States (US) government, mostly likely influencing the National Congress' fast ratification of the UN Organized Crime Convention and the two Protocols in 2004.

In December 2001 UNODC began a pilot project with the Brazilian Ministry of Justice prioritising measures against trafficking of women for sexual exploitation. In 2002, an OAS-commissioned study 'National Research on Trafficking in Children, Women and Adolescents for Commercial Sexual Exploitation' (PESTRAF) had a large impact, claiming to have found 241 domestic and international trafficking routes. ${ }^{1}$ It

M Leal, (coord.), 'Pesquisa sobre Tráfico de Mulheres, Crianças e Adolescentes para fins de Exploração Sexual e Comercial-PESTRAF: Relatório Nacional-Brasil', Brazil, CECRIA, 2002. PESTRAF has been critiqued for instance in: $T G$ Blanchette \& A P Silva, 'On Bullshit and the Trafficking of Women: Moral entrepreneurs and the invention of trafficking of persons in Brazil', Dialectical Anthropology, vol. 36, 2012, pp. 107-125. 
compelled the Brazilian Congress to set up a Mixed Parliamentary Committee of Inquiry ${ }^{2}$ in 2003 to investigate networks of commercial sexual exploitation of children and adolescents.

This early period involved other international players concerned with Brazil's anti-trafficking policy. In 2003, the US Consulate in São Paulo supported the Secretariat of Justice of São Paulo in establishing a Human Trafficking Prevention and Combat Office. $^{3}$

The ILO supported efforts against both sexual and labour exploitation under one human trafficking umbrella. It also folded the issue of migration into discussions on trafficking. The ILO's Combat Human Trafficking Project, operational from 2006-2009, had a budget of over three million dollars funded by the United States Agency for International Development (USAID). ${ }^{4}$

Anti-Trafficking Review: How did national policy begin to develop after this external influence?

Castilho: Direct assistance to trafficked persons was a key driver of State and federal engagement in anti-trafficking. ${ }^{5}$

Collaboration on direct service provision between nongovernmental organisations (NGOs) and State actors also led to the first national public awareness campaign on trafficking

2 The committee is composed of congressmen and senators.

3 In 2003 the Ministry of Justice established the Human Trafficking Prevention and Combat Office in partnership with the governments of the states of Ceará, Goiás, Rio de Janeiro and São Paulo. The US Consulate supported the São Paulo office.

4 The Independent Project Evaluation Report in 2009 highlighted 'the difficulty that the concept of human trafficking was necessary to bring together, on one hand, considerations on the subject of slavery and on the other, the sexual exploitation of idea. In Brazil, this difficulty reflected the existence of frameworks, policies and committees or previously established technical advice'. G M Dias, 'Migração e Crime: desconstrução das políticas de segurança e tráfico de pessoas', doctoral thesis, Campinas: Unicamp, 2014.

5 As the Ministry of Justice recognised in its 2003-2006 management report. 
for sexual exploitation. At the end of 2005, the government decided to establish a National Policy to Combat Human Trafficking (PNETP I), approved 26 October 2006, coordinated by the Ministry of Justice. ${ }^{6}$ Stakeholders in justice, public security and human rights, as well as victim assistance providers and sex worker representatives took part in this process. For the first time, efforts to implement the Trafficking Protocol included both experts on labour and sexual exploitation.

Between May and June 2006, civil society was invited to contribute to a broad public consultation process, characteristic of President Lula's government, and one of the first topics of national discussion was whether under existing Brazilian legislation human trafficking constituted a crime. At the time, I declared that there were existing provisions in the Penal Code and in special laws that sanctioned conduct with characteristics of trafficking. While these give a response to trafficking, they are not systematised or coherent.

The absence of a systemised legal response to the crime of human trafficking in law did not prevent international legal cooperation nor did it violate the provisions of the Trafficking Protocol. However, in order for Brazil to join the global effort against trafficking, I argued that a systematising of criminal types, which observed proportionality of penalties, was desirable. ${ }^{7}$ This has not been a straightforward process, given the multiplicity of behaviours constituting human trafficking (e.g. enslavement, sexual exploitation of children and adolescents, removal and sale of parts of the human body) all of which constitute existing crimes. Establishment of the crime of human trafficking is currently being discussed by the National Congress, but no consensus has been reached.

6 Secretaria Nacional de Justiça (SNJ), 'Relatório Final de Execução do Plano Nacional de Enfrentamento ao Tráfico de Pessoas', Ministério da Justiça, first edition, Brazil, 2010.

7 E W V de Castilho, 'A legislação penal brasileira sobre tráfico de pessoas e imigração ilegal/irregular frente aos Protocolos Adicionais à Convenção de Palermo', text presented at the First Luso-Brazilian conference on human trafficking and illegal immigration, Cascais, 2006. 
Anti-Trafficking Review: What tensions did you see as the government tried to develop policy?

Castilho: Bringing together NGOs, social movements and governmental bodies, with separately developed plans-the National Plan for Combating Sexual Commercial Exploitation of Children and Adolescents (2000), the National Plan for Eradication of Slave Work (2003) and the National Plan for Eradication of Child Labour (2004)-was challenging. Reconciling a security and a human rights approach was difficult. The Brazilian government believes in a perspective that recognises and guarantees rights, while the Convention and its Protocols are primarily driven by security concerns rather than human rights.

Anti-Trafficking Review: How did people respond to these tensions between crime control and human rights frameworks?

Castilho: The presence of Brazilian women in the global sex industry affected the balance between human rights and security paradigms in Brazil. Research by Silva et $\mathrm{al}^{8}$ and Piscitelli ${ }^{9}$ showed that Brazilian women and transgender people working in the sex industry abroad were the object of prejudice, xenophobia and racism. Silva and Grupo Davida, a research group, claimed that most adult women in prostitution in Europe were workers rather than victims of trafficking. ${ }^{10}$ To treat them as victims was a violation of their right to work in the sex industry. By contrast, women and transgender migrants working in Brazil who did need protection as trafficking victims were not receiving due protection according to Brazilian law. They were simply detained and deported as immigrants with no documentation.

8 A P Silva, Grupo Davida et al., Prostitutas, "traficadas" e pânicos morais; uma análise da produção de fatos em pesquisas sobre o "tráfico de seres humanos", Cadernos Pagu, Campinas, vol. 25, 2005, pp. 153-184.

9 A Piscitelli (coord.), 'Pesquisas em tráfico de pessoas. Parte 2-Relatório indícios de tráfico de pessoas no universo de deportadas e não admitidas que regressam ao Brasil via aeroporto de Guarulhos', SNJ/OIT, Brazil, 2006.

10 A P Silva, \& Grupo Davida et al. 
Anti-Trafficking Review: In addition to sex workers having problems with the introduction of an anti-trafficking framework, did labour rights activists who had previously been working under an anti-slavery framework perceive they would be negatively impacted? What about other groups?

Castilho: Since the 1980s the Comissão Pastoral da Terra (Pastoral Land Committee) had been publicising the issue of rural labour exploitation and the term 'slave labour', saw in PNETP a loss of space for public activism of the National Committee for Eradication of Slave Work (CONATRAE).

Groups working on the rights of migrant workers were also concerned about developments. For them the Smuggling Protocol (the second protocol that Brazil signed alongside the Trafficking Protocol) posed a direct threat to the rights of migrant workers because it increased State resolve to collaborate internationally on border enforcement. Any benefits that might accrue to workers from the Trafficking Protocol would, in their view, be better protected by encouraging the Brazilian government to sign and ratify the 1990 International Convention concerning the Protection of the Human Rights of all the Migrant Workers and their Families. In short, several key constituencies opposed the priorities and language of the anti-trafficking framework.

The words of Sprandel ${ }^{11}$ describe anti-trafficking work in the Brazilian context perfectly:

Everything has become trafficking, for evil: I refer mainly to prostitution of women and transvestites... A sort of moral panic has come to the fore in relation to prostitution, such like I have not seen for a long while... Debates sometimes take on tones of good and evil that really have little to do with the reality of the people that we intend to protect...

11 M A Sprandel, 'Conceito de Tráfico e Migrações', lecture given at the Second National Meeting of Fight Network to Combat Human Trafficking, Recife, 2011. 
Everything has become trafficking, for good: In these twenty years of passionate struggle for the benefit of migrants, with no real advancement in the issue, the human trafficking agenda arrived with full force and was rapidly incorporated by our Government and by all of us, with more or less resistance... To a certain extent we put many of our expectations related to migration policies into the policies for combating human trafficking. ${ }^{12}$

Anti-Trafficking Review: Does the Brazilian National Policy diverge from concepts in the Trafficking Protocol?

Castilho: A first difference is that human trafficking in the Protocol is understood as a transnational crime associated with criminal organisations. In Brazil, the National Policy created a category of internal trafficking, with the same elements defining international trafficking.

Second, under Brazilian law the consent of any victim, whether under or over eighteen years, is irrelevant provided the other elements of the crime are present. The intent here is to protect not only child victims of trafficking (as in international law) but also grant protection to a broader category of adults, specifically migrant Brazilians working abroad. People who qualify as trafficked victims will receive special protection they would otherwise be ineligible for if they are only considered as undocumented migrants.

Anti-Trafficking Review: Tell us more about consent.

Castilho: In order to do that I need to tell you about a significant change to the Penal Code. A law introduced in 2009 equated prostitution to sexual exploitation, a change with many implications for the concept of consent. ${ }^{13}$

12 Ibid.

13 As per Law number 12,015, dated 7 August 2009. That law also broadened the scope of concern to include internal trafficking. The Penal Code was also changed in 2005: in law number 11,106, the word 'women' was replaced by the word 'people'. 
As a crime, human trafficking in Brazilian law is characterised by the irrelevance of the consent of the passive subject, as per Penal Code, Article 231.

It is a crime, not only to facilitate entrance to and exit from Brazil, but also to help anyone who intends to enter or leave Brazil in order to enter in the sex industry. Thus even an adult voluntarily engaged in prostitution is considered by law a victim in need of assistance. Where there is violence, serious threat or fraud-in other words, where consent is invalidatedthe penalty is higher.

By contrast, under the Trafficking Protocol consent is irrelevant only for persons under eighteen and a person engaged voluntarily in prostitution is not necessarily a victim. ${ }^{14}$

The Trafficking Protocol points to prohibited 'purposes', including the 'exploitation of the prostitution of another person or other forms of sexual exploitation.' However, the articles in the Brazilian Penal Code criminalise the 'exercise of prostitution or another form of sexual exploitation.' There is a big difference here.

The Brazilian Penal Code equates the autonomous exercise of prostitution to sexual exploitation and makes it an illicit activity, even if the person who is exercising the act cannot be denounced as a trafficker. With these two semantic changes, Brazilian legislation, without the extensive discussion that preceded creation of the Trafficking Protocol, strengthened the abolitionist approach to prostitution and with it the 1949 UN Convention for the Suppression of the Traffic in Persons and of the Exploitation of the Prostitution of Others and the stance of organisations such as the Coalition Against Trafficking in Women (CATW). ${ }^{15}$

14 UNODC, 'The Role of "Consent" in the Trafficking in Persons Protocol', UNODC Issue Paper, 2014, retrieved 29 January 2015, http://www.unodc.org/documents/human-trafficking/2014/UNODC_2014_Issue_Paper_Consent.pdf

15 The penal code suggests abolitionism, even if current national policy does not. 
The result is a 'system of repression of dissident female sexual activities and of restriction of international mobility for sex professionals'. ${ }^{16}$

'Consent', like the term 'abuse of the situation of vulnerability,' reveals ambiguity in the Trafficking Protocol. Individual governments, like that of Brazil, can translate the concept of consent into law in a way that is a de facto response of repression, rather than protection. Interpretation of 'consent' determines whether the government's response is one of protection or repression.

Anti-Trafficking Review: Changing topic, do you think that enough is known about trafficking in Brazil to be able to develop responsive policy?

Castilho: Without doubt, speculative and inconclusive statistics about the scale of trafficking in Brazil ensured prompt acceptance of the anti-trafficking agenda in Brazil.

One of the strong arguments justifying the anti-trafficking agenda has always been the large profits gained from human trafficking. It is sometimes asserted that traffickers make around USD 32 billion per year, ${ }^{17}$ and trafficking is the third most lucrative crime in the world, coming only behind drugs and arms. ${ }^{18}$ These declarations have never been supported by sufficient evidence, but they have been appropriated by the representatives of the countries that are signatory to the Convention Against Transnational Organised Crime and continuously reproduced.

${ }^{16}$ M X L de Medeiros, 'A Criminalização da Migração Internacional das Trabalhadoras do Sexo e o seu Tratamento como Vítimas do Tráfico de Pessoas: o Papel do Livre Consentimento', Master's dissertation, João Pessoa: UFPB, 2013.

17 ILO, 'ILO Action Against Trafficking in Human Beings', ILO, 2008, retrieved 29 January 2015, http://www.ilo.org/wcmsp5/groups/public/@ed_norm/ @declaration/documents/publication/wcms_090356.pdf

18 UNODC, 'Prevention of Human Trafficking', UNODC, 2009, retrieved 29 January 2015, http://www.unodc.org/southasia/en/topics/frontpage/ 2009/preventin-of-human-trafficking.html 
After this rationale for anti-trafficking efforts, the next justification typically used is that anti-trafficking efforts must be undertaken even though research is difficult and offers little evidence of the problem. The fact that victims are in a state of total submission and concealment is a justification for the low number of studies conducted.

Similarly, the low number of cases taken to court is interpreted as impunity-not as evidence that there is not much trafficking happening.

According to Brazilian data from 2005 to 2011, the Federal Police conducted 514 trafficking-related investigations. Of those, 157 were for international trafficking, 13 for internal trafficking and 344 for slave labour. There is no data available from State Police departments, but the State Police have no means to verify international trafficking, or slave labour.

This information contradicts the idea that trafficking is a large problem and that it demands priority and arguably disproportionately high investment, to the detriment of other issues such as domestic violence and the current high number of deaths of Afro-Descendent people.

Anti-Trafficking Review: Has meaningful research been done into trafficking trends following the early commitment from the government to prioritise research?

Castilho: The first national plan, PNETP I, in operation from 2008 to 2010 included research priorities. An evaluation by the government, civil society and ILO recommended a thorough revision of it based on complexities seen.

The evaluation partly showed that research activities in PNETP I had generated little meaningful information. The second phase, PNETP II, has also prioritised research on trafficking. ${ }^{19}$

19 SNJ, 'Il Plano Nacional de Enfrentamento ao Tráfico de Pessoas', Ministério da Justiça, Brazil, 2013. 
Promisingly, PNETP II includes the creation of a computerised, integrated and multidisciplinary data system to be continuously updated by its creators. After a participatory process, in 2013 the Brazilian government introduced the Integrated Methodology for Collection and Analysis of Data and Information about Human Trafficking. One of the advantages of this methodology is that identification of the cases of human trafficking does not depend on a particularised enumeration of specific trafficking-related crimes. Data related to all penal types related to trafficking will be correlated, allowing for production of statistics that show us what human trafficking looks like in Brazil.

Anti-Trafficking Review: What does the future hold? What developments and debates are on the horizon in Brazil?

Castilho: Disputes on whether to situate anti-trafficking in security or human rights arenas will continue. Further, contradictory agendas regarding the sexual commercial exploitation of children and adolescents, slave labour, sex workers' rights and migrants' rights have still not been effectively integrated into the overarching anti-trafficking framework.

Has the Protocol been appropriate for Brazil? Brazil's Penal Code certainly differs from the Protocol in not insignificant ways, particularly around prostitution. The government's position is that prostitution by an adult person is not a civil disturbance or criminal act. However, the structure necessary to protect sex workers is precarious and vulnerable, and various barriers exist to the realisation of their rights.

In seminars about human trafficking, government officials have publically admitted the need for discussion around prostitution, but the government does not seem in a rush to act on this. So much so that in the two recent changes to the law, no effective effort was made to remove the equation of prostitution to sexual exploitation, or to approve legislation protecting sex workers' rights. 
The debate and the political decisions on human trafficking, at national and international levels, are based on estimates, and alarming numbers continue to be propagated. In Brazil, a methodology for data collection has just been established. This will hopefully allow us to understand what trafficking looks like in Brazil, and whether the social phenomena we have here actually meet the Trafficking Protocol's definition of trafficking. I hope this sheds light on whether the definition should subsist, and whether it accurately reflects realities on the ground.

We are waiting to see whether crime or rights-based governance of human trafficking will carry the day.

Ela Wiecko V. de Castilho has a PhD in Law from the Federal University of Santa Catarina, Brazil (1996). She is Professor in the Faculty of Law at the University of Brasilia, where she leads the Candango Criminology Group and Moitará-Research Group on Ethnic Rights. Her teaching and research fall within research programmes 'Systems of Justice, Human Rights and Legal Education' and 'Law Found in the Street'. She has published and worked on issues of violence against women, alternatives to prison, rights of indigenous peoples, drug policy and human trafficking. She is also a member of the Federal Prosecution Service, where she has served as Federal Attorney for Citizens' Rights, Coordinator of 6th Board for Coordination (Indigenous peoples and minorities), Inspector General, and Ombudsman General of the Federal Prosecutor. Currently she is the Vice-Prosecutor General of the Republic. 



\section{ANTI-TRAFFICKING REVIEW \\ Guidelines for Contributors}

We welcome submissions from a diverse range of actors, including academics, practitioners, trafficked persons and advocates. The Anti-Trafficking Review particularly welcomes contributions from those with direct experiences and insights to share.

The Anti-Trafficking Review is aimed at a wide readership. It therefore encourages submissions that are in clear, jargon-free English with appropriate but not excessive citation.

Articles should be previously unpublished and should not be under consideration for publication elsewhere. All articles go through a rigorous double-blind peer review process.

Please refer to the journal's website (www.antitraffickingreview.org) for the journal's full style guide and guidelines for contributors.

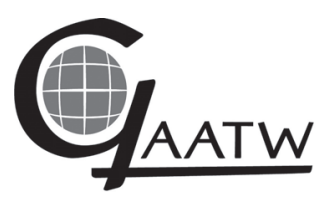

GLOBAL ALLIANCE AGAINST TRAFFIC IN WOMEN

P.O. Box 36, Bangkok Noi Post Office

10700 Bangkok, Thailand

Website: www.antitraffickingreview.org 


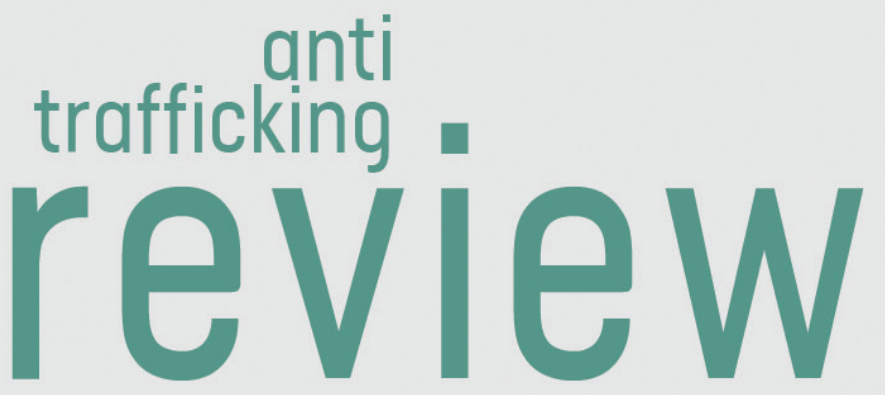

The Anti-Trafficking Review promotes a human rights-based approach to anti-trafficking. It explores trafficking in its broader context including gender analyses and intersections with labour and migrant rights. It offers an outlet and space for dialogue between academics, practitioners, trafficked persons and advocates seeking to communicate new ideas and findings to those working for and with trafficked persons. 